\title{
Hyperjapones A-E, Terpenoid Polymethylated acylphloroglucinols from Hypericum japonicum
}

Xing-Wei Yang, Yan-Ping Li, Jia Su, Wei-Guang Ma, and Gang Xu

\section{Supporting Information}

\section{Table of Contents}

- SI-1. The ${ }^{1} \mathrm{H}$ and ${ }^{13} \mathrm{C}$ NMR data of compounds 3-5 (Page S2-S3).

- SI-2. Experimental procedures (Page S4-S6).

- SI-3. Physical data of the new compounds (Page S6-S8).

- SI-4. Chiral resolution of 1 by different materials (Page S8-S11)

- SI-5. The original NMR and MS spectra of the new isolates (Page S12-S36). 
SI-1. The ${ }^{1} \mathrm{H}$ and ${ }^{13} \mathrm{C}$ NMR data of compounds $3-5$

Table S1. ${ }^{13} \mathrm{C}(150 \mathrm{MHz})$ NMR spectral data $\left(\delta\right.$ in ppm) of compounds $3-5$ in acetone- $d_{6}$

\begin{tabular}{|c|c|c|c|}
\hline no. & 3 & 4 & 5 \\
\hline 1 & $105.7, \mathrm{C}$ & 104.9, C & $105.6, \mathrm{C}$ \\
\hline 2 & 189.2, C & 189.1, C & 189.3, C \\
\hline 3 & $102.8, \mathrm{C}$ & $102.7, \mathrm{C}$ & $102.8, \mathrm{C}$ \\
\hline 4 & $173.4, \mathrm{C}$ & $173.9, \mathrm{C}$ & $173.8, \mathrm{C}$ \\
\hline 5 & $48.9, \mathrm{C}$ & $48.9, \mathrm{C}$ & $48.8, \mathrm{C}$ \\
\hline 6 & 196.7, C & $196.8, \mathrm{C}$ & $196.8, \mathrm{C}$ \\
\hline 7 & $207.1, \mathrm{C}$ & 207.9, C & 207.2, C \\
\hline 8 & $42.1, \mathrm{CH}$ & $35.8, \mathrm{CH}$ & $42.1, \mathrm{CH}$ \\
\hline 9 & 17.1, $\mathrm{CH}_{3}$ & $19.2, \mathrm{CH}_{3}$ & $16.9, \mathrm{CH}_{3}$ \\
\hline 10 & 27.3, $\mathrm{CH}_{2}$ & $19.4, \mathrm{CH}_{3}$ & 27.3, $\mathrm{CH}_{2}$ \\
\hline 11 & $12.1, \mathrm{CH}_{3}$ & & $12.1, \mathrm{CH}_{3}$ \\
\hline 12 & $25.2, \mathrm{CH}_{2}$ & $24.1, \mathrm{CH}_{2}$ & $24.0, \mathrm{CH}_{2}$ \\
\hline 13 & $25.5, \mathrm{CH}_{3}$ & $25.4, \mathrm{CH}_{3}$ & $25.1, \mathrm{CH}_{3}$ \\
\hline 14 & $23.8, \mathrm{CH}_{3}$ & $24.2, \mathrm{CH}_{3}$ & $24.3, \mathrm{CH}_{3}$ \\
\hline $1^{\prime}$ & $34.5, \mathrm{CH}$ & $35.2, \mathrm{CH}$ & $35.1, \mathrm{CH}$ \\
\hline $2^{\prime}$ & $33.7, \mathrm{CH}_{2}$ & $34.4, \mathrm{CH}_{2}$ & $34.4, \mathrm{CH}_{2}$ \\
\hline $3^{\prime}$ & $35.8, \mathrm{CH}_{2}$ & $37.3, \mathrm{CH}_{2}$ & 37.2, $\mathrm{CH}_{2}$ \\
\hline $4^{\prime}$ & 152.7, C & $156.0, \mathrm{C}$ & $159.9, \mathrm{C}$ \\
\hline $5^{\prime}$ & $42.7, \mathrm{CH}$ & $43.0, \mathrm{CH}$ & $42.8, \mathrm{CH}$ \\
\hline $6^{\prime}$ & $36.9, \mathrm{CH}_{2}$ & $39.3, \mathrm{CH}_{2}$ & $39.2, \mathrm{CH}_{2}$ \\
\hline $7^{\prime}$ & $34.1, \mathrm{C}$ & $33.9, \mathrm{C}$ & $33.8, \mathrm{C}$ \\
\hline $8^{\prime}$ & 53.7, $\mathrm{CH}$ & $57.1, \mathrm{CH}$ & $57.1, \mathrm{CH}$ \\
\hline $9^{\prime}$ & $23.3, \mathrm{CH}_{2}$ & 23.3, $\mathrm{CH}_{2}$ & 23.2, $\mathrm{CH}_{2}$ \\
\hline $10^{\prime}$ & $37.7, \mathrm{CH}_{2}$ & $39.2, \mathrm{CH}_{2}$ & $39.1, \mathrm{CH}_{2}$ \\
\hline $11^{\prime}$ & $85.3, \mathrm{C}$ & $85.6, \mathrm{C}$ & $85.5, \mathrm{C}$ \\
\hline $12^{\prime}$ & $22.3, \mathrm{CH}_{3}$ & 22.6, $\mathrm{CH}_{3}$ & $22.5, \mathrm{CH}_{3}$ \\
\hline $13^{\prime}$ & $30.3, \mathrm{CH}_{3}$ & $29.8, \mathrm{CH}_{3}$ & $29.8, \mathrm{CH}_{3}$ \\
\hline $14^{\prime}$ & $21.1, \mathrm{CH}_{3}$ & $20.1, \mathrm{CH}_{3}$ & $20.0, \mathrm{CH}_{3}$ \\
\hline $15^{\prime}$ & $110.6, \mathrm{CH}_{2}$ & $110.3, \mathrm{CH}_{2}$ & $110.2, \mathrm{CH}_{2}$ \\
\hline
\end{tabular}


Table S2. ${ }^{1} \mathrm{H}(600 \mathrm{MHz})$ NMR data $\left(\delta\right.$ in ppm, $J$ in Hz) of compounds $3-5$ in acetone- $d_{6}$

\begin{tabular}{|c|c|c|c|}
\hline no. & 3 & 4 & 5 \\
\hline 8 & $3.84, \mathrm{~m}$ & 3.96 , sept (6.8) & $3.86, \mathrm{~m}$ \\
\hline 9 & $1.08, \mathrm{~d}(6.8)$ & $1.08, \mathrm{~d}(6.8)$ & $1.08, \mathrm{~d}(6.8)$ \\
\hline \multirow[t]{2}{*}{10} & $1.68, \mathrm{~m}$ & $1.09, \mathrm{~d}(6.8)$ & $1.72, \mathrm{~m}$ \\
\hline & $1.35, \mathrm{~m}$ & & $1.37, \mathrm{~m}$ \\
\hline 11 & $0.86, \mathrm{t}(7.6)$ & & \\
\hline \multirow[t]{2}{*}{12} & $2.35, \mathrm{dd}(16.5,5.0)$ & $2.65, \mathrm{dd}(16.3,5.1)$ & $2.66, \mathrm{dd}(16.3,5.1)$ \\
\hline & $1.91, \mathrm{~m}$ & $1.82, \mathrm{dd}(16.3,12.0)$ & $1.83, \mathrm{dd}(16.3,12.0)$ \\
\hline 13 & $1.26, \mathrm{~s}$ & $1.26, \mathrm{~s}$ & $1.26, \mathrm{~s}$ \\
\hline 14 & $1.31, \mathrm{~s}$ & $1.32, \mathrm{~s}$ & $1.33, \mathrm{~s}$ \\
\hline $1^{\prime}$ & $2.05, \mathrm{~m}$ & $2.10, \mathrm{~m}$ & $2.09, \mathrm{~m}$ \\
\hline \multirow[t]{2}{*}{$2^{\prime}$} & $1.76, \mathrm{~m}$ & $1.57, \mathrm{~m}$ & $1.57, \mathrm{~m}$ \\
\hline & $1.56, \mathrm{~m}$ & $1.47, \mathrm{~m}$ & $1.49, \mathrm{~m}$ \\
\hline \multirow[t]{2}{*}{$3^{\prime}$} & $2.46, \mathrm{~m}$ & $2.46, \mathrm{~m}$ & $2.47, \mathrm{~m}$ \\
\hline & $2.18, \mathrm{~m}$ & $2.13, \mathrm{~m}$ & $2.15, \mathrm{~m}$ \\
\hline $5^{\prime}$ & $2.49, \mathrm{~m}$ & $2.77, \mathrm{q}(9.4)$ & $2.78, \mathrm{q}(9.4)$ \\
\hline \multirow[t]{2}{*}{$6^{\prime}$} & $1.71, \mathrm{t}(10.5)$ & $1.72, \mathrm{dd}(10.8,9.4)$ & $1.72, \mathrm{dd}(10.8,9.4)$ \\
\hline & $1.58, \mathrm{dd}(10.5,7.7)$ & $1.68, \mathrm{t}(10.8)$ & $1.67, \mathrm{t}(10.8)$ \\
\hline $8^{\prime}$ & $1.93, \mathrm{~m}$ & $1.62, \operatorname{td}(10.8,2.4)$ & $1.63, \operatorname{td}(10.8,2.4)$ \\
\hline \multirow[t]{2}{*}{$9^{\prime}$} & 1.78 , overlap & $1.54, \mathrm{~m}$ & $1.54, \mathrm{~m}$ \\
\hline & $1.47, \mathrm{~m}$ & 1.47 , overlap & 1.49 , overlap \\
\hline \multirow[t]{2}{*}{$10^{\prime}$} & $2.22, \mathrm{~m}$ & $2.15, \mathrm{~m}$ & 2.15 , overlap \\
\hline & 1.93 , overlap & $1.87, \mathrm{dd}(15.3,8.6)$ & $1.87, \mathrm{dd}(15.3,8.6)$ \\
\hline $12^{\prime}$ & $0.99, \mathrm{~s}$ & $0.96, \mathrm{~s}$ & $0.97, \mathrm{~s}$ \\
\hline $13^{\prime}$ & $0.96, \mathrm{~s}$ & $0.98, \mathrm{~s}$ & $0.99, \mathrm{~s}$ \\
\hline $14^{\prime}$ & $1.19, \mathrm{~s}$ & $1.12, \mathrm{~s}$ & $1.13, \mathrm{~s}$ \\
\hline \multirow[t]{2}{*}{$15^{\prime}$} & 4.90, brs & $4.82, \mathrm{brs}$ & 4.83, brs \\
\hline & 4.89 , brs & 4.74 , brs & 4.75 , brs \\
\hline
\end{tabular}




\section{SI-2. Experimental procedures}

\subsection{General experimental procedures}

Melting points were obtained on an X-4 micro melting point apparatus. Optical rotations were measured on a Jasco P-1020 polarimeter. UV spectra were detected on a Shmadzu UV-2401PC spectrometer. IR spectra were determined on a Bruker FT-IR Tensor-27 infrared spectrophotometer with $\mathrm{KBr}$ disks. All the 1D and 2D NMR spectra were recorded on Bruker DRX-600 spectrometers using TMS as an internal standard. Unless otherwise specified, chemical shifts $(\delta)$ were expressed in ppm with reference to the solvent signals. ESIMS and HR-ESIMS analysis were carried out on Waters Xevo TQS and Agilent G6230 TOF mass spectrometers, respectively. Semi-preparative HPLC was performed on an Agilent $1100 \mathrm{HPLC}$ with a ZORBAX SB-C ${ }_{18}(9.4 \times 250 \mathrm{~mm})$ column and a Waters 2695 HPLC with a CHIRALCEL OJ-RH column $[4.6 \times 150 \mathrm{~mm}$ cellulose tris-(4-methylbenzoate) coated on $5 \mu \mathrm{m}$ silica-gel]. Silica gel (100-200 and 200-300 mesh, Qingdao Marine Chemical Co., Ltd., People' s Republic of China), and MCI gel (75-150 $\mu \mathrm{m}$, Mitsubishi Chemical Corporation, Tokyo, Japan) were used for column chromatography. Fractions were monitored by TLC (GF 254, Qingdao Marine Chemical Co., Ltd.), and spots were visualized by heating silica gel plates immersed in $\mathrm{H}_{2} \mathrm{SO}_{4}$ in ethanol.

\subsection{Extraction and isolation}

The whole plants (Hypericum japonicum) were bought in Kunming, People's Republic of China, in March 2014. Later, the materials were found out to be collected in Jingxi county, Guangxi province, China. The plant was identified by Dr. W. Fang, and a voucher specimen $201403 \mathrm{H} 01$ has been deposited at the Kunming Institute of Botany. The plants material of $H$. japonicum (14.0 kg) were powdered and percolated with $\mathrm{MeOH}(2 \times 16 \mathrm{~L})$ at room temperature for $24 \mathrm{~h}$, filtered, and the solvent evaporated in vacuo. The crude extract $(2.5 \mathrm{~kg})$ was subjected to silica gel column chromatography eluted with $\mathrm{CHCl}_{3}$ to afford a fraction $(164.2 \mathrm{~g})$. This fraction was separated on an MCI-gel column (MeOH-H $\mathrm{H}_{2} \mathrm{O}$ from 7:3 to 10:0) to obtain five fractions (Fr. A-E). Fr. B (25.5 g) was chromatographed on a silica gel column, eluted with petroleum ether-acetone (from 1:0 to 10:1), to yield four fractions (Fr. B1-B4). Fr. B2 (7.5 g) was further purified by preparative HPLC ( $\left.\mathrm{MeOH}-\mathrm{H}_{2} \mathrm{O}, 92: 8\right)$ to afford $\mathbf{1}(130 \mathrm{mg}), 2$ (540 mg) 3 (250 mg), 4 (520 mg), and 5 (260 mg). 


\subsection{Cytotoxicity Bioassay}

Colorimetric assays were performed to evaluate compound activity. The following human tumor cell lines were used: AGS human gastric cancer, Hela human cervical carcinoma, HepG2 human liver cancer, HCT116 human colon cancer, MDA-MB-468 human breast cancer, and PANC-1 human pancreatic carcinoma. All cells were cultured in RPMI-1640 or DMEM medium (Hyclone, Logan, UT), supplemented with $10 \%$ fetal bovine serum (Hyclone) at $37{ }^{\circ} \mathrm{C}$ in a humidified atmosphere with $5 \% \mathrm{CO}_{2}$. Cell viability was assessed by conducting colorimetric measurements of the amount of insoluble formazan formed in living cells based on the reduction of 3-(4,5-dimethylthiazol-2-yl)-2,5-diphenyltetrazolium bromide (MTT). Briefly, $100 \mu \mathrm{L}$ adherent cells were seeded into each well of a 96-well cell culture plate and allowed to adhere for $12 \mathrm{~h}$ before test compound addition, while suspended cells were seeded just before this step, both with initial density of $1 \times 10^{5}$ cells $/ \mathrm{mL}$ in $100 \mu \mathrm{L}$ of medium. Each tumor cell line was exposed to the test compound at various concentrations in triplicate for $48 \mathrm{~h}$, with cis-platin (Sigma) as positive control. After the incubation, MTT $(100 \mu \mathrm{g})$ was added to each well, and the incubation continued for $4 \mathrm{~h}$ at $37{ }^{\circ} \mathrm{C}$. The cells were lysed with $100 \mu \mathrm{L}$ of $20 \%$ SDS-50\% DMF after removal of $100 \mu \mathrm{L}$ of medium. The optical density of the lysate was measured at $595 \mathrm{~nm}$ in a 96-well microtiter plate reader (Bio-Rad 680). The $\mathrm{IC}_{50}$ value of each compound was calculated by Reed and Muench's method.

\subsection{Hsp90 dependent luciferase refolding assay}

Introduction for Hsp90: The $90 \mathrm{kDa}$ heat-shock protein (Hsp90) and other cochaperones allow for proper folding of nascent or misfolded polypeptides. Cancer cells exploit these chaperones by maintaining the stability of mutated and misfolded oncoproteins and allowing them to evade proteosomal deg-radation. Inhibiting Hsp90 is an attractive strategy for cancer therapy, as the concomitant degradation of multiple oncoproteins may lead to effective anti-neoplastic agents.

Briefly, refolding of denatured firefly luciferase was performed on the basis of rabbit reticulocyte lysate system, which contains Hsp90 and all the requisite co-chaperones and partner proteins necessary to facilitate Hsp90 client protein folding, maturation and activation. Firefly luciferase was prewarmed $\left(41^{\circ} \mathrm{C}\right)$ for 10 minutes to denature the activity. Compounds were added and renaturation mixture containing denatured firefly luciferase and rabbit reticulocyte lysate was dispensed in each 
well. Three hours later, luciferase activity was measured by the addition of $40 \mu \mathrm{L}$ luciferin substrate solution and read on a Synergy ${ }^{\mathrm{TM}} \mathrm{HT}$ multi-detection reader. $\mathrm{IC}_{50}$ values were calculated from data normalized to control using a non-linear regression and sigmoidal dose response curves (GraphPad Prism).

\section{SI-3. The physical data of the new compounds}

Hyperjapone A (1): colorless block crystal; $\mathrm{mp} 180-181^{\circ} \mathrm{C} ;[\alpha]^{21}{ }_{\mathrm{D}}+17(c \mathrm{c} 0.24, \mathrm{MeOH})$ for $(+)-1$; $[\alpha]^{21}{ }_{\mathrm{D}}-20(c 0.24, \mathrm{MeOH})$ for (-)-1; UV (MeOH) $\lambda_{\max }(\log \varepsilon) 201$ (3.97), 242 (2.94), 293 (3.82), 320 (3.90) nm; IR (KBr) $v_{\max } 3435,2964,2932,2868,1660,1627,1561,1532,1471,1414,1382,1315$, 1189, 1160, 1135, 1103, 1048, $984 \mathrm{~cm}^{-1}$; CD (0.0022 M, MeOH) $\lambda_{\max }(\Delta \varepsilon) 196(-5.3), 205(+1.5)$, $238(+2.8), 348(-0.33) \mathrm{nm}$ for (+)-1; $\mathrm{CD}(0.0016 \mathrm{M}, \mathrm{MeOH}) \lambda_{\max }(\Delta \varepsilon) 196(+8.1), 205(-1.8), 238$ (-3.1), $348(+0.31) \mathrm{nm}$ for $(-)-\mathbf{1} ;{ }^{1} \mathrm{H}$ and ${ }^{13} \mathrm{C}$ NMR data, see Table 1; TOFMS $\mathrm{m} / \mathrm{z}, 441[\mathrm{M}+\mathrm{H}]^{+}$; HRESIMS $m / z 441.2999[\mathrm{M}+\mathrm{H}]^{+}\left(\right.$calcd for $\left.\mathrm{C}_{28} \mathrm{H}_{41} \mathrm{O}_{4}, 441.2999\right)$.

Hyperjapone $B(2)$ : colorless block crystal; mp $148-149{ }^{\circ} \mathrm{C} ;[\alpha]^{23}{ }_{\mathrm{D}}+5(c 0.15, \mathrm{MeOH})$; UV (MeOH) $\lambda_{\max }(\log \varepsilon) 203$ (4.15), 243 (4.15), 320 (4.10) nm; IR (KBr) $v_{\max }$ 3437, 2954, 2930, 2869, $1660,1629,1527,1470,1382,1321,1276,1199,1118,892 \mathrm{~cm}^{-1}$; CD $(0.0007 \mathrm{M}, \mathrm{MeOH}) \lambda_{\max }(\Delta \varepsilon)$ $198(-8.5), 230(+8.5), 272(+2.4), 310(+1.5) \mathrm{nm} ;{ }^{1} \mathrm{H}$ and ${ }^{13} \mathrm{C}$ NMR data, see Table 1; ESIMS $\mathrm{m} / \mathrm{z}$ $441[\mathrm{M}+\mathrm{H}]^{+} ;$HRESIMS $\mathrm{m} / z 441.2998[\mathrm{M}+\mathrm{H}]^{+}\left(\right.$calcd for $\left.\mathrm{C}_{28} \mathrm{H}_{41} \mathrm{O}_{4}, 441.2999\right)$.

Hyperjapone $C$ (3): colorless block crystal; mp $146-148{ }^{\circ} \mathrm{C} ;[\alpha]^{23}{ }_{\mathrm{D}}+13($ c $0.10, \mathrm{MeOH})$; UV (MeOH) $\lambda_{\max }(\log \varepsilon) 202$ (4.05), 243 (4.03), 298 (3.94), 321 (4.01) nm; IR (KBr) $v_{\max }$ 3442, 2957, $2929,2870,1659,1629,1553,1469,1415,1382,1199,891 \mathrm{~cm}^{-1}$; CD $(0.001 \mathrm{M}, \mathrm{MeOH}) \lambda_{\max }(\Delta \varepsilon)$ 197 (-7.5), $228(+7.2), 273(+2.6), 320(+0.9) \mathrm{nm} ;{ }^{1} \mathrm{H}$ and ${ }^{13} \mathrm{C}$ NMR data, see Tables S1 and S2; ESIMS $m / z 455[\mathrm{M}+\mathrm{H}]^{+} ;$HRESIMS $m / z 455.3158[\mathrm{M}+\mathrm{H}]^{+}\left(\right.$calcd for $\left.\mathrm{C}_{29} \mathrm{H}_{43} \mathrm{O}_{4}, 455.3156\right)$.

Hyperjapone D (4): colorless gum; $[\alpha]^{23}{ }_{\mathrm{D}}-50(c$ 0.10, $\mathrm{MeOH}) ; \mathrm{UV}(\mathrm{MeOH}) \lambda_{\max }(\log \varepsilon) 201$ (4.12), 243 (4.09), 296 (3.97), 320 (4.03) nm; IR (KBr) $v_{\max }$ 3435, 2931, 2867, 1658, 1629, 1564, $1467,1414,1382,1282,1203,1164,1145,1061,888 \mathrm{~cm}^{-1}$; CD (0.001 M, MeOH) $\lambda_{\max }(\Delta \varepsilon) 200$ (+14.4), $235(-5.1), 319(-1.2) \mathrm{nm} ;{ }^{1} \mathrm{H}$ and ${ }^{13} \mathrm{C}$ NMR data, see Tables S1 and S2; TOFMS $\mathrm{m} / \mathrm{z} 441$ $[\mathrm{M}+\mathrm{H}]^{+} ;$HRESIMS $m / z 441.3001[\mathrm{M}+\mathrm{H}]^{+}\left(\right.$calcd for $\left.\mathrm{C}_{28} \mathrm{H}_{41} \mathrm{O}_{4}, 441.2999\right)$. 
Hyperjapone E (5): colorless block crystal; mp $145-146{ }^{\circ} \mathrm{C}$; $[\alpha]^{23}{ }_{\mathrm{D}}-41$ (c $\left.0.10, \mathrm{MeOH}\right)$; UV $(\mathrm{MeOH}) \lambda_{\max }(\log \varepsilon) 200$ (4.16), 243 (4.19), 298 (4.10), 317 (4.14) nm; IR (KBr) $v_{\max }$ 3442, 2956, 2933, 2870, 1660, 1628, 1530, 1469, 1382, 1282, 1202, 1145, 1061, $886 \mathrm{~cm}^{-1}$; CD (0.0006 M, $\mathrm{MeOH}) \lambda_{\max }(\Delta \varepsilon) 199(+18.2), 235(-5.5), 320(-1.7) \mathrm{nm} ;{ }^{1} \mathrm{H}$ and ${ }^{13} \mathrm{C}$ NMR data, see Tables $\mathrm{S} 1$ and S2; ESIMS $m / z 455[\mathrm{M}+\mathrm{H}]^{+}$; HRESIMS $m / z 455.3159[\mathrm{M}+\mathrm{H}]^{+}$(calcd for $\mathrm{C}_{29} \mathrm{H}_{43} \mathrm{O}_{4}, 455.3156$ ).

Crystallographic Data of 1: $\mathrm{C}_{28} \mathrm{H}_{40} \mathrm{O}_{4}, M=440.60$, monoclinic, $a=11.2485(3) \AA, b=11.2825(3) \AA$, $c=20.3694(6) \AA, \alpha=90.00^{\circ}, \beta=100.5590(10)^{\circ}, \gamma=90.00^{\circ}, V=2541.33(12) \AA^{3}, T=100(2) \mathrm{K}$, space group $P 2{ }_{1} / n, Z=4, \mu(\mathrm{CuK} \alpha)=0.592 \mathrm{~mm}^{-1}, 21467$ reflections measured, 4364 independent reflections $\left(R_{\text {int }}=0.0339\right)$. The final $R_{I}$ values were $0.0500(I>2 \sigma(I))$. The final $w R\left(F^{2}\right)$ values were $0.1211(I>2 \sigma(I))$. The final $R_{l}$ values were 0.0505 (all data). The final $w R\left(F^{2}\right)$ values were 0.1214 (all data). The goodness of fit on $F^{2}$ was 1.126. Crystallographic data for $\mathbf{1}$ have been deposited at the Cambridge Crystallographic Data Center (deposition number CCDC 1430903). Copies of the data can be obtained free of charge via www. ccdc.cam.ac.uk.

Crystallographic Data of 2: $\mathrm{C}_{28} \mathrm{H}_{40} \mathrm{O}_{4}, M=440.60$, orthorhombic, $a=8.6184(2) \AA$, $b=16.3163(4)$ $\AA, c=17.7667(4) \AA, \alpha=\beta=\gamma=90^{\circ}, V=2498.36(10) \AA^{3}, T=100(2) \mathrm{K}$, space group $P 2{ }_{1} 2_{1} 2_{1}, Z=4$, $\mu(\mathrm{CuK} \alpha)=0.602 \mathrm{~mm}^{-1}, 13566$ reflections measured, 4287 independent reflections $\left(R_{\text {int }}=0.0475\right)$. The final $R_{l}$ values were $0.0336(I>2 \sigma(I))$. The final $w R\left(F^{2}\right)$ values were $0.0864(I>2 \sigma(I))$. The final $R_{l}$ values were 0.0338 (all data). The final $w R\left(F^{2}\right)$ values were 0.0866 (all data). The goodness of fit on $F^{2}$ was 1.062. Flack parameter $=0.15(16)$. The Hooft parameter is 0.09(7) for 1741 Bijvoet pairs. (CCDC 1430904).

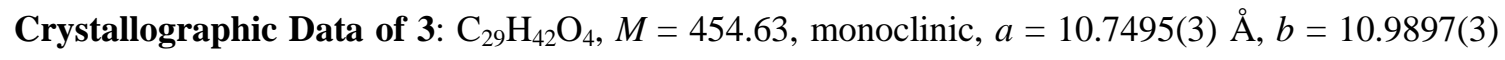
$\AA, c=11.3193(3) \AA, \alpha=90.00^{\circ}, \beta=106.9280(10)^{\circ}, \gamma=90.00^{\circ}, V=1279.25(6) \AA^{3}, T=100(2) \mathrm{K}$, space group $P 2_{1}, Z=2, \mu(\mathrm{CuK} \alpha)=0.602 \mathrm{~mm}^{-1}, 10207$ reflections measured, 4140 independent reflections $\left(R_{\text {int }}=0.0303\right)$. The final $R_{l}$ values were $0.0313(I>2 \sigma(I))$. The final $w R\left(F^{2}\right)$ values were $0.0803(I>2 \sigma(I))$. The final $R_{l}$ values were 0.0313 (all data). The final $w R\left(F^{2}\right)$ values were 0.0804 (all data). The goodness of fit on $F^{2}$ was 1.050. Flack parameter $=0.13(15)$. The Hooft parameter is 0.06(5) for 1716 Bijvoet pairs. (CCDC 1430905).

Crystallographic Data of 5: $\mathrm{C}_{29} \mathrm{H}_{42} \mathrm{O}_{4}, M=454.63$, monoclinic, $a=11.0867(4) \AA, b=10.5463(4) \AA$, 
$c=11.7485(4) \AA, \alpha=90.00^{\circ}, \beta=109.1970(10)^{\circ}, \gamma=90.00^{\circ}, V=1297.29(8) \AA^{3}, T=100(2) \mathrm{K}$, space group $P 2_{1}, Z=2, \mu(\mathrm{CuK} \alpha)=0.594 \mathrm{~mm}^{-1}, 10495$ reflections measured, 4012 independent reflections $\left(R_{\text {int }}=0.0460\right)$. The final $R_{l}$ values were $0.0709(I>2 \sigma(I))$. The final $w R\left(F^{2}\right)$ values were $0.1900(I>$ $2 \sigma(I)$ ). The final $R_{l}$ values were 0.0710 (all data). The final $w R\left(F^{2}\right)$ values were 0.1902 (all data). The goodness of fit on $F^{2}$ was 1.116 . Flack parameter $=-0.2(2)$. The Hooft parameter is $0.00(7)$ for 1568 Bijvoet pairs. (CCDC 1430906).

\section{SI-4 Chiral resolution of 1 by different materials}

Table S3. Chiral materials and methods to separate ( \pm )-1

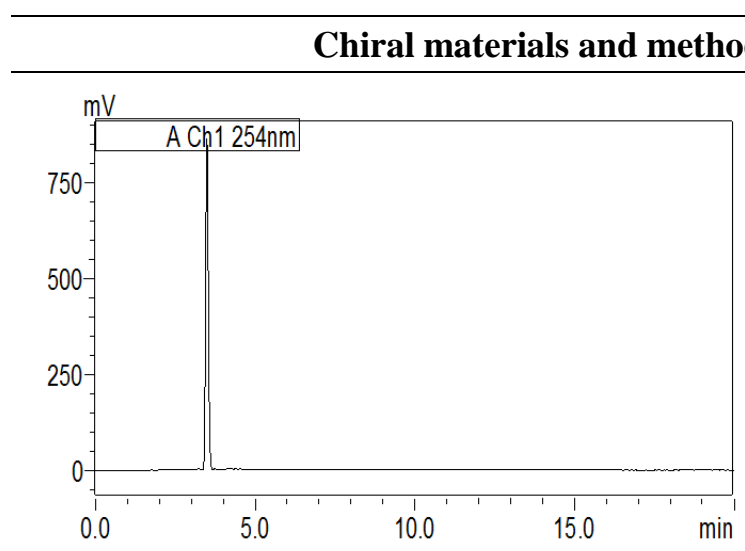

Column type: CHIRALCEL IA

Material: amylose tris-(3,5-

dimethylphenylcarbamate) immobilized on $3 \mu \mathrm{m} \&$ $5 \mu \mathrm{m}$ silica support

Mobile phase: 95 hexane-5 isopropanol (0.1\% TFA)

Flow rate: $1 \mathrm{~mL} / \mathrm{min}$; temperature: $35^{\circ} \mathrm{C}$

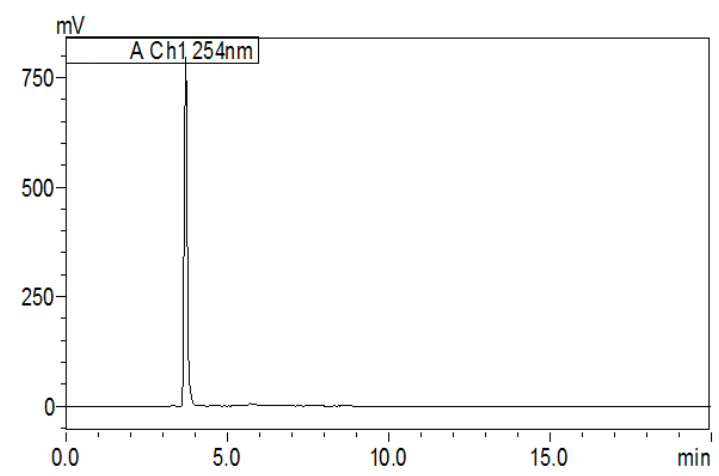

Column type: CHIRALCEL IC

Material: cellulose tris-(3,5-

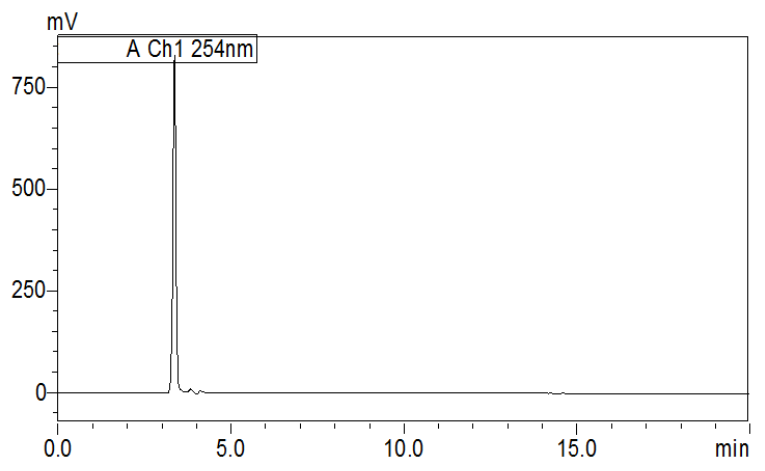

Column type: CHIRALCEL IB

Material: cellulose tris-(3,5-

dimethylphenylcarbamate) immobilized on $3 \mu \mathrm{m} \& 5$ $\mu \mathrm{m}$ silica support

Mobile phase: 95 hexane-5 isopropanol (0.1\% TFA)

Flow rate: $1 \mathrm{~mL} / \mathrm{min}$; temperature: $35^{\circ} \mathrm{C}$

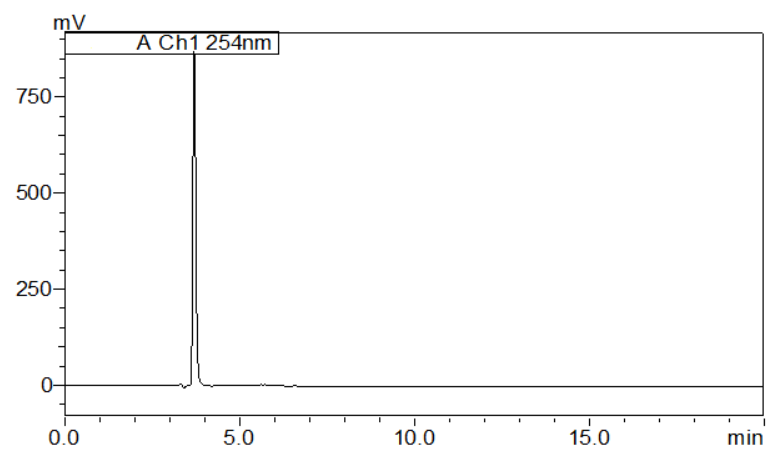

Column type: CHIRALCEL ID

Material: amylose tris-(3dichlorophenylcarbamate) immobilized on $3 \mu \mathrm{m} \&$ $5 \mu \mathrm{m}$ silica support chlorophenylcarbamate) immobilized on $3 \mu \mathrm{m} \& 5$ $\mu \mathrm{m}$ silica support 
Mobile phase: 95 hexane-5 isopropanol (0.1\% TFA) Mobile phase: 95 hexane-5 isopropanol (0.1\% TFA)

Flow rate: $1 \mathrm{~mL} / \mathrm{min}$; temperature: $35^{\circ} \mathrm{C}$

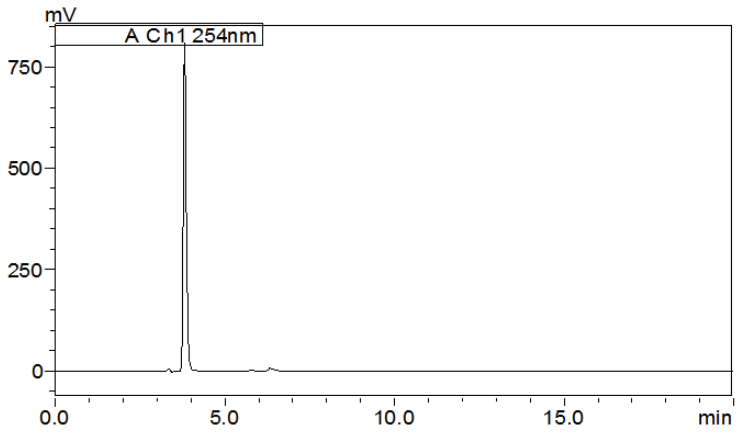

Column type: CHIRALCEL IE

Material: amylose tris-(3,5-

dichlorophenylcarbamate) immobilized on $3 \mu \mathrm{m} \&$ $5 \mu \mathrm{m}$ silica support

Mobile phase: 95 hexane-5 isopropanol (0.1\% TFA)

Flow rate: $1 \mathrm{~mL} / \mathrm{min}$; temperature: $35^{\circ} \mathrm{C}$

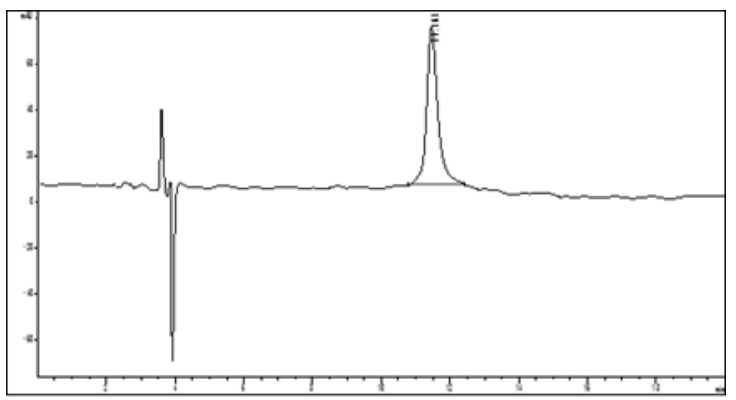

Column type: CHIRALCEL IA

Material: amylose tris-(3,5-

dimethylphenylcarbamate) immobilized on $3 \mu \mathrm{m} \&$

$5 \mu \mathrm{m}$ silica support

Mobile phase: $80 \mathrm{ACN}-20 \mathrm{H}_{2} \mathrm{O}\left(10 \mathrm{mM} \mathrm{NH}_{4} \mathrm{Ac}\right)$

Flow rate: $0.8 \mathrm{~mL} / \mathrm{min}$; temperature: $25^{\circ} \mathrm{C}$

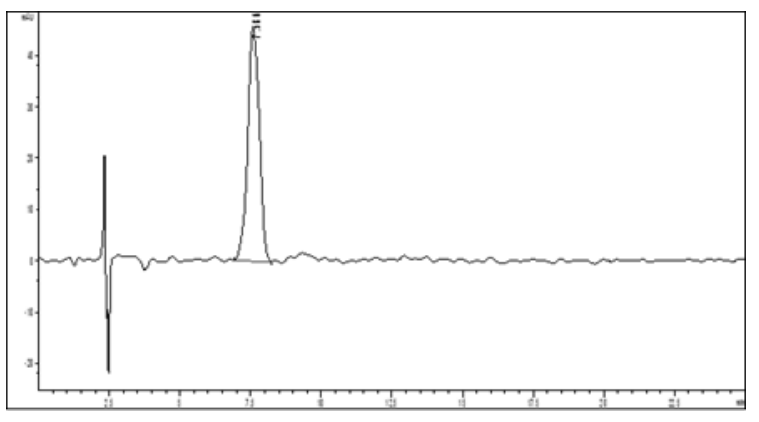

Column type: CHIRALCEL IC

Material: cellulose tris-(3,5-

dichlorophenylcarbamate) immobilized on $3 \mu \mathrm{m} \&$

$5 \mu \mathrm{m}$ silica support

Mobile phase: $80 \mathrm{ACN}-20 \mathrm{H}_{2} \mathrm{O}\left(10 \mathrm{mM} \mathrm{NH}_{4} \mathrm{Ac}\right)$

Flow rate: $0.8 \mathrm{~mL} / \mathrm{min}$; temperature: $25^{\circ} \mathrm{C}$
Flow rate: $1 \mathrm{~mL} / \mathrm{min}$; temperature: $35^{\circ} \mathrm{C}$

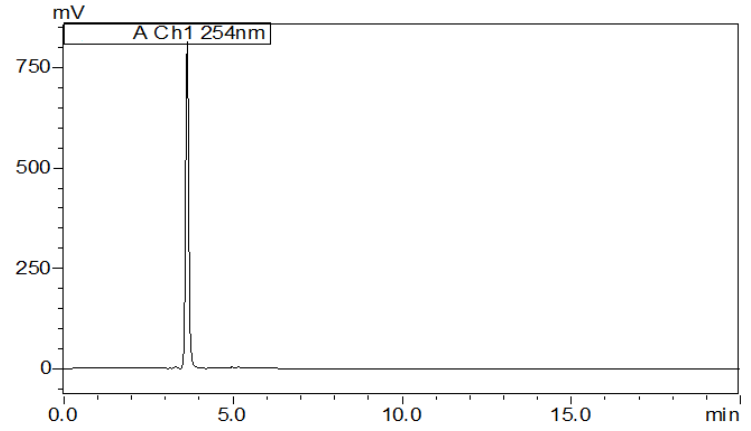

Column type: CHIRALCEL IF

Material: amylose tris-(3-chloro-4-

methylphenylcarbamate) immobilized on $3 \mu \mathrm{m} \& 5$ $\mu \mathrm{m}$ silica support

Mobile phase: 95 hexane-5 isopropanol ( $0.1 \%$ TFA)

Flow rate: $1 \mathrm{~mL} / \mathrm{min}$; temperature: $35{ }^{\circ} \mathrm{C}$

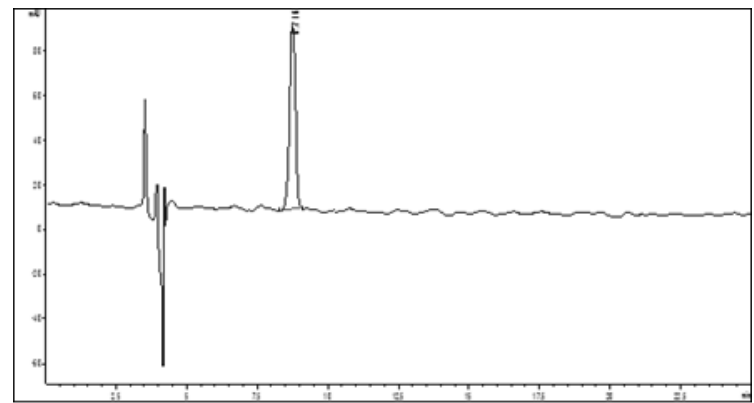

Column type: CHIRALCEL IB

Material: cellulose tris-(3,5-

dimethylphenylcarbamate) immobilized on $3 \mu \mathrm{m} \& 5$ $\mu \mathrm{m}$ silica support

Mobile phase: $80 \mathrm{ACN}-20 \mathrm{H}_{2} \mathrm{O}\left(10 \mathrm{mM} \mathrm{NH}_{4} \mathrm{Ac}\right)$

Flow rate: $0.8 \mathrm{~mL} / \mathrm{min}$; temperature: $25^{\circ} \mathrm{C}$

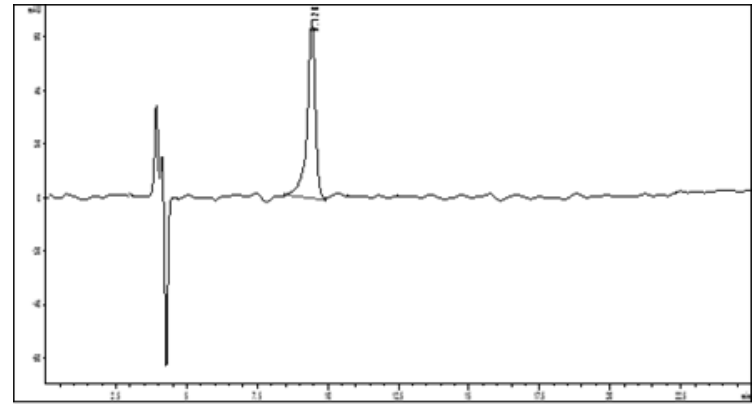

Column type: CHIRALCEL ID

Material: amylose tris-(3-

chlorophenylcarbamate) immobilized on $3 \mu \mathrm{m} \& 5$

$\mu \mathrm{m}$ silica support

Mobile phase: $80 \mathrm{ACN}-20 \mathrm{H}_{2} \mathrm{O}\left(10 \mathrm{mM} \mathrm{NH}_{4} \mathrm{Ac}\right)$

Flow rate: $0.8 \mathrm{~mL} / \mathrm{min}$; temperature: $25^{\circ} \mathrm{C}$ 


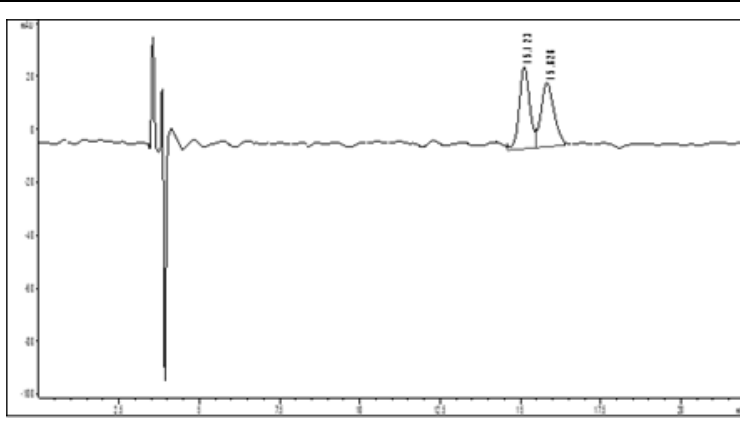

Column type: CHIRALCEL IF

Material: amylose tris-(3-chloro-4methylphenylcarbamate) immobilized on $3 \mu \mathrm{m} \& 5$ $\mu \mathrm{m}$ silica support

Mobile phase: $80 \mathrm{ACN}-20 \mathrm{H}_{2} \mathrm{O}\left(10 \mathrm{mM} \mathrm{NH}_{4} \mathrm{Ac}\right)$

Flow rate: $0.8 \mathrm{~mL} / \mathrm{min}$; temperature: $25^{\circ} \mathrm{C}$

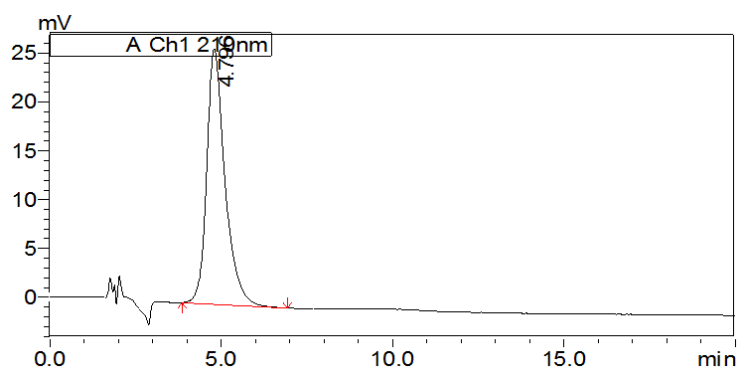

Column type: CHIRALCEL AD-RH

Material: amylose tris-(3,5-

dimthylphenylcarbamate) coated on silica support Mobile phase: $80 \mathrm{ACN}-20 \mathrm{H}_{2} \mathrm{O}$

Flow rate: $1 \mathrm{~mL} / \mathrm{min}$; temperature: $25{ }^{\circ} \mathrm{C}$

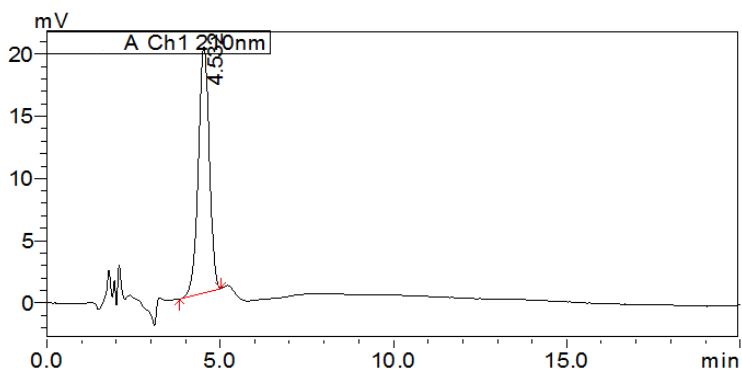

Column type: CHIRALCEL AY-H

Material: amylose tris-(5-chloro-2-

mthylphenylcarbamate) on $3 \mu \mathrm{m} \& 5 \mu \mathrm{m}$ silica-gel

Mobile phase: $80 \mathrm{ACN}-20 \mathrm{H}_{2} \mathrm{O}$

Flow rate: $1 \mathrm{~mL} / \mathrm{min}$; temperature: $25^{\circ} \mathrm{C}$

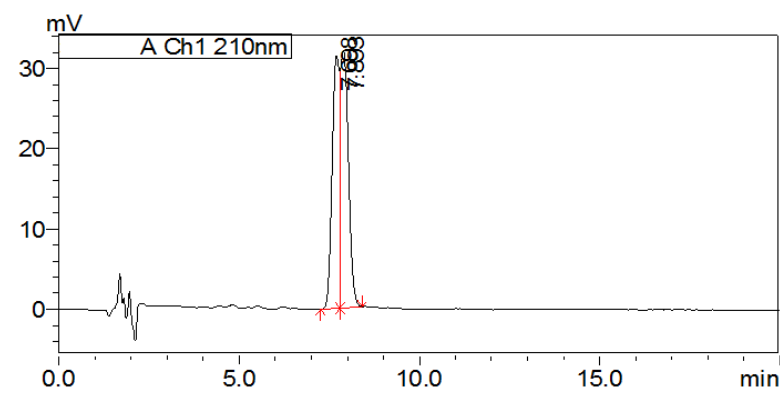

Column type: CHIRALCEL OD-RH

Material: cellulose tris-(3,5-dimethylbenzoate) coated on a silica support

Mobile phase: $80 \mathrm{ACN}-20 \mathrm{H}_{2} \mathrm{O}\left(10 \mathrm{mM} \mathrm{NH}_{4} \mathrm{Ac}\right)$

Flow rate: $0.8 \mathrm{~mL} / \mathrm{min}$; temperature: $25^{\circ} \mathrm{C}$

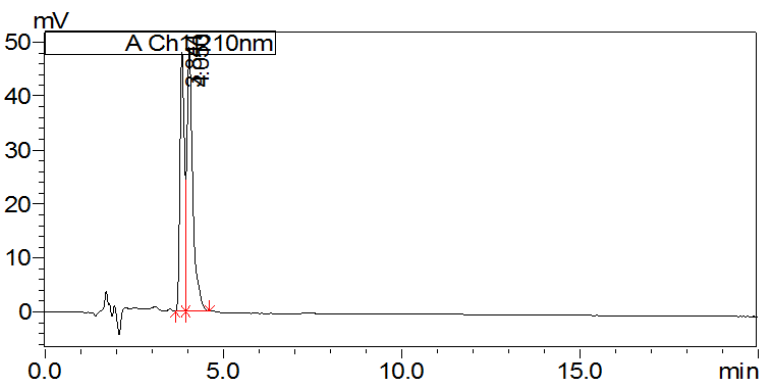

Column type: CHIRALCEL AS-RH

Material: amylose tris- $[(S)-\alpha-3,5-$

mthylphenylcarbamate) coated on silica support

Mobile phase: $80 \mathrm{ACN}-20 \mathrm{H}_{2} \mathrm{O}$

Flow rate: $1 \mathrm{~mL} / \mathrm{min}$; temperature: $25^{\circ} \mathrm{C}$

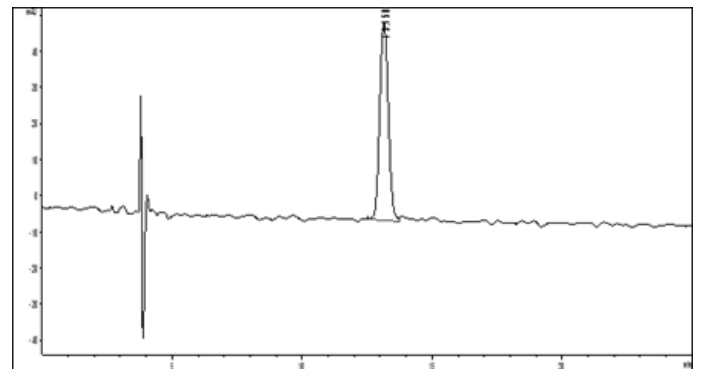

Column type: CHIRALCEL AZ-H

Material: amylose tris-(3-chloro-4-

mthylphenylcarbamate) on $3 \mu \mathrm{m} \& 5 \mu \mathrm{m}$ silica-gel

Mobile phase: $80 \mathrm{ACN}-20 \mathrm{H}_{2} \mathrm{O}$

Flow rate: $1 \mathrm{~mL} / \mathrm{min}$; temperature: $25^{\circ} \mathrm{C}$ 


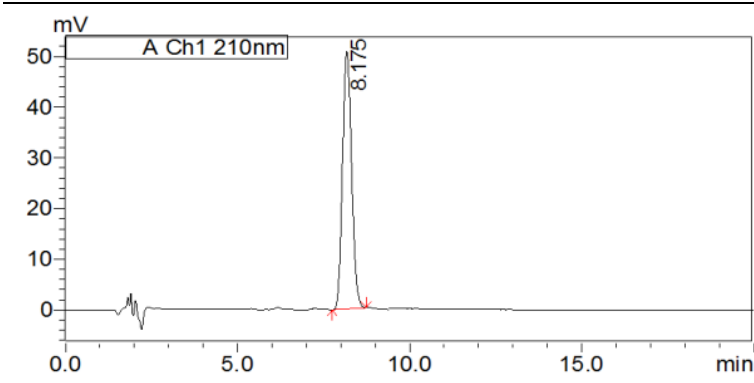

Column type: CHIRALCEL OX-RH

Material: cellulose tris-(4-chloro-3- silica support

Mobile phase: $80 \mathrm{ACN}-20 \mathrm{H}_{2} \mathrm{O}$

Flow rate: $1 \mathrm{~mL} / \mathrm{min}$; temperature: $25^{\circ} \mathrm{C}$

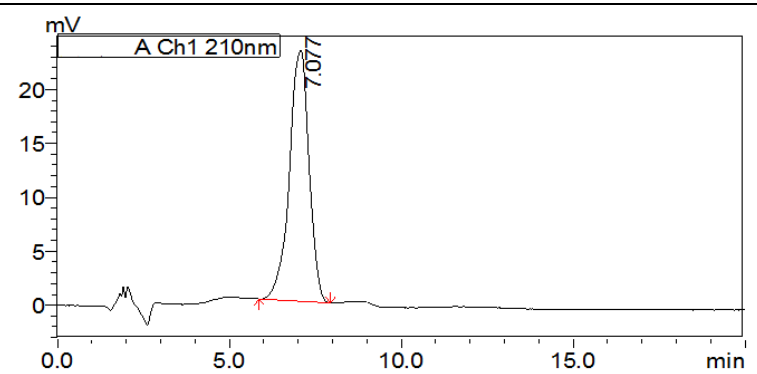

Column type: CHIRALCEL OZ-H

Material: cellulose tris-(3-chloro-4-

Chiral material and methods succeeded to separate the two enantiomers

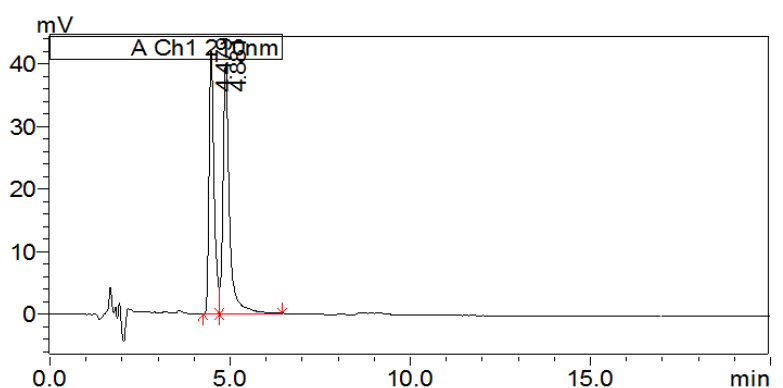

Column type: CHIRALCEL OJ-RH

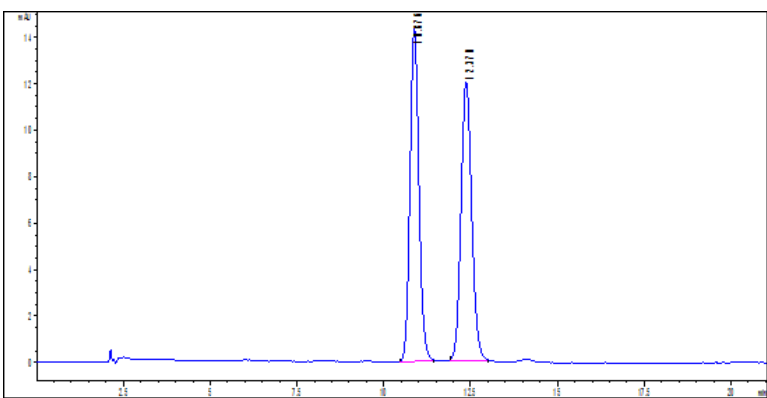

Column type: CHIRALCEL OJ-RH

Material: cellulose tris-(4-methylbenzoate) coated Material: cellulose tris-(4-methylbenzoate) coated on on $5 \mu \mathrm{m}$ silica-gel $5 \mu \mathrm{m}$ silica-gel

Mobile phase: $80 \mathrm{ACN}-20 \mathrm{H}_{2} \mathrm{O}$

Mobile phase: $70 \mathrm{ACN}-30 \mathrm{H}_{2} \mathrm{O}\left(20 \mathrm{mM} \mathrm{NH}_{4} \mathrm{COOH}\right)$

Flow rate: $1 \mathrm{~mL} / \mathrm{min}$; temperature: $25^{\circ} \mathrm{C}$ 


\section{SI-5 The original NMR and MS spectra of the new isolates}
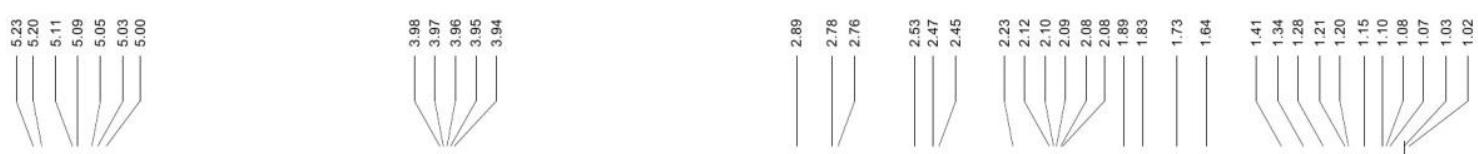<smiles>C/C1=C\CC(C)(C)/C=C/C[C@@]2(C)OC3=C(C[C@H]2CC1)C(C)(C)C(=O)C(C(=O)C(C)C)=C3O</smiles>

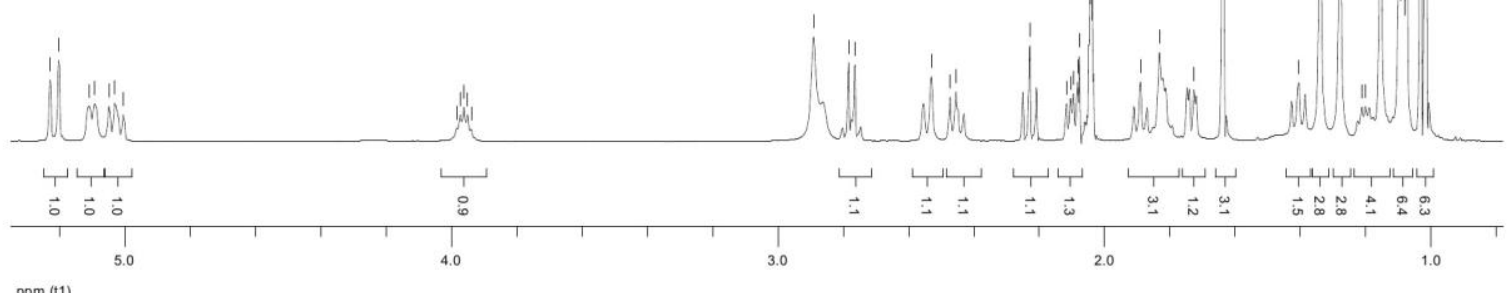

Figure S1. ${ }^{1} \mathrm{H}$ (in acetone- $d_{6}$ ) spectrum of hyperjapone A (1).

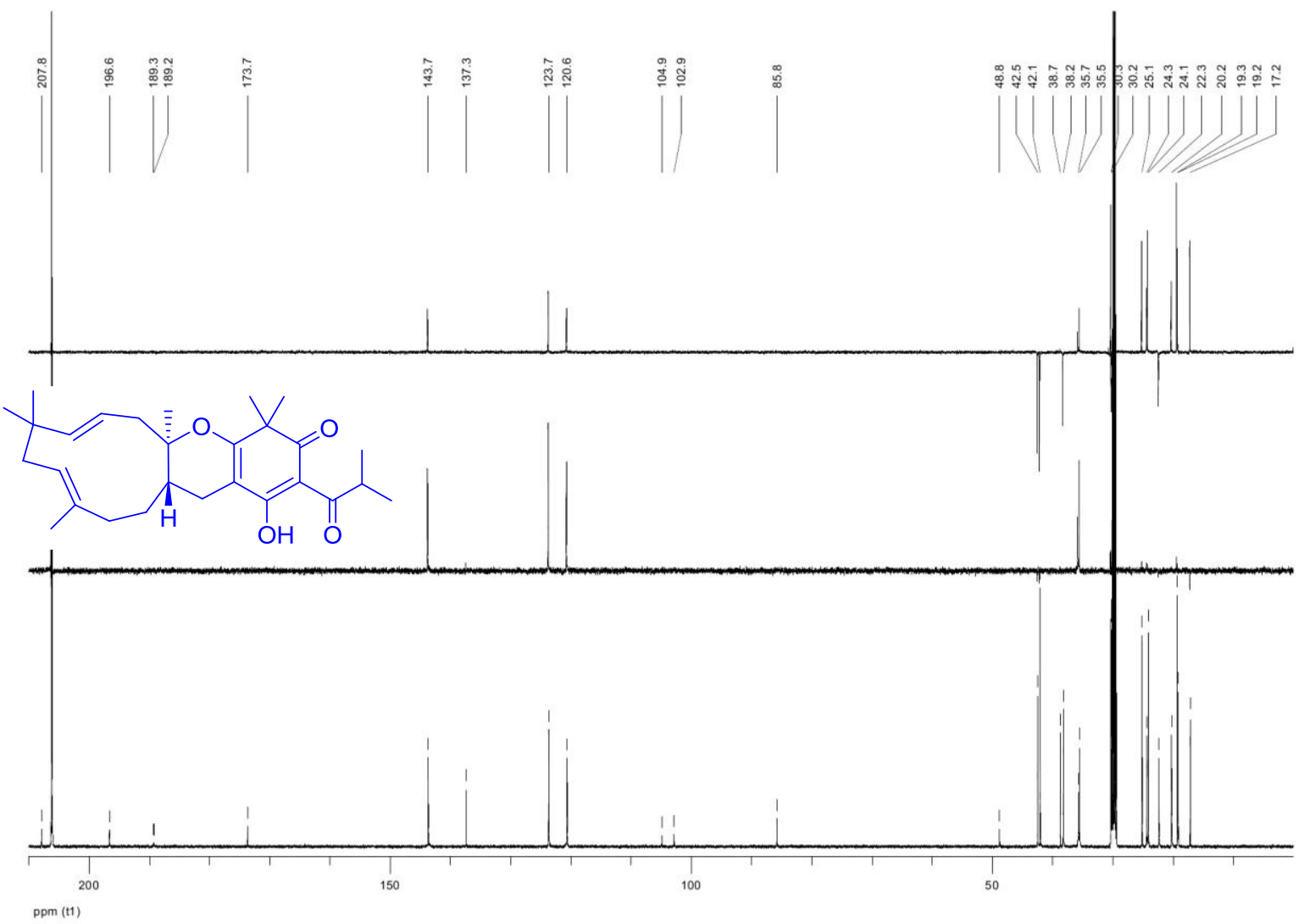

Figure S2. ${ }^{13} \mathrm{C}$ and DEPT (in acetone- $d_{6}$ ) spectra of hyperjapone A (1). 


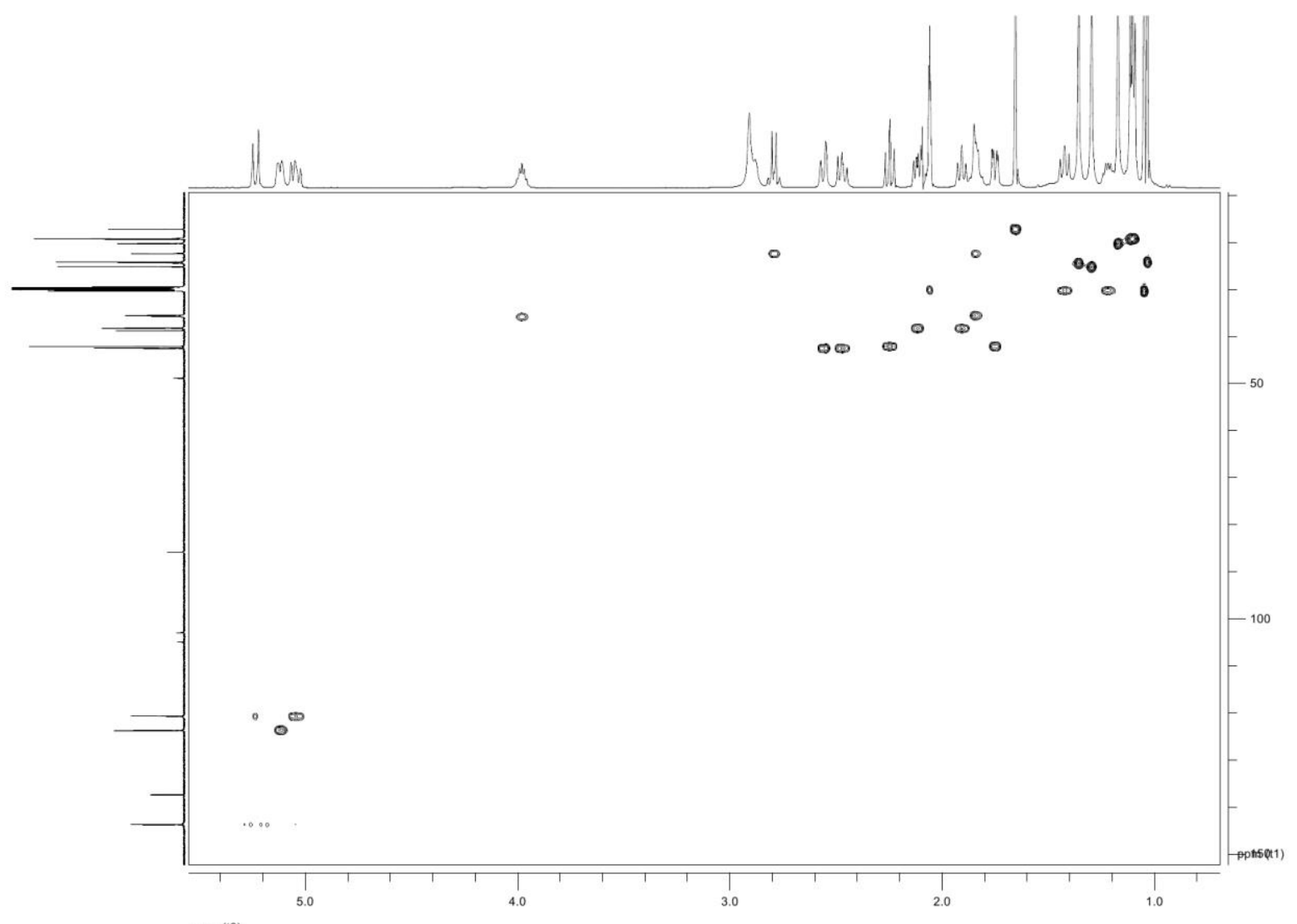

Figure S3. HSQC spectrum of hyperjapone A (1).

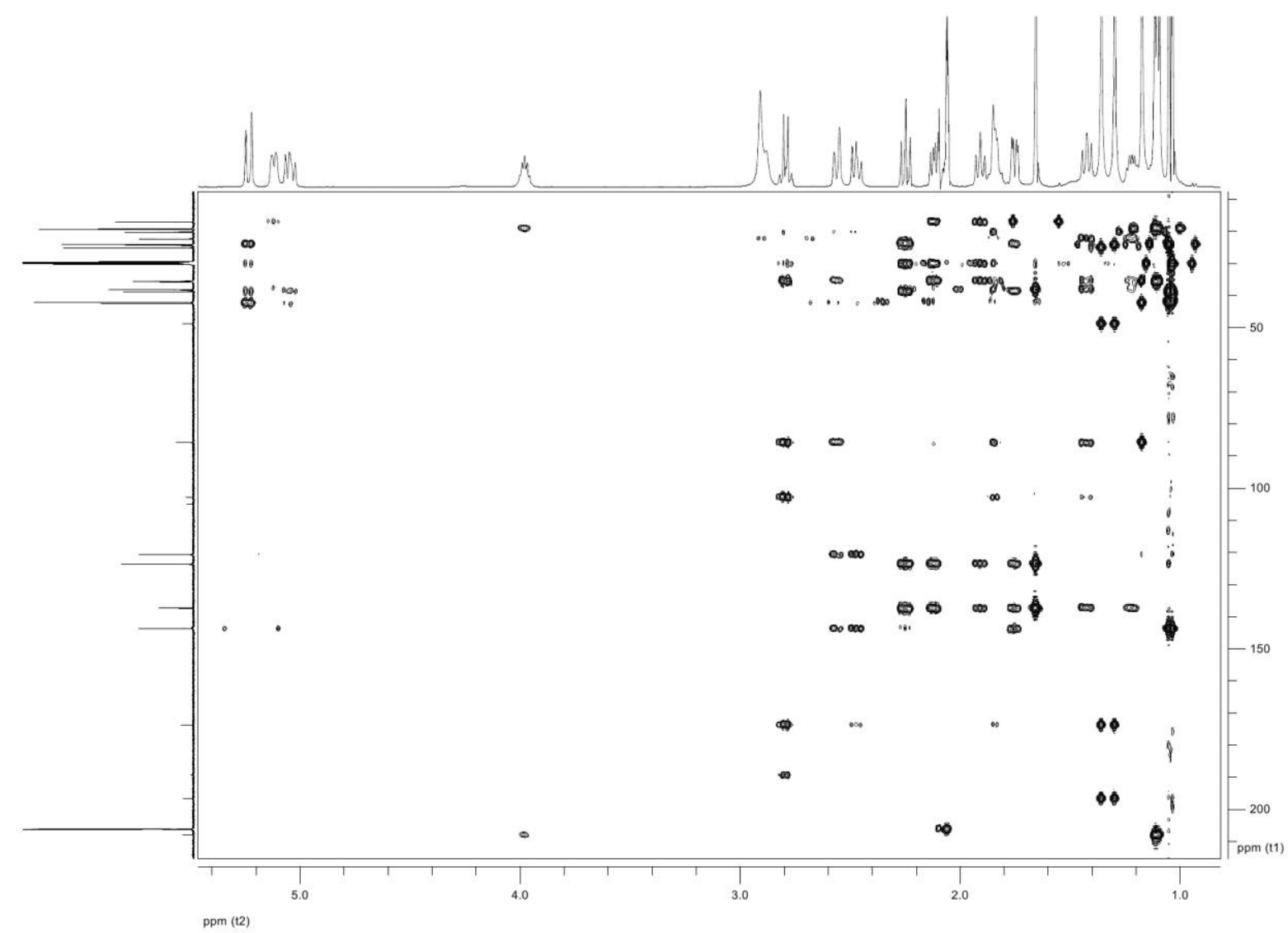

Figure S4. HMBC spectrum of hyperjapone A (1). 


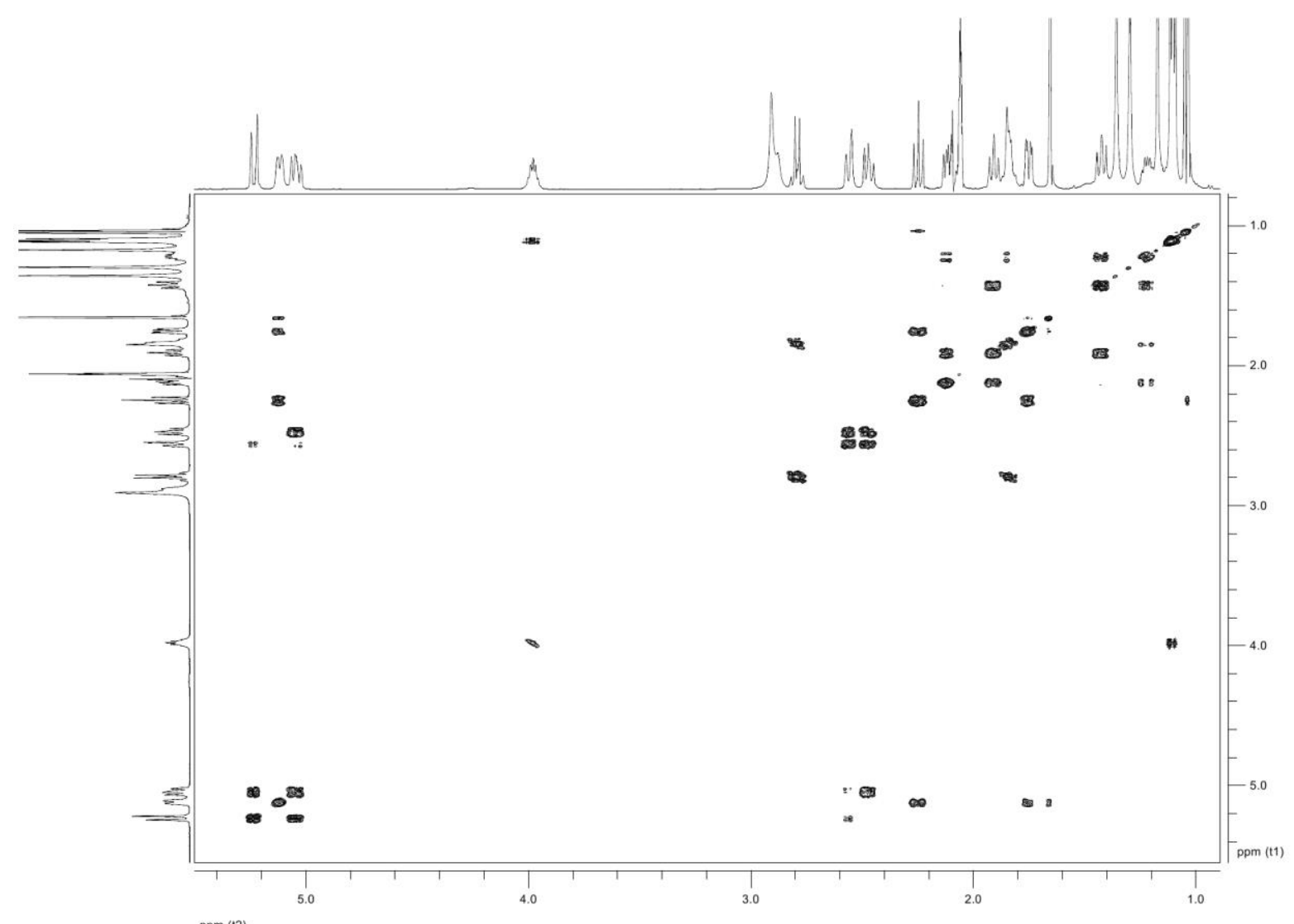

Figure S5. ${ }^{1} \mathrm{H}-{ }^{1} \mathrm{H}$ COSY spectrum of hyperjapone A (1).

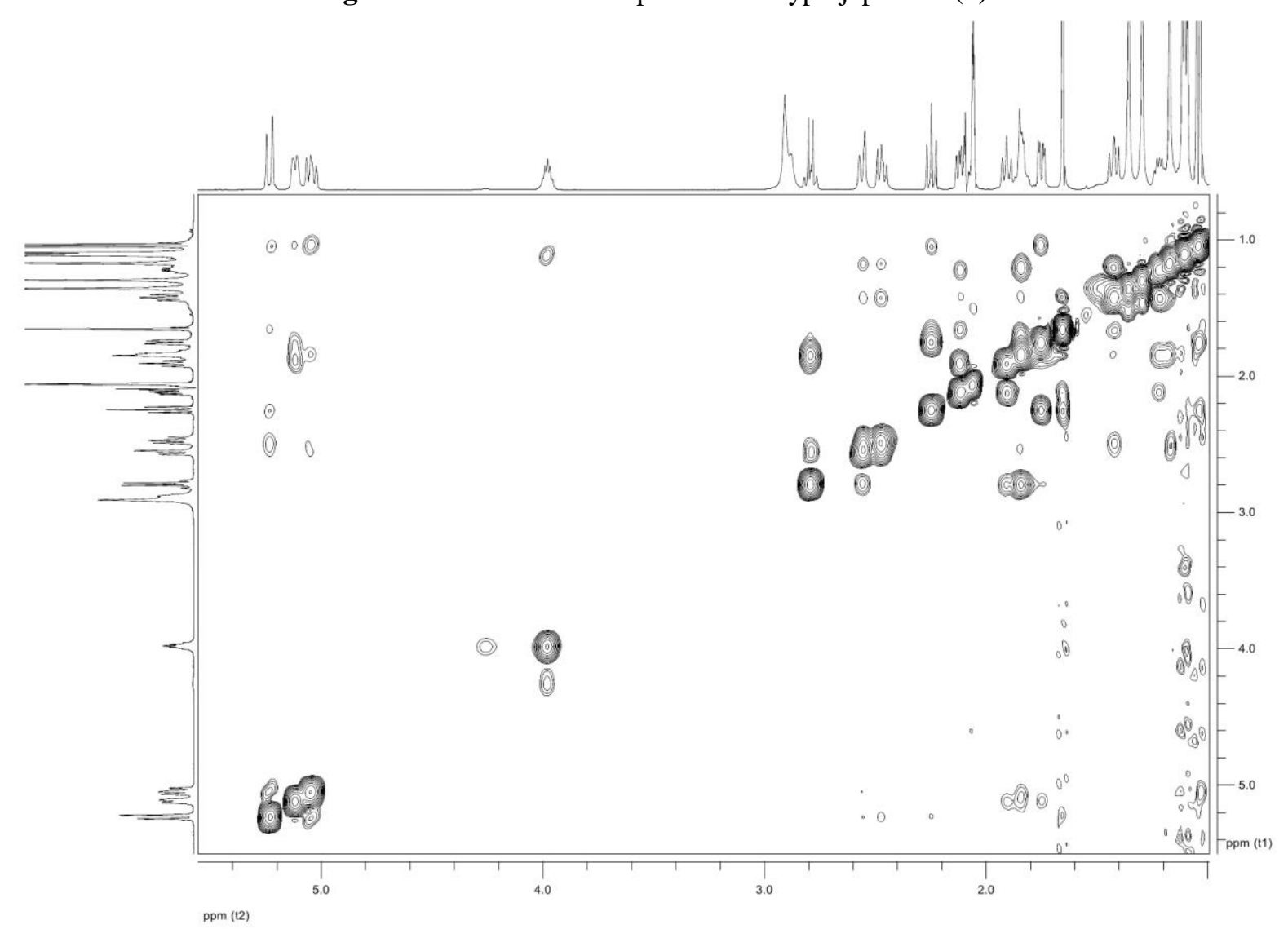

Figure S6. ROESY spectrum of hyperjapone A (1). 


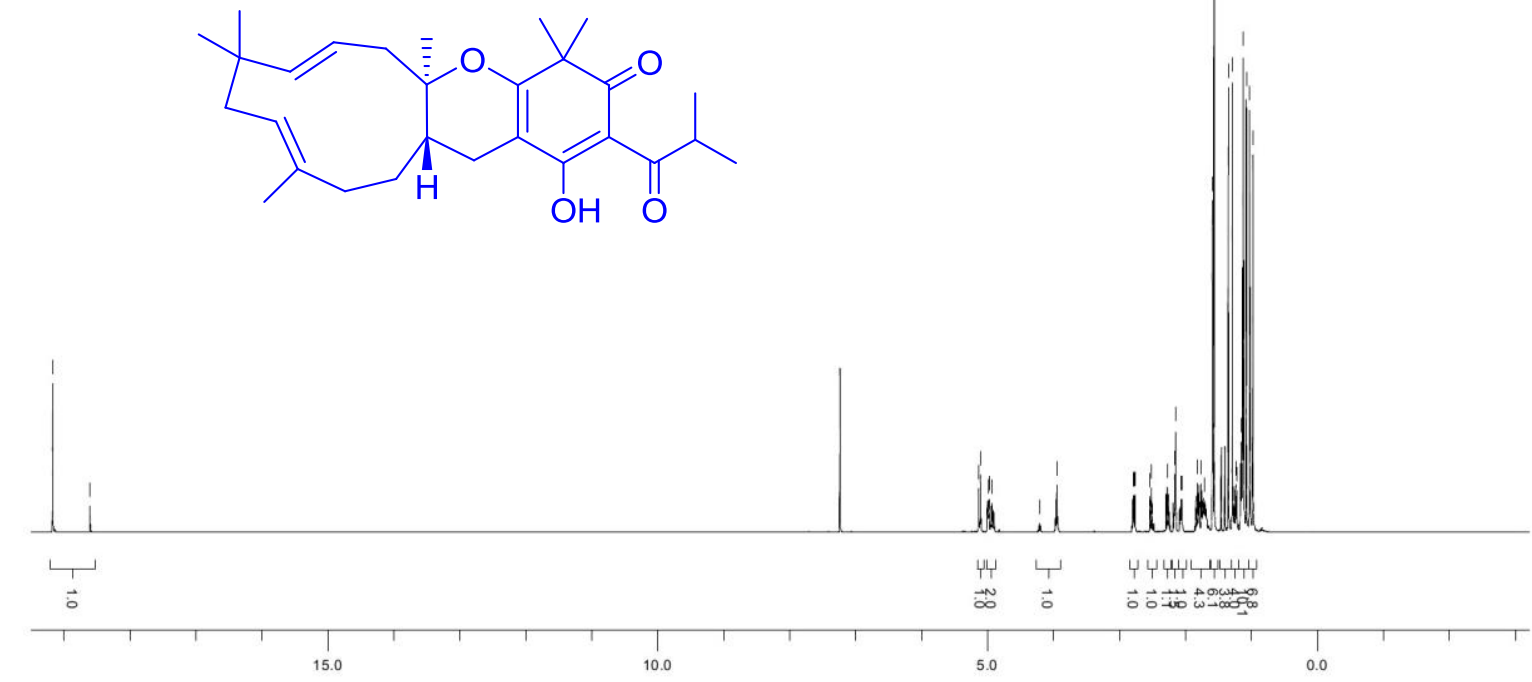

ppm (11)

Figure S7. ${ }^{1} \mathrm{H}$ (in $\mathrm{CDCl}_{3}$ ) spectrum of hyperjapone $\mathrm{A}(\mathbf{1})$.

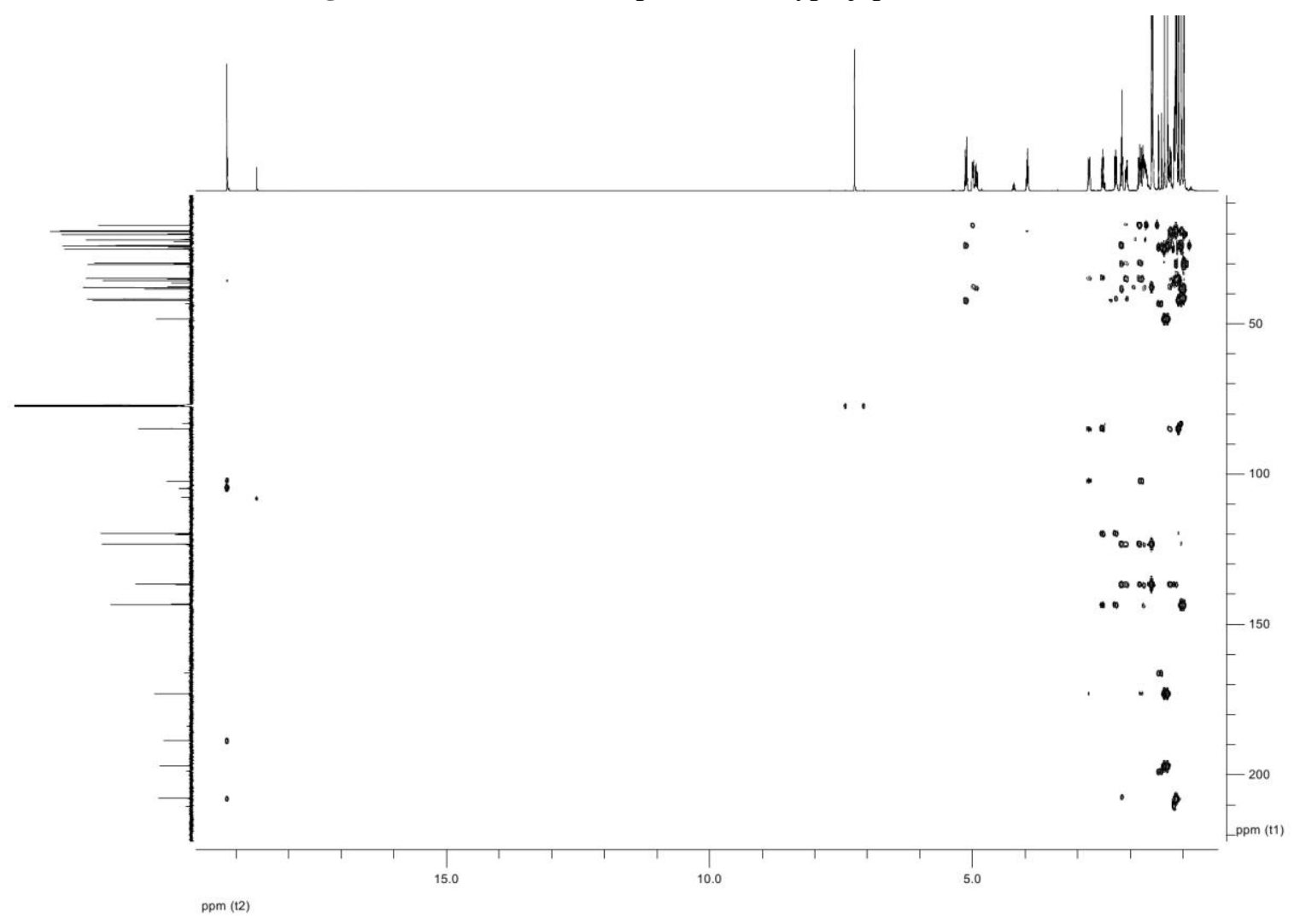

Figure S8. $\mathrm{HMBC}$ (in $\mathrm{CDCl}_{3}$ ) spectrum of hyperjapone $\mathrm{A}(\mathbf{1})$. 


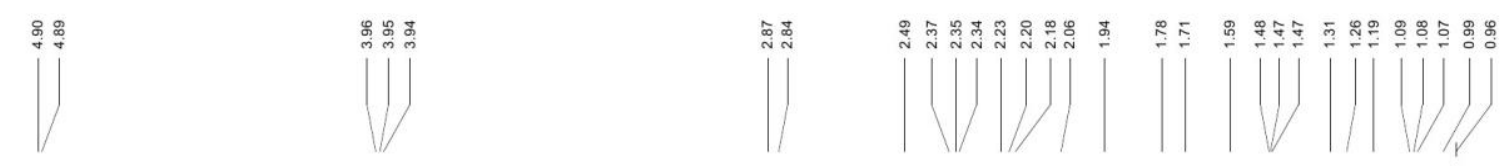<smiles>C=C1C[C@@H]2C(=C)CC[C@H]3CC4=C(O[C@@]3(C)CC[C@H]1C2(C)C)C(C)(C)C(=O)C(C(=O)C(C)C)=C4O</smiles>

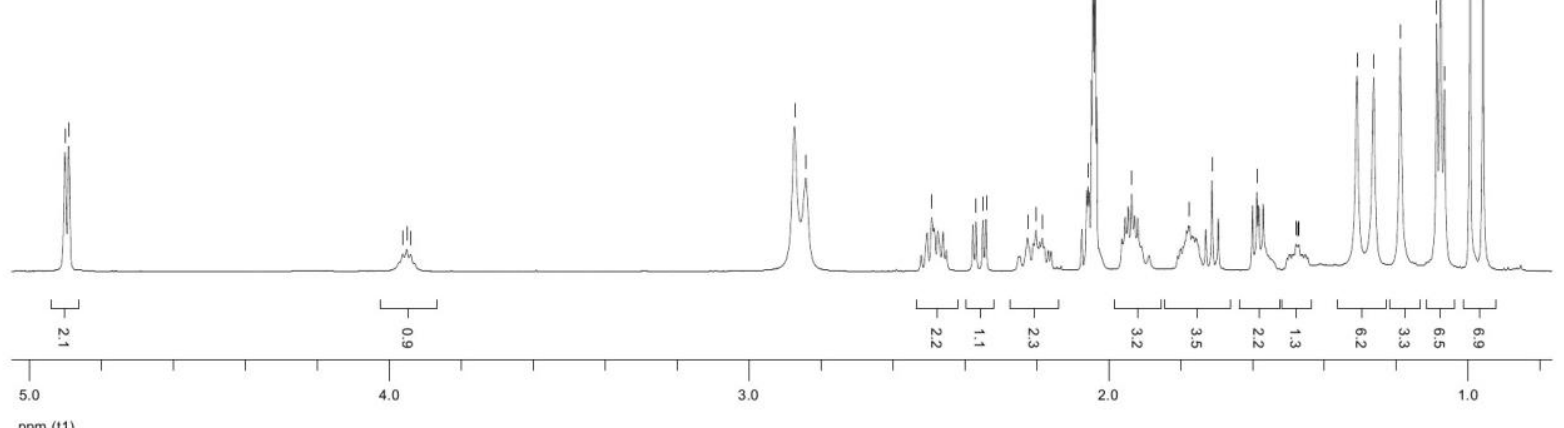

Figure S9. ${ }^{1} \mathrm{H}$ (in acetone- $d_{6}$ ) spectrum of hyperjapone B (2).

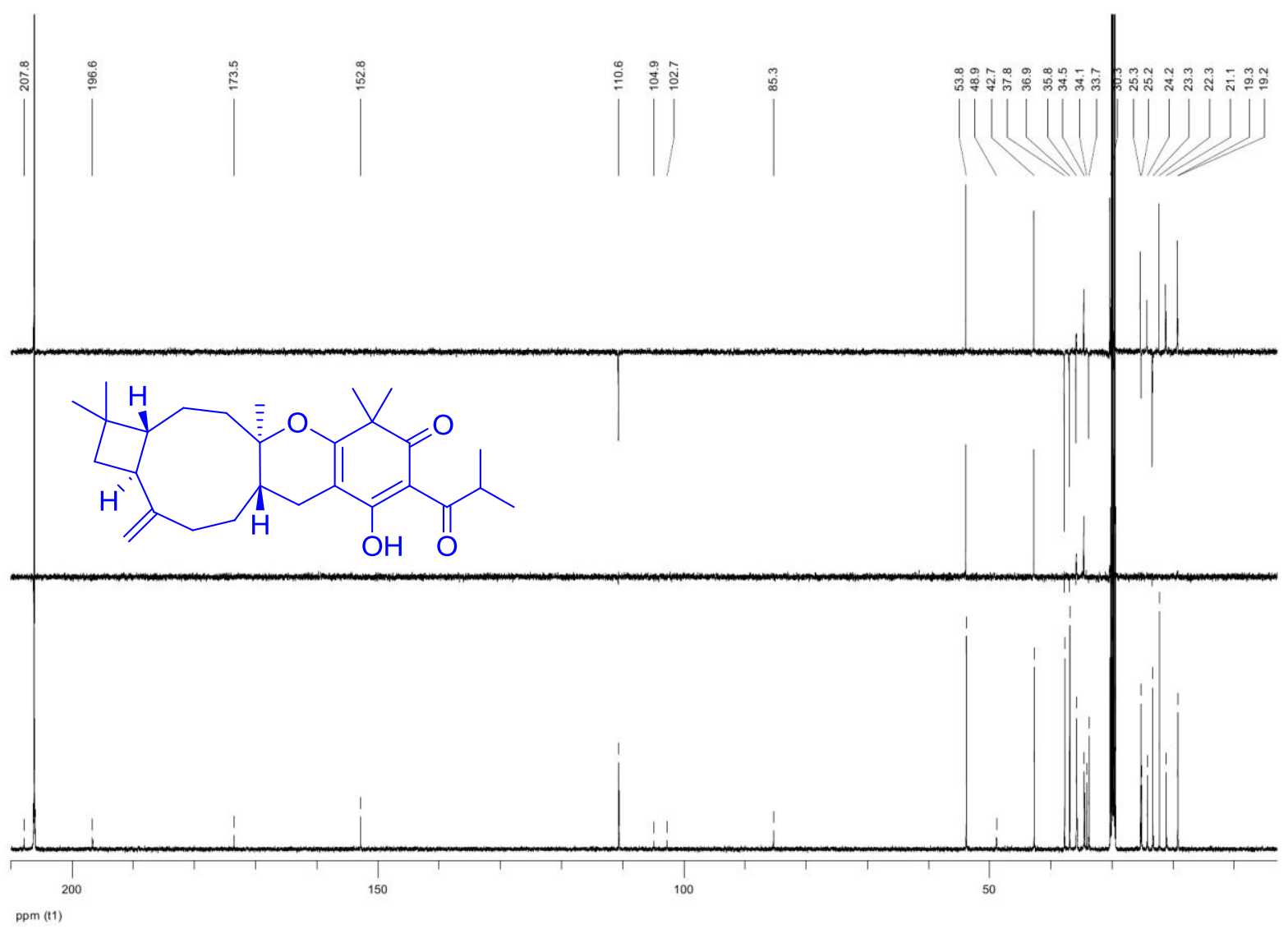

Figure S10. ${ }^{13} \mathrm{C}$ and DEPT (in acetone- $d_{6}$ ) spectra of hyperjapone B (2). 


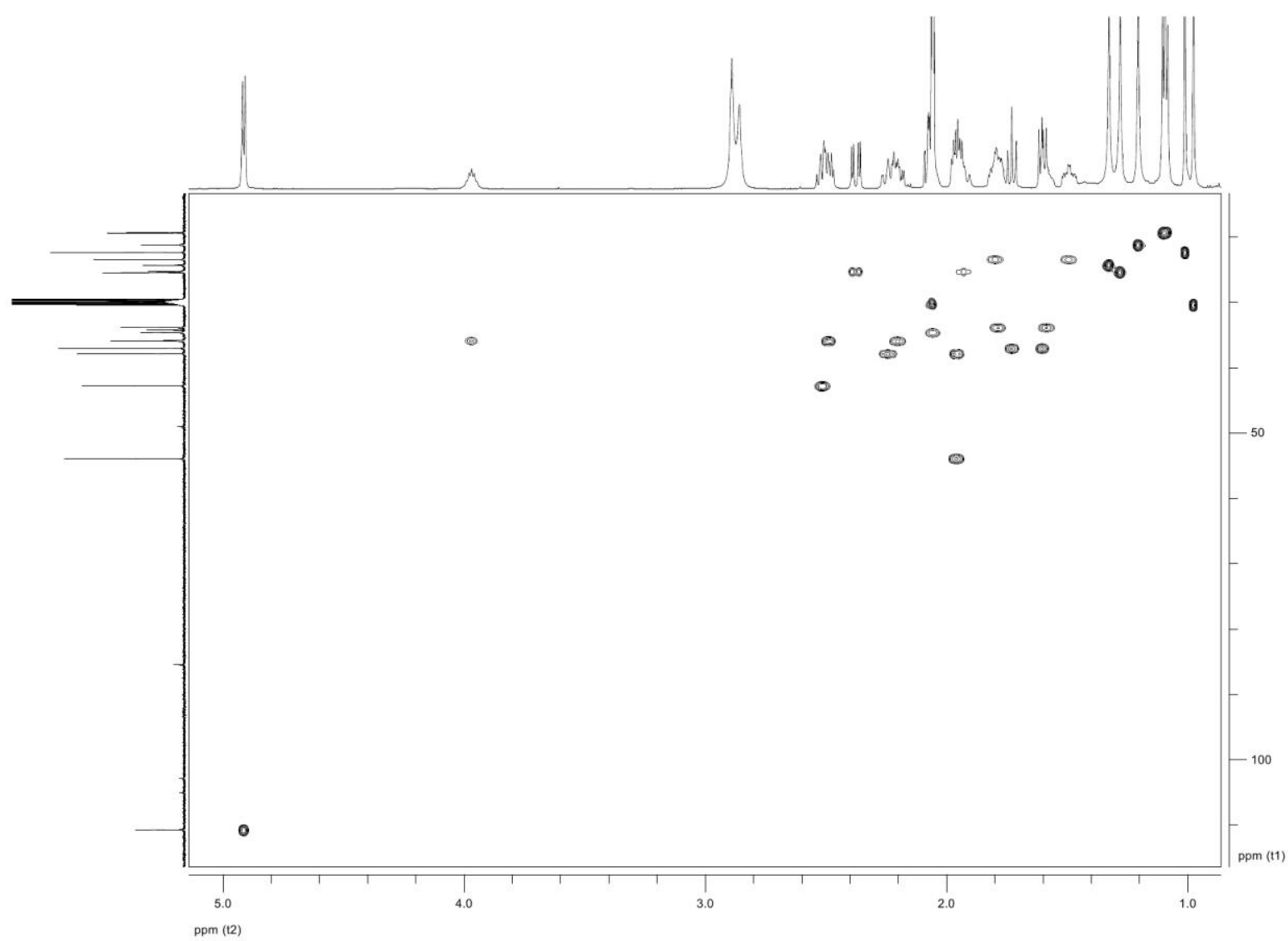

Figure S11. HSQC spectrum of hyperjapone B (2).

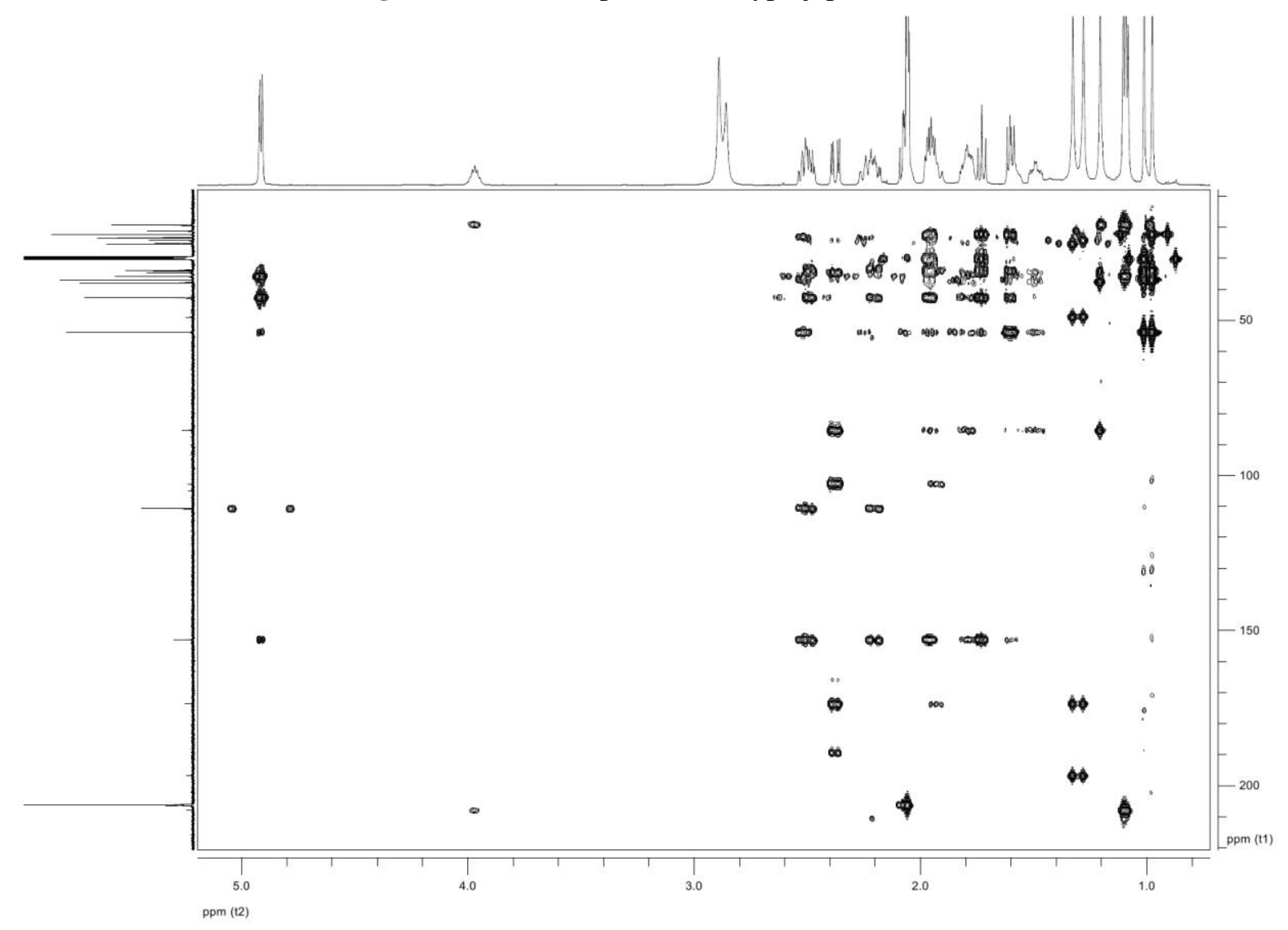

Figure S12. HMBC spectrum of hyperjapone B (2). 


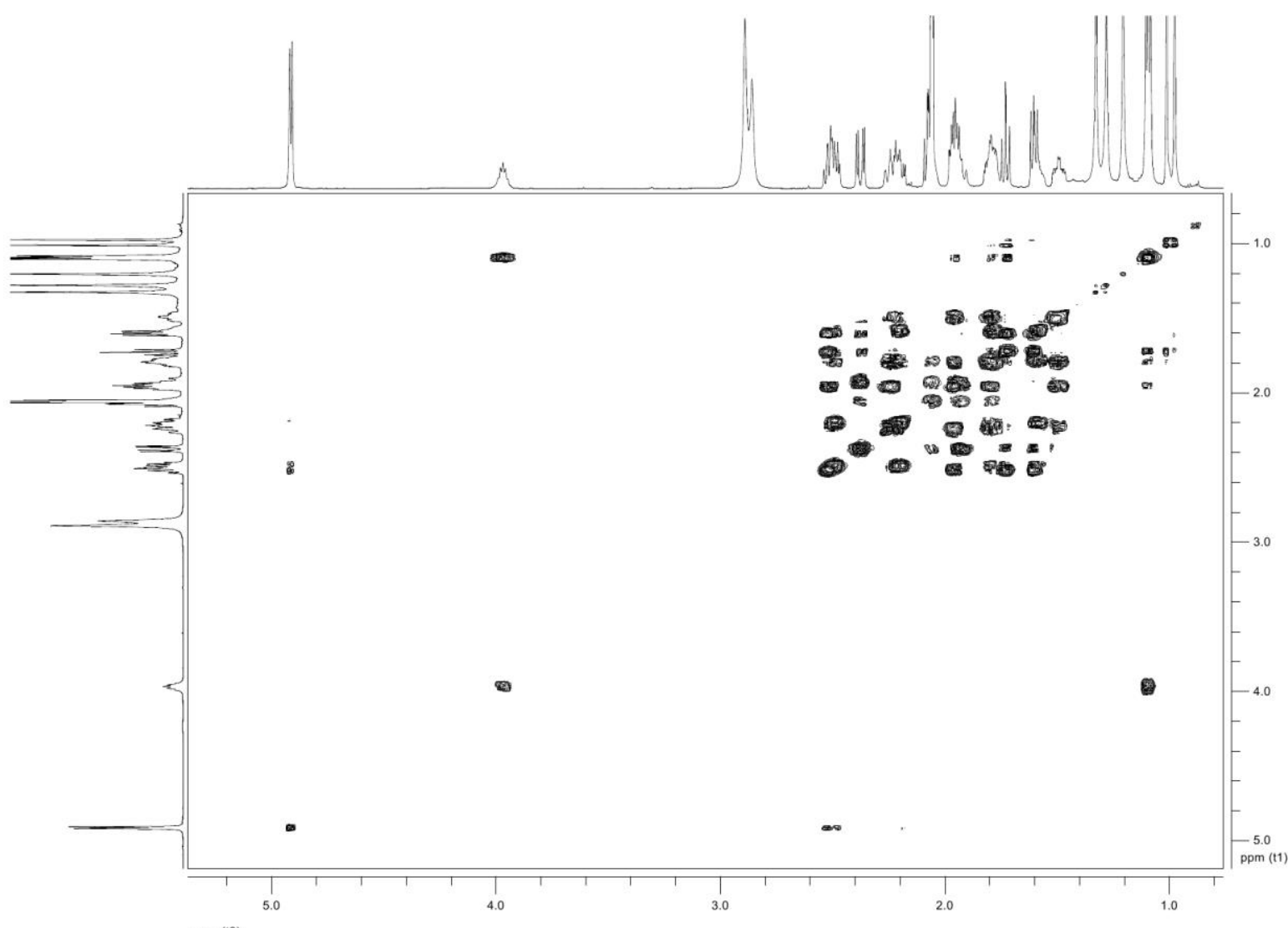

Figure S13. ${ }^{1} \mathrm{H}-{ }^{1} \mathrm{H}$ COSY spectrum of hyperjapone B (2).

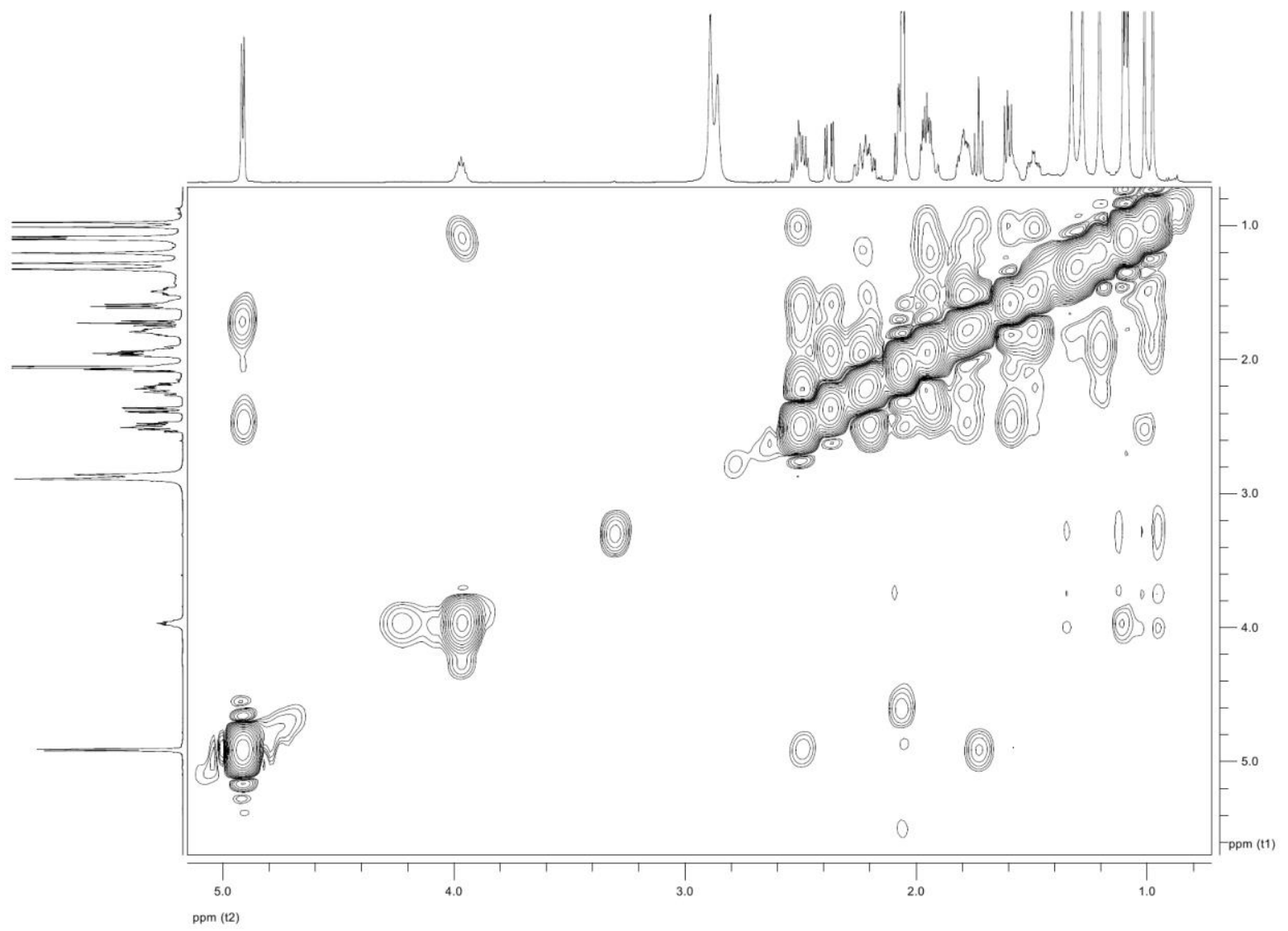

Figure S14. ROESY spectrum of hyperjapone B (2). 


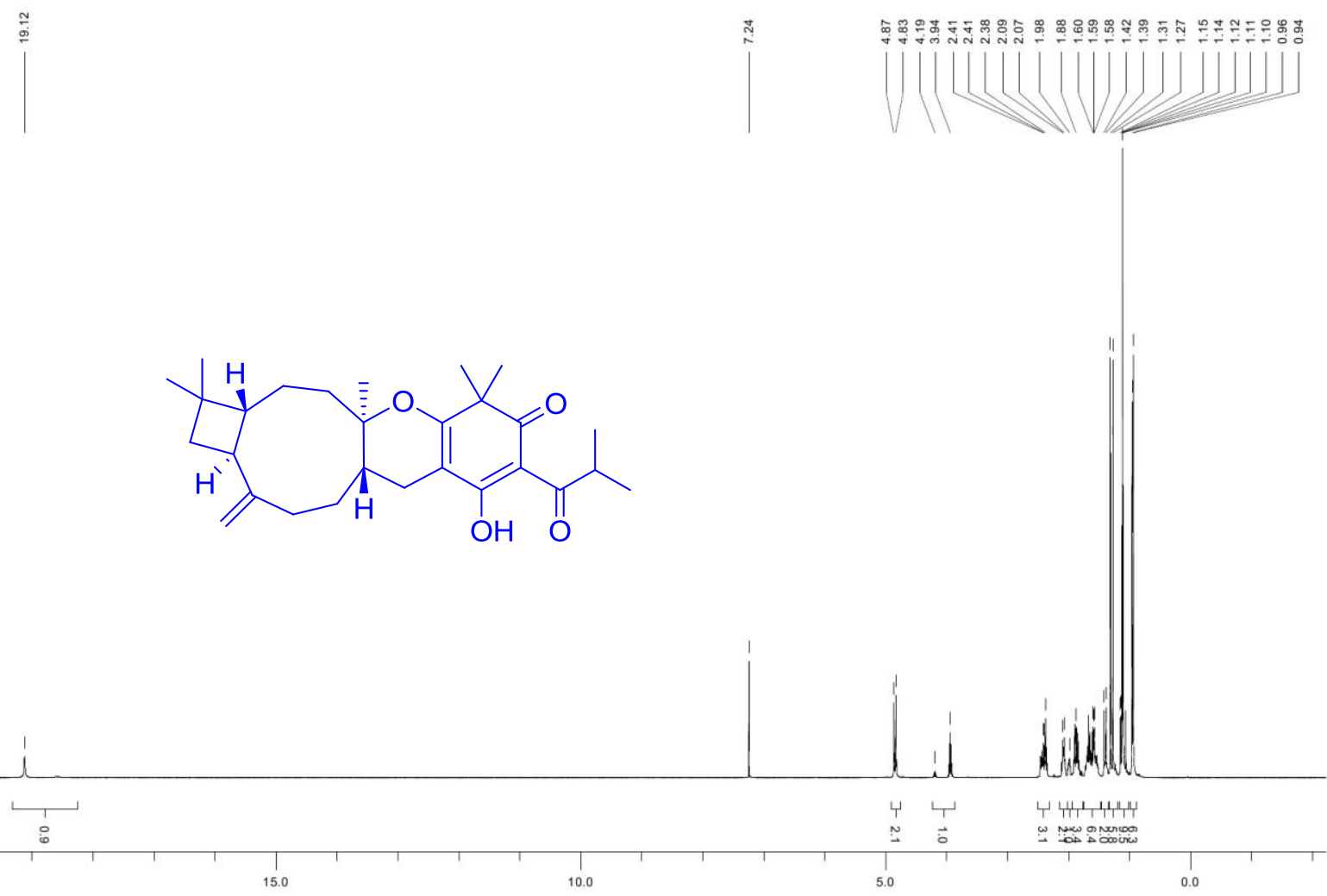

ppm (11)

Figure S15. ${ }^{1} \mathrm{H}$ (in $\mathrm{CDCl}_{3}$ ) spectrum of hyperjapone B (2).

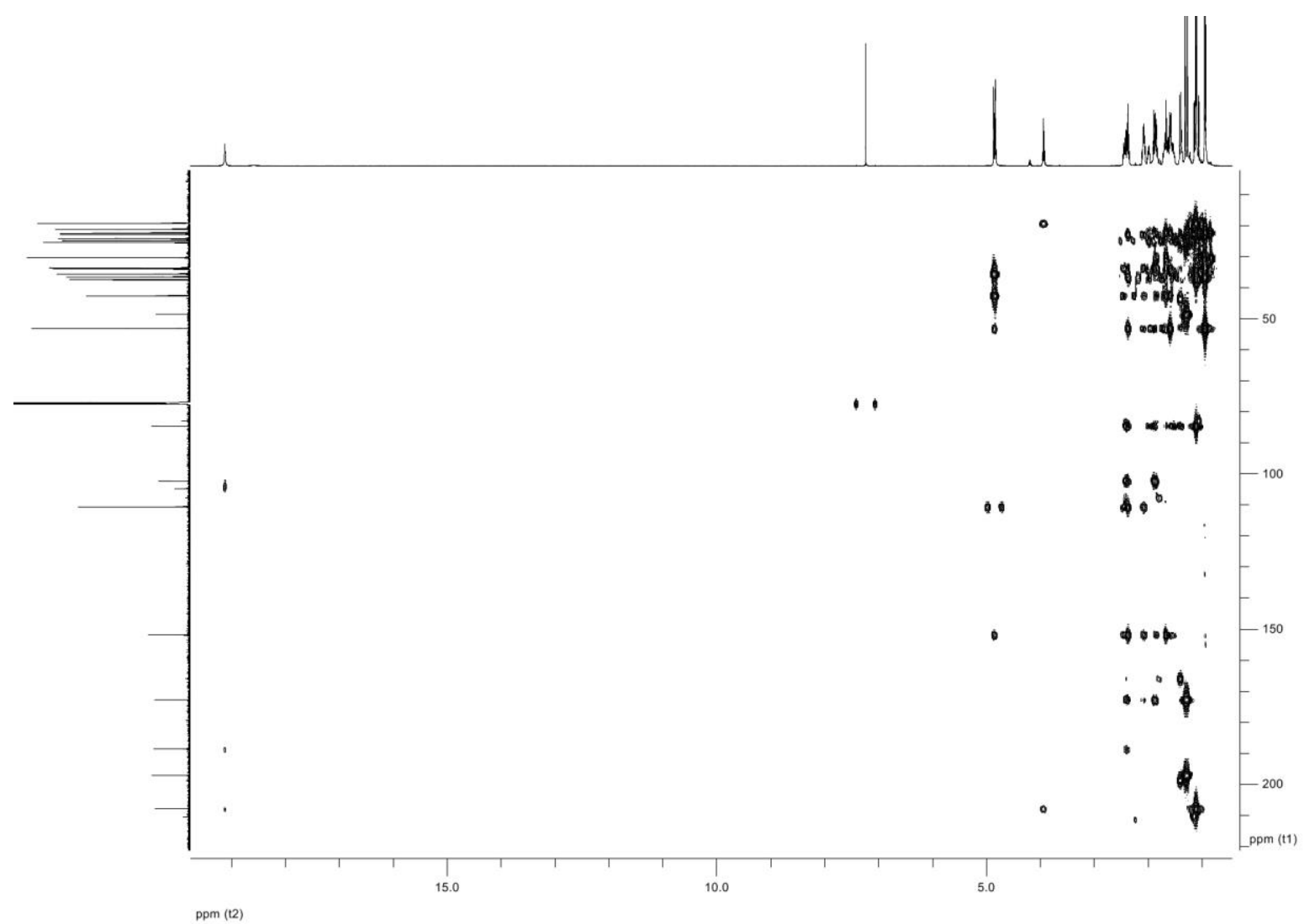

Figure S16. HMBC $\left(\mathrm{CDCl}_{3}\right)$ spectrum of hyperjapone B (2). 


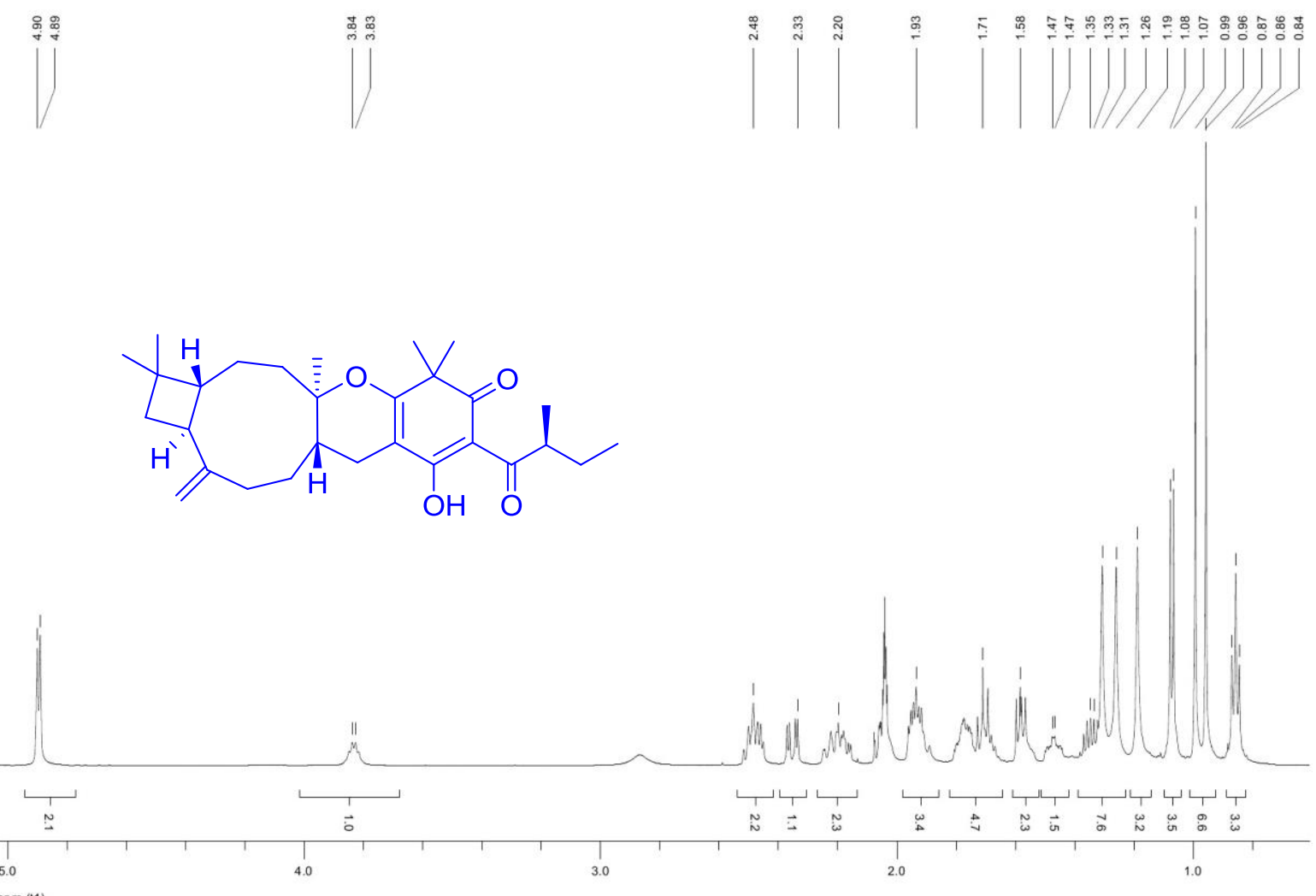

Figure S17. ${ }^{1} \mathrm{H}$ (in acetone- $d_{6}$ ) spectrum of hyperjapone $\mathrm{C}(\mathbf{3})$.
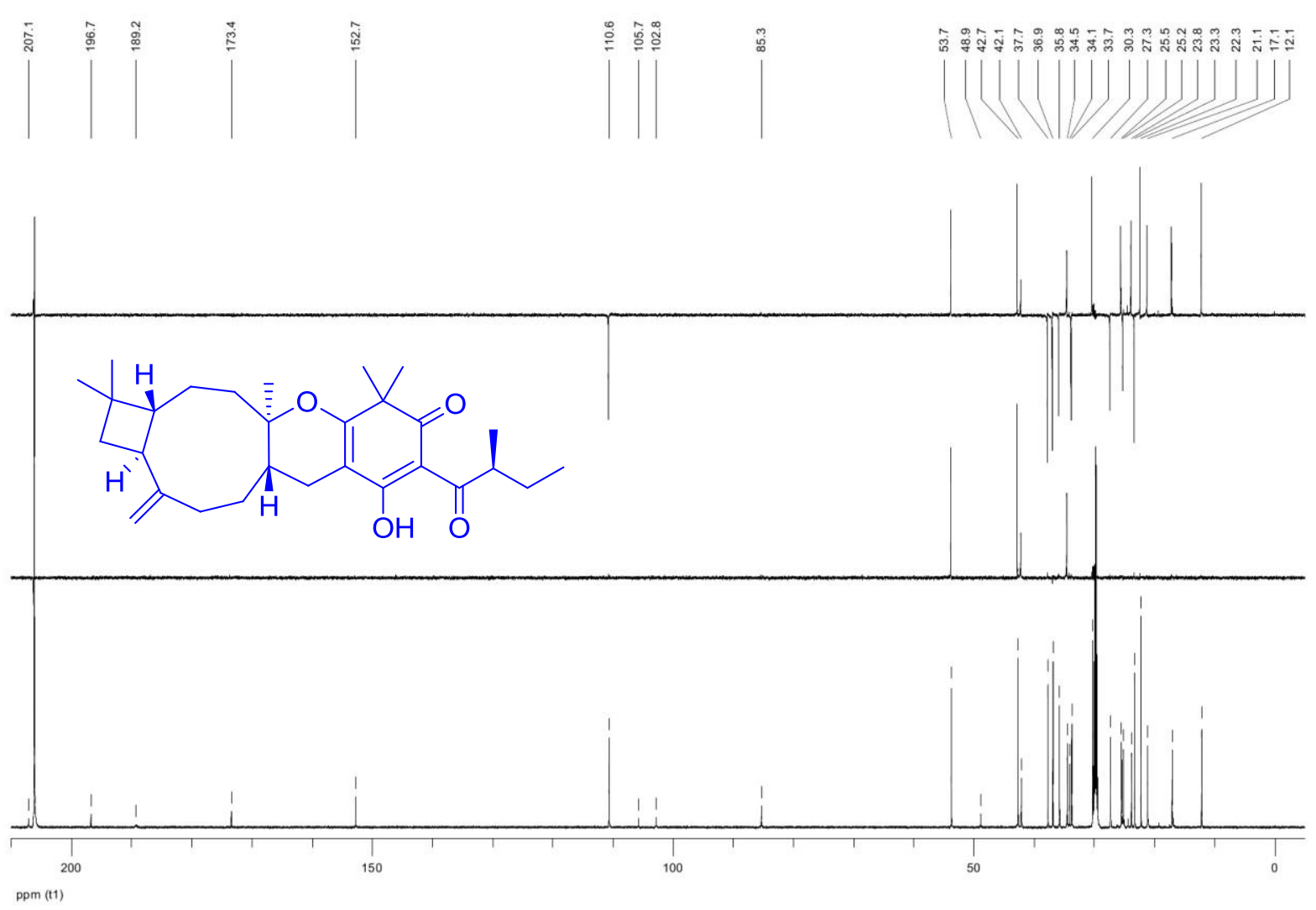

Figure S18. ${ }^{13} \mathrm{C}$ and DEPT (in acetone- $d_{6}$ ) spectra of hyperjapone C (3). 


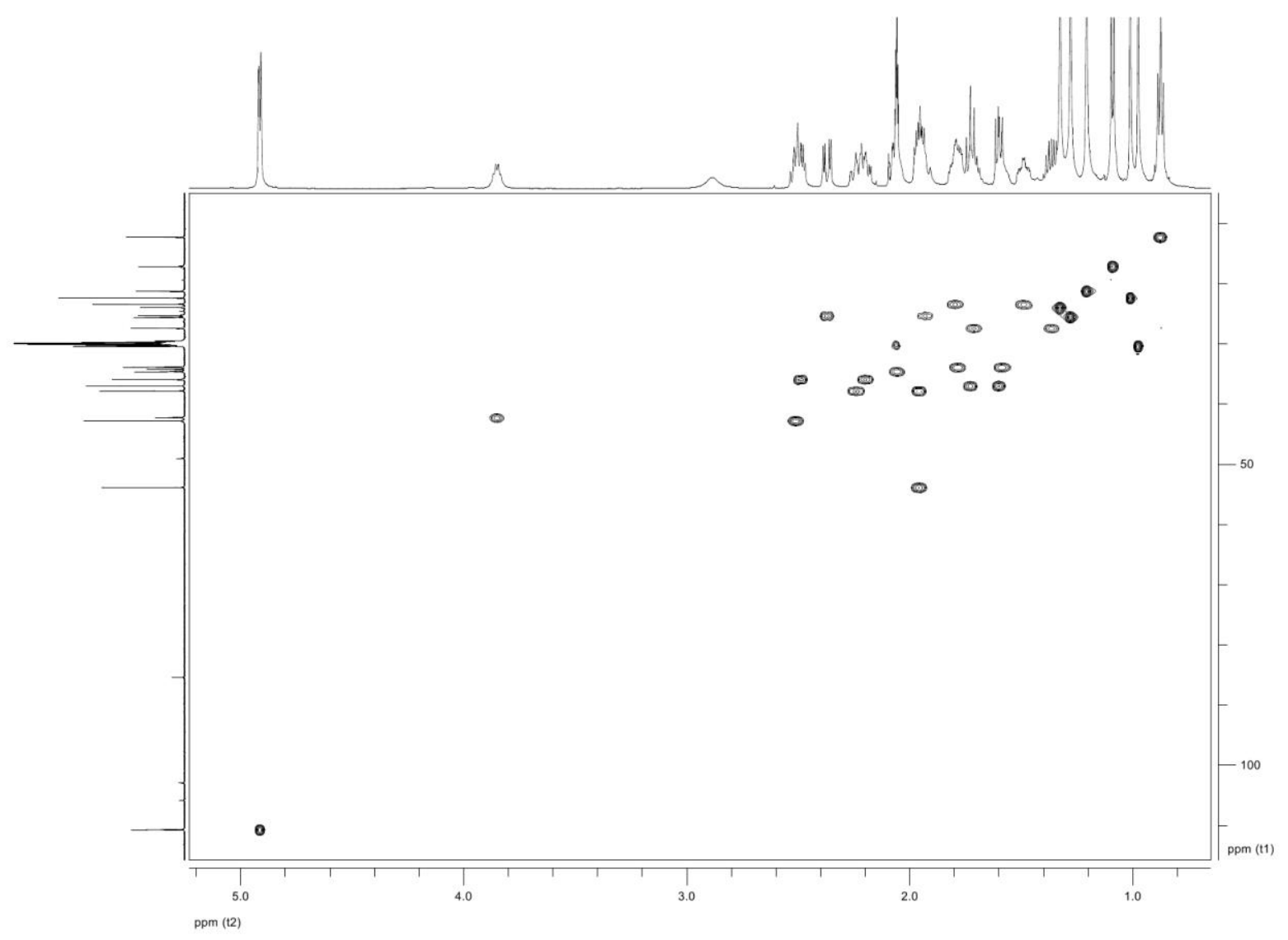

Figure S19. HSQC spectrum of hyperjapone C (3).

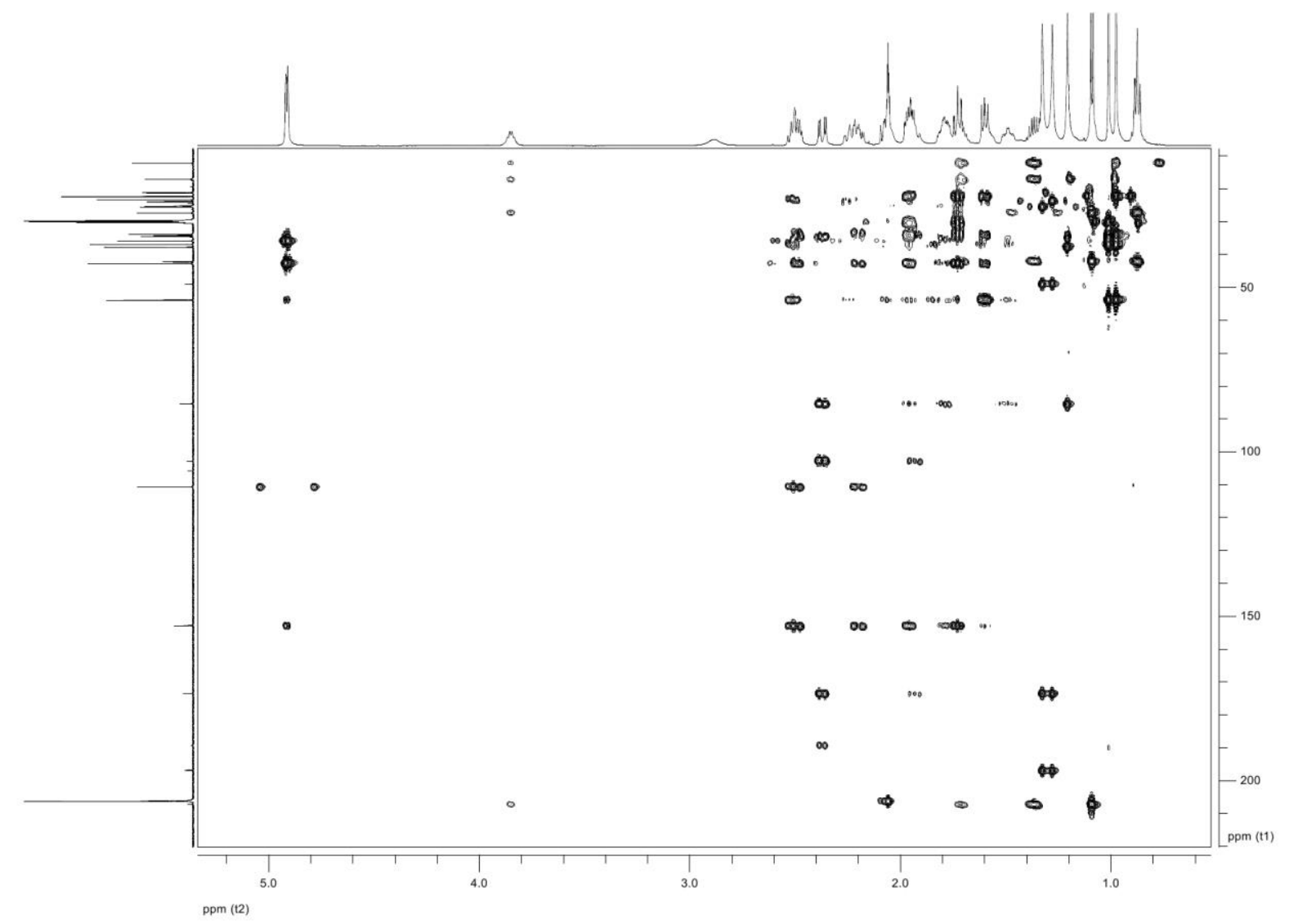

Figure S20. HMBC spectrum of hyperjapone C (3). 


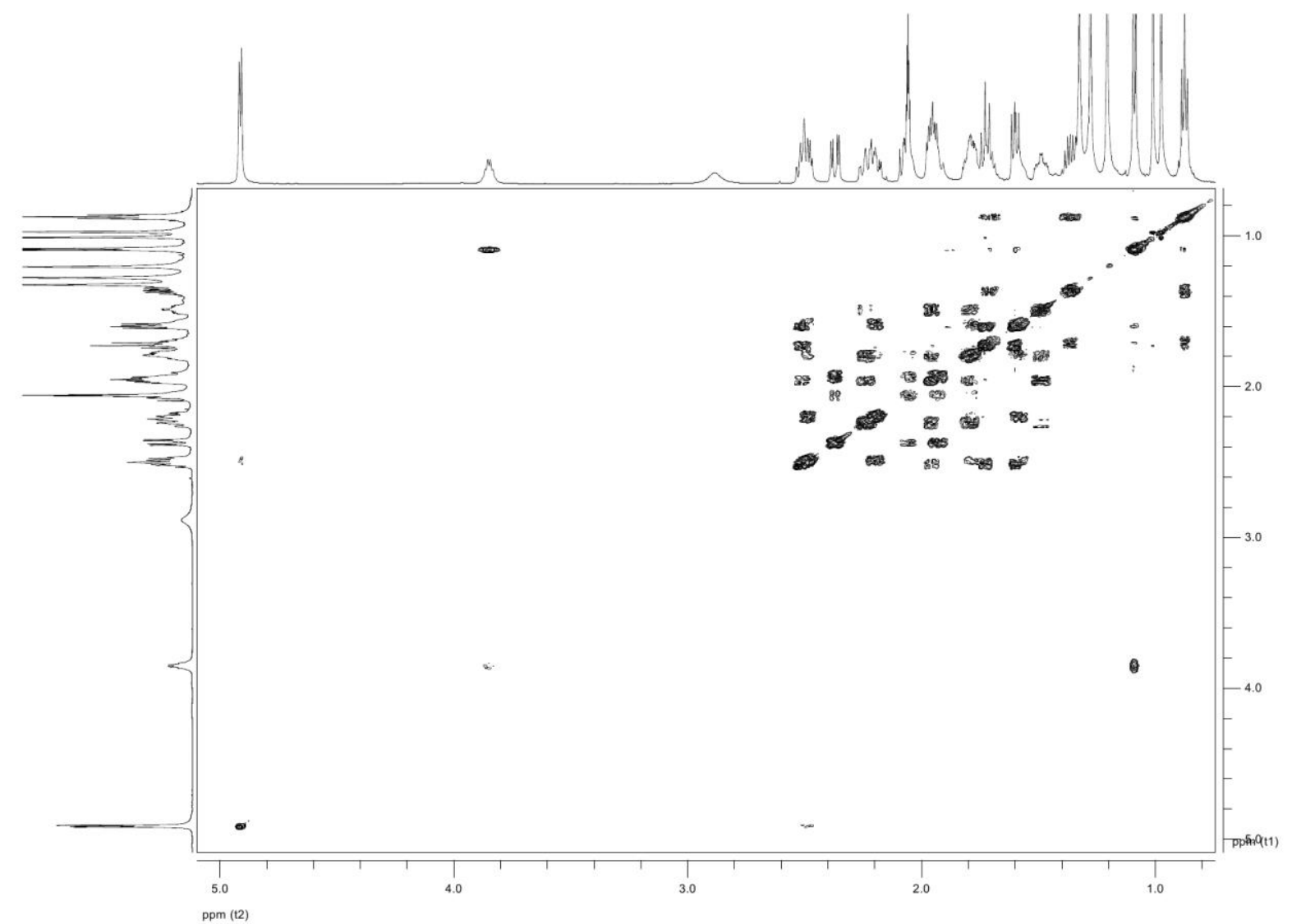

Figure S21. ${ }^{1} \mathrm{H}-{ }^{1} \mathrm{H}$ COSY spectrum of hyperjapone $\mathrm{C}(\mathbf{3})$.

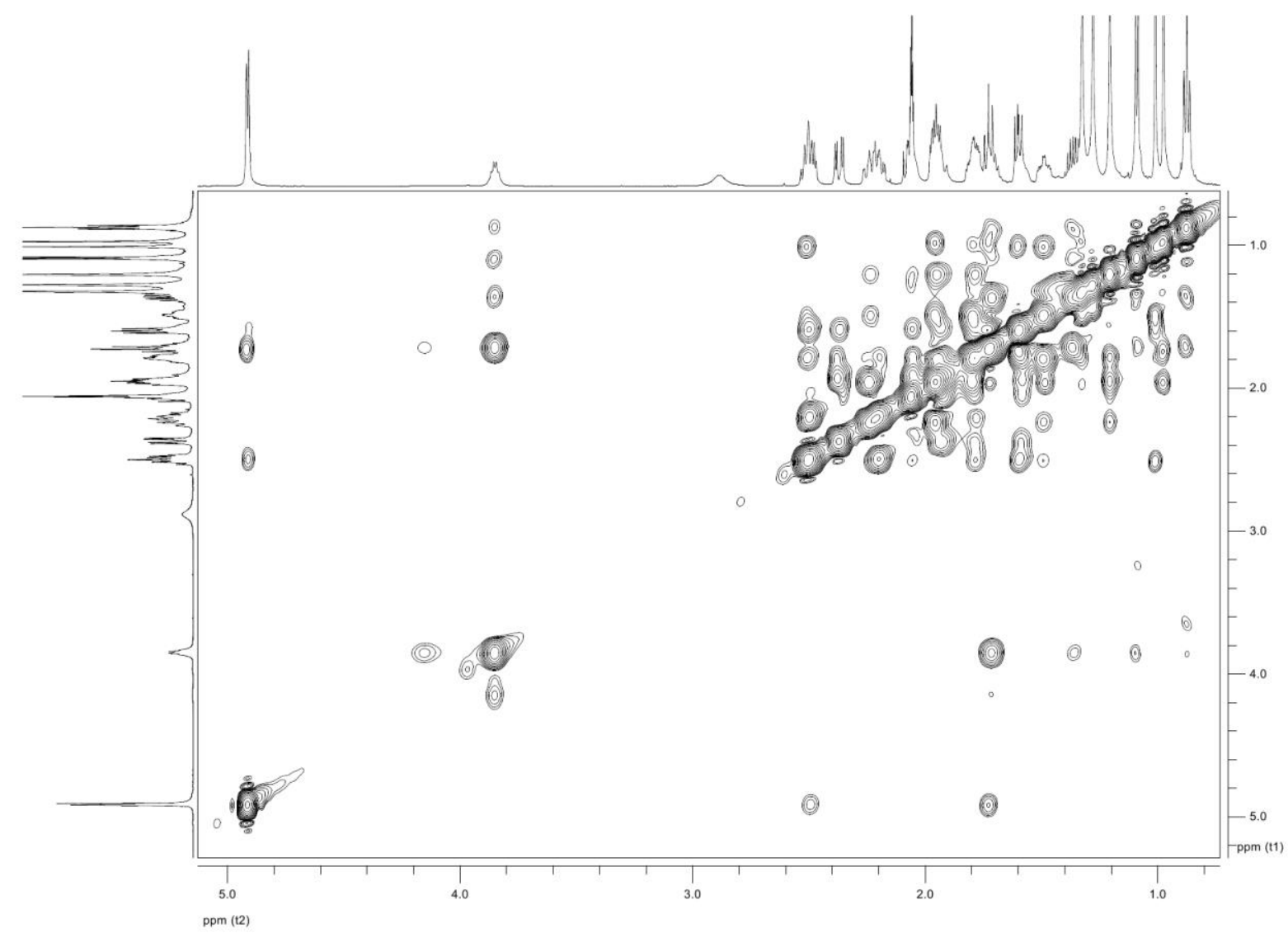

Figure S22. ROESY spectrum of hyperjapone C (3). 


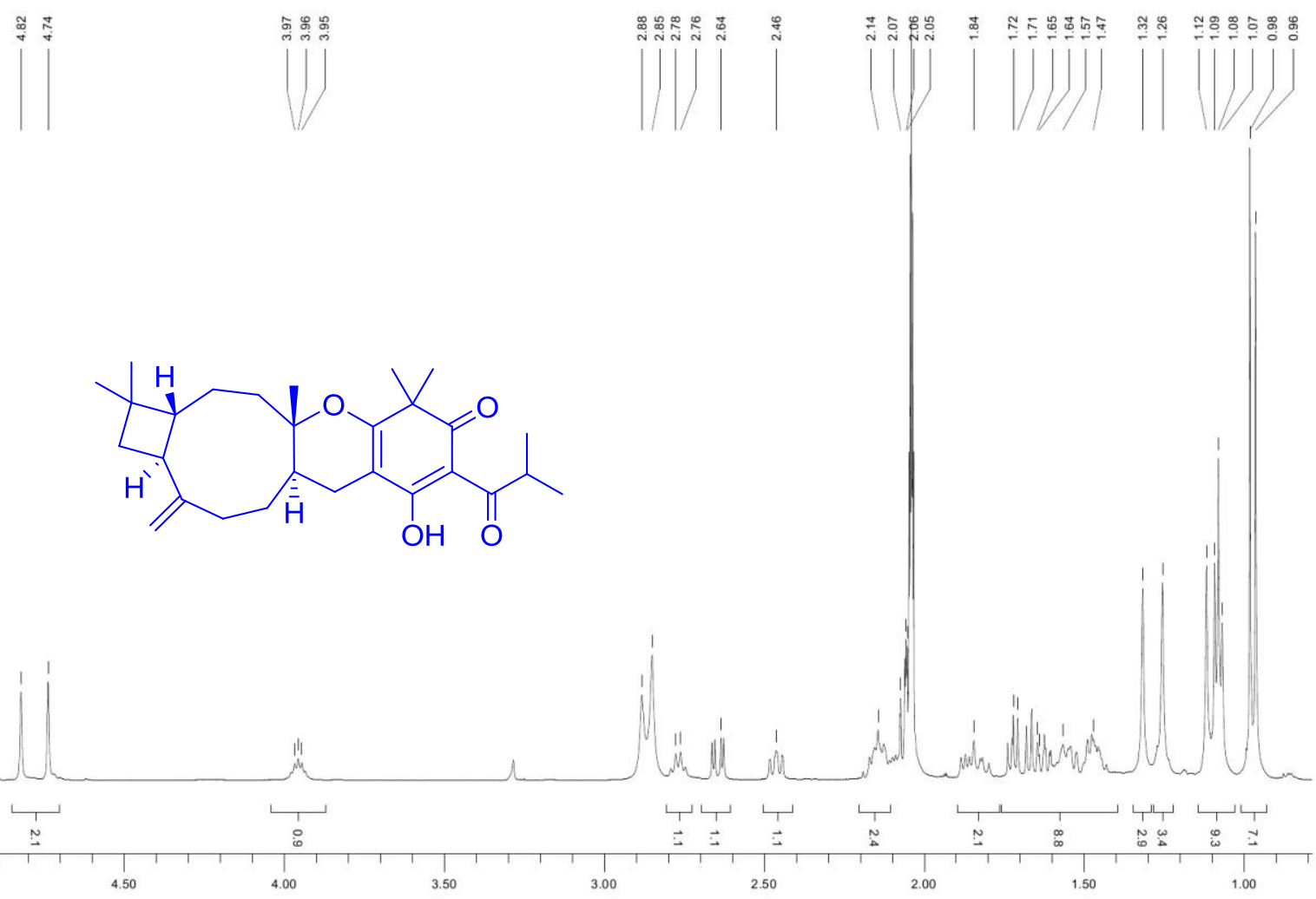

Figure S23. ${ }^{1} \mathrm{H}$ (in acetone- $d_{6}$ ) spectrum of hyperjapone D (4).

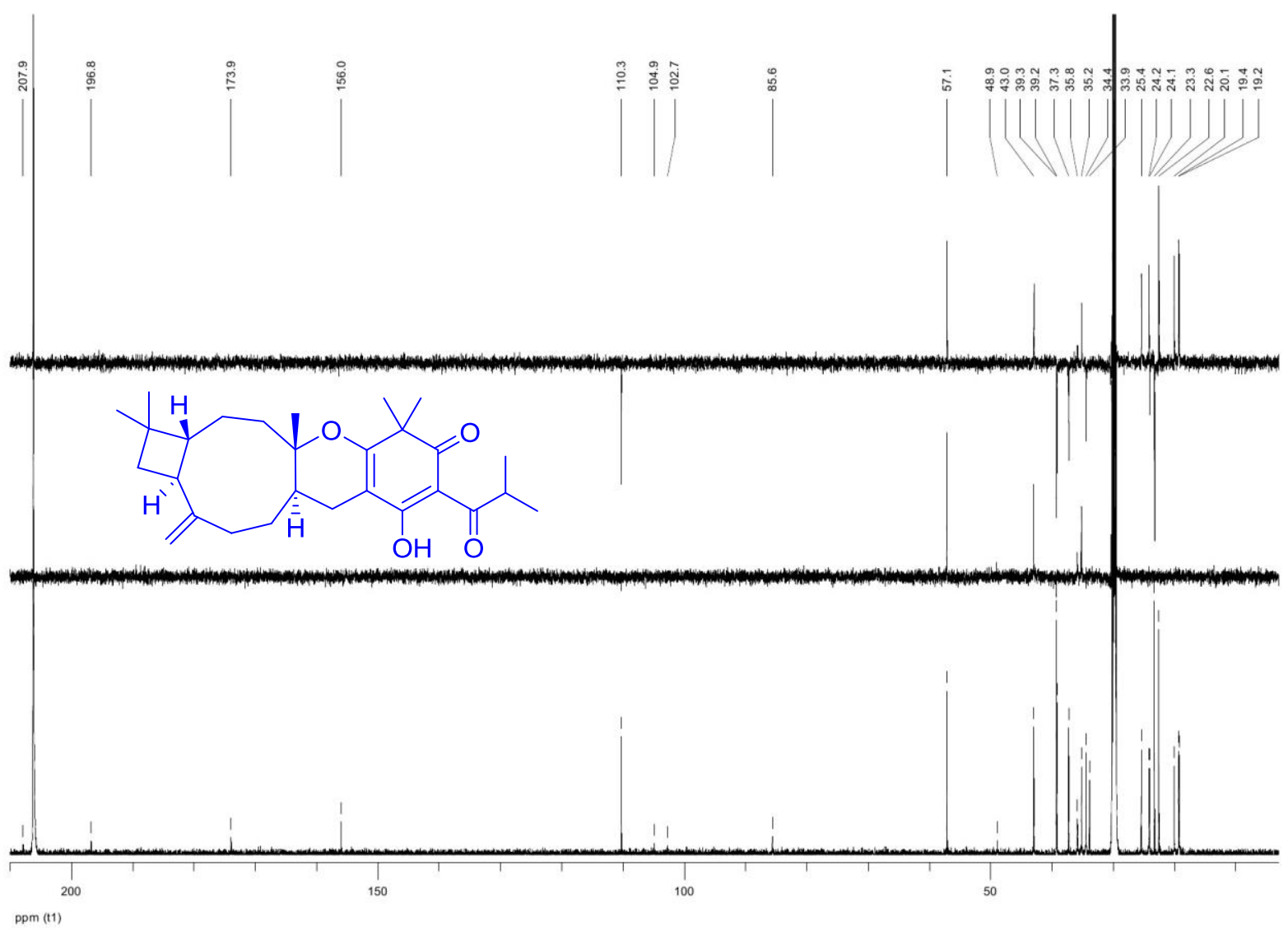

Figure S24. ${ }^{13} \mathrm{C}$ and DEPT (in acetone- $d_{6}$ ) spectra of hyperjapone D (4). 


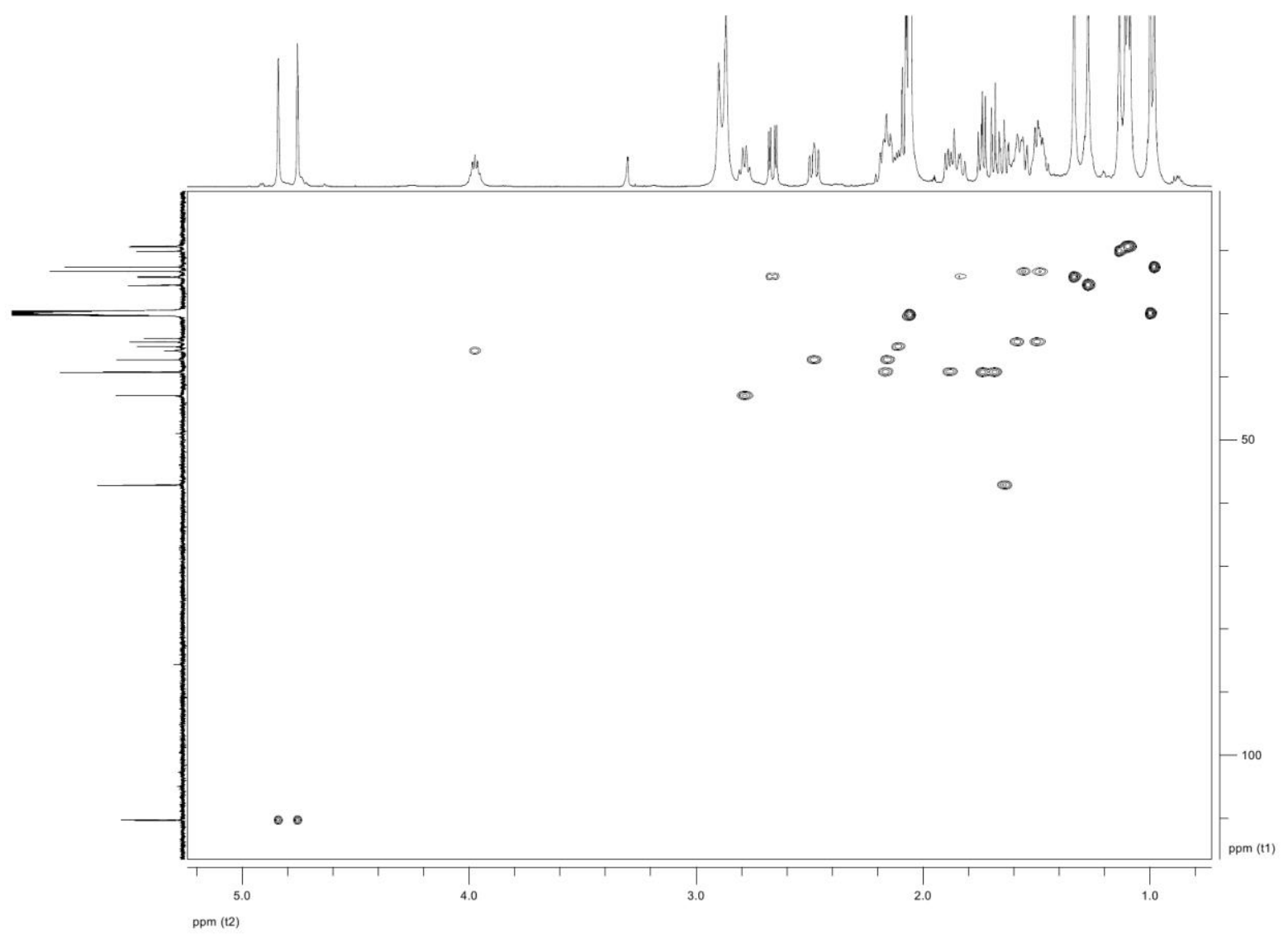

Figure S25. HSQC spectrum of hyperjapone D (4).

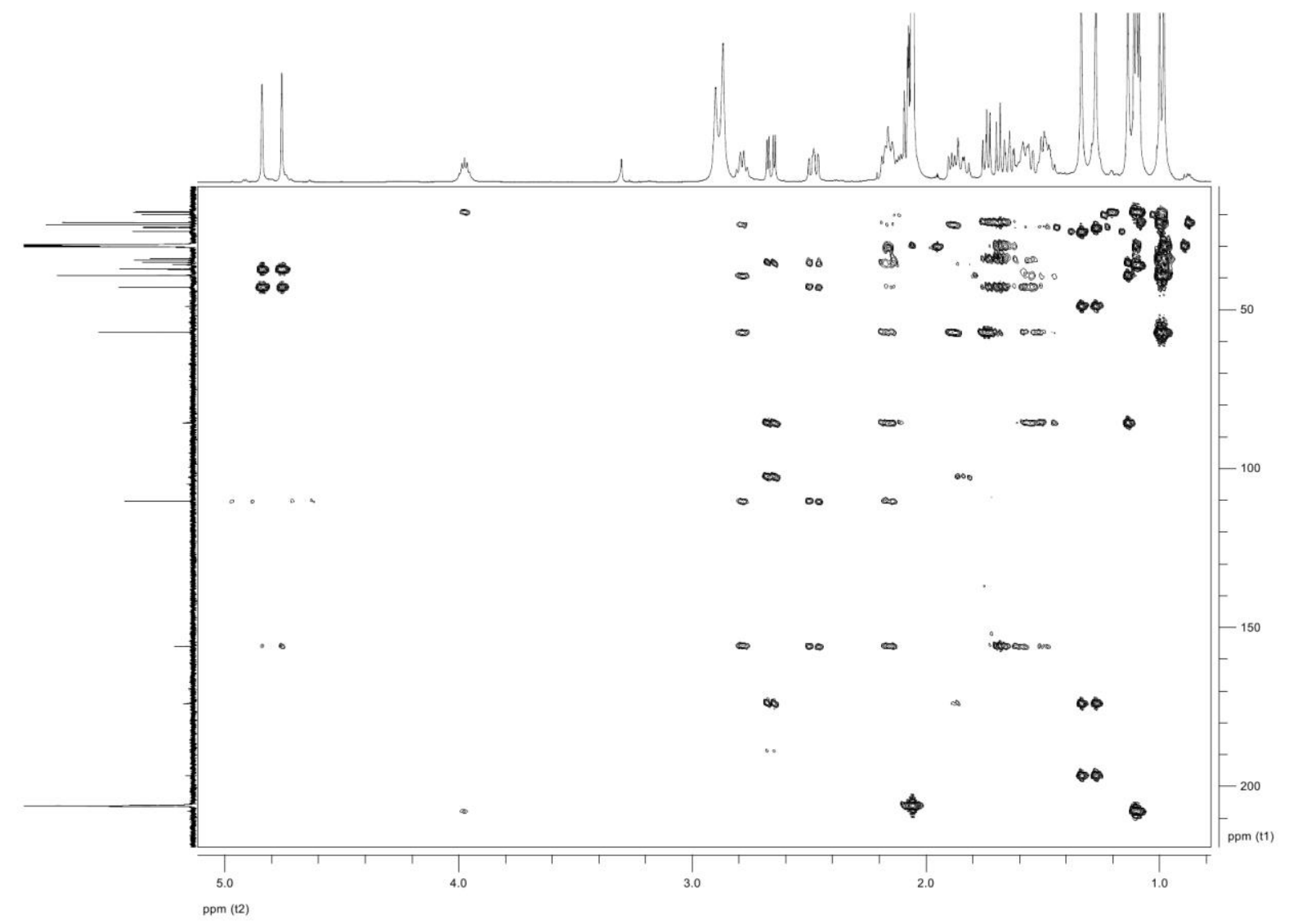

Figure S26. HMBC spectrum of hyperjapone D (4). 


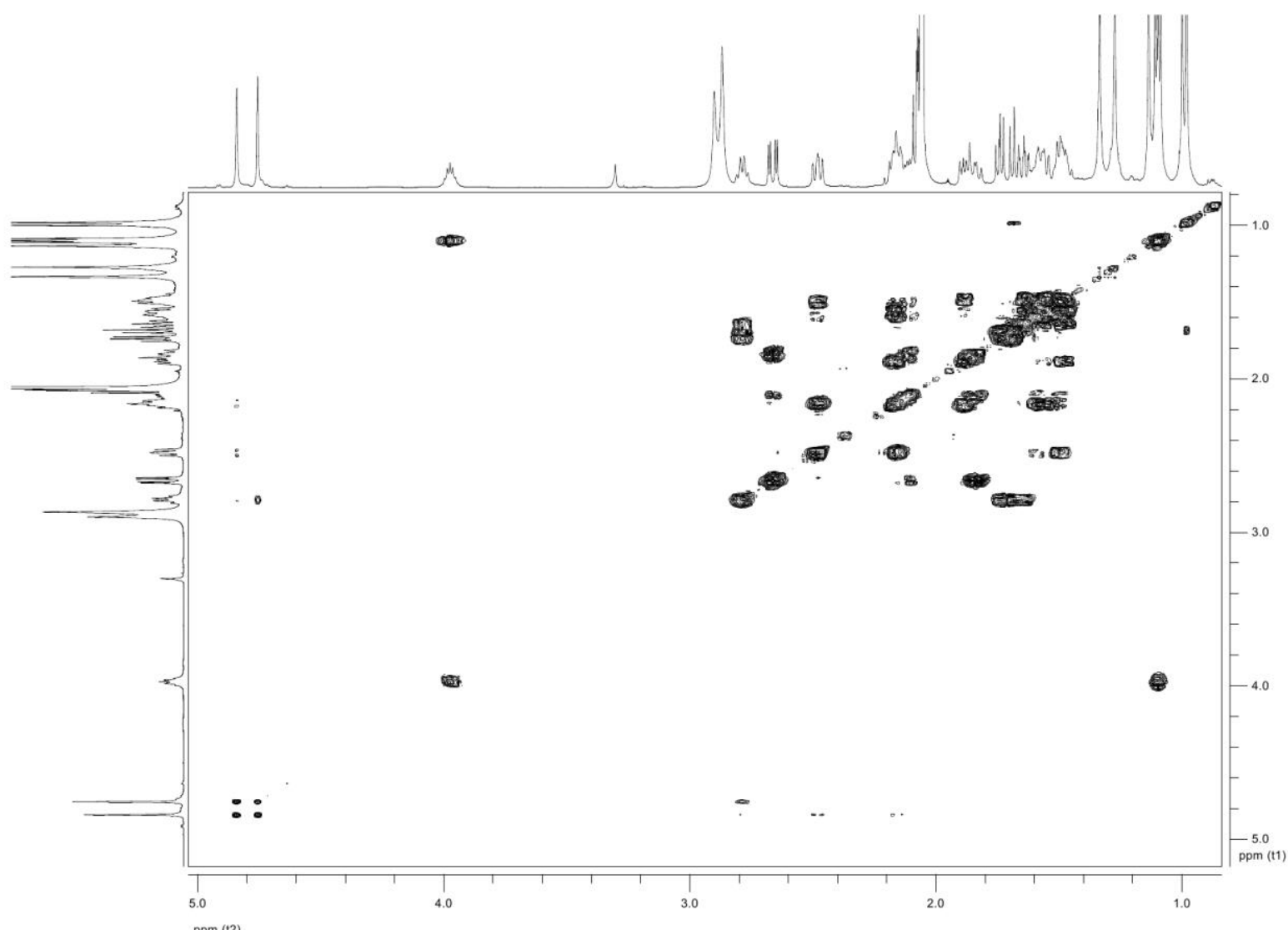

Figure S27. ${ }^{1} \mathrm{H}-{ }^{1} \mathrm{H}$ COSY spectrum of hyperjapone D (4).

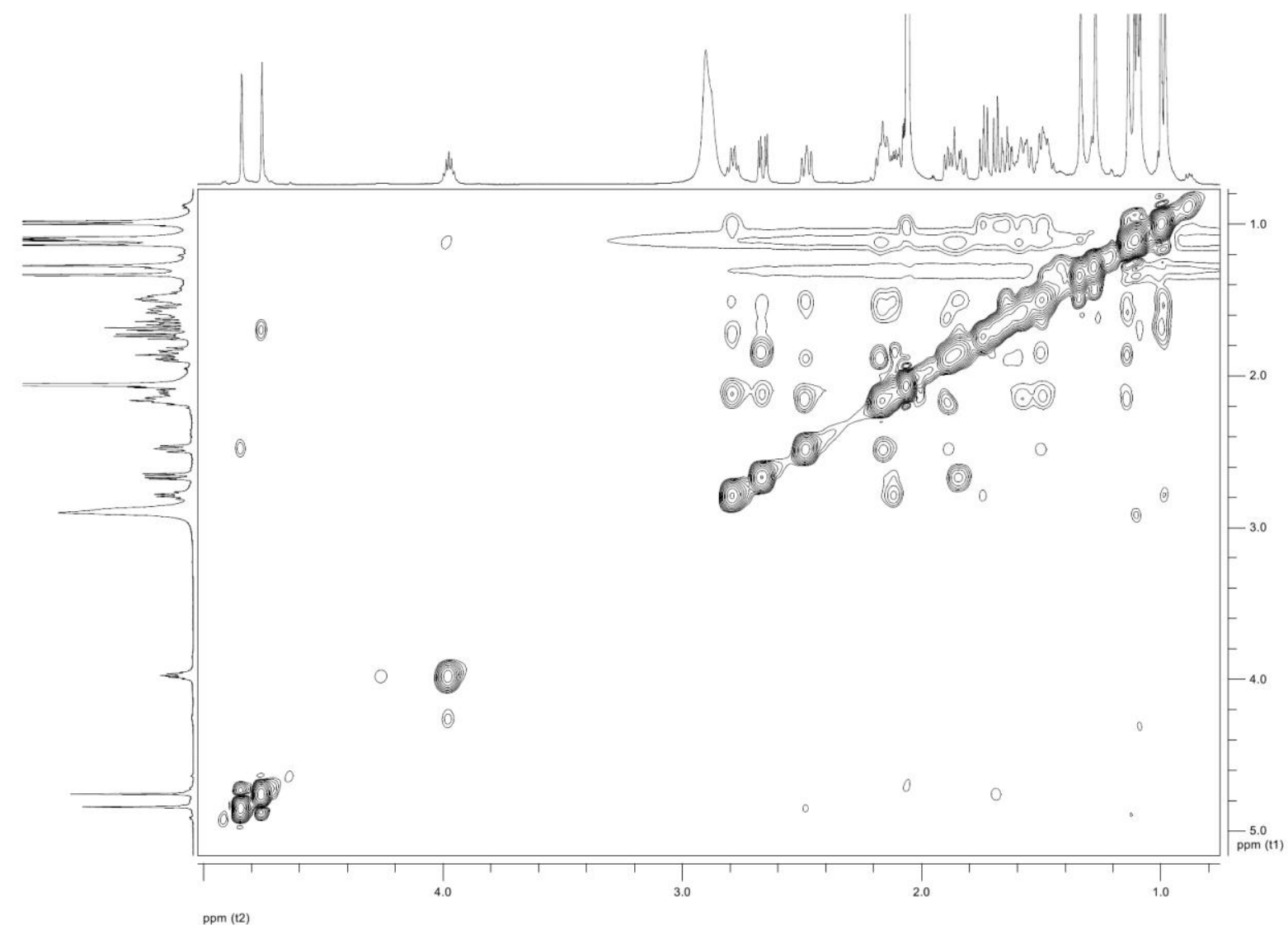

Figure S28. ROESY spectrum of hyperjapone D (4). 


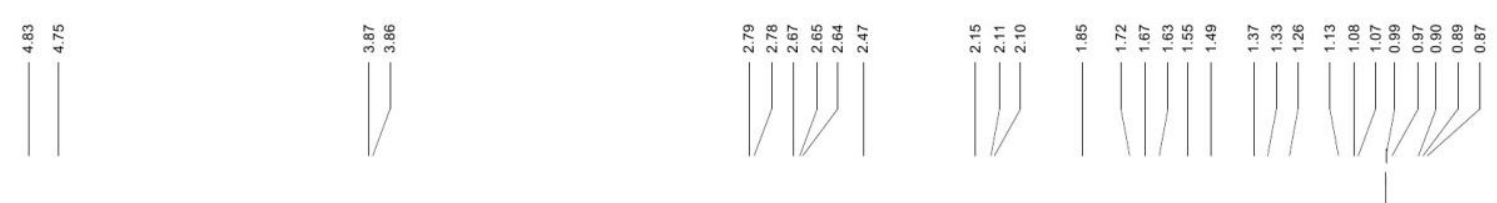<smiles>C=C1CCC2CC3=C(O[C@]2(C)CC[C@@H]2C(=C)CC2C3(C)C)C(C)(C)C(=O)C(C(=O)[C@H](C)CC)=C1O</smiles>

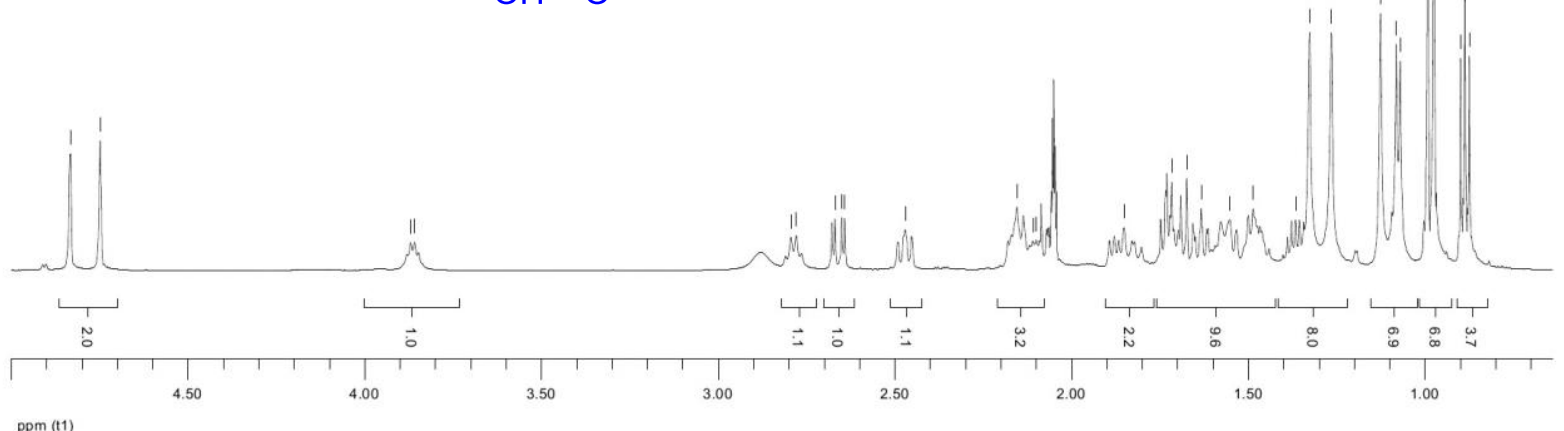

Figure S29. ${ }^{1} \mathrm{H}$ (in acetone- $d_{6}$ ) spectrum of hyperjapone E (5).

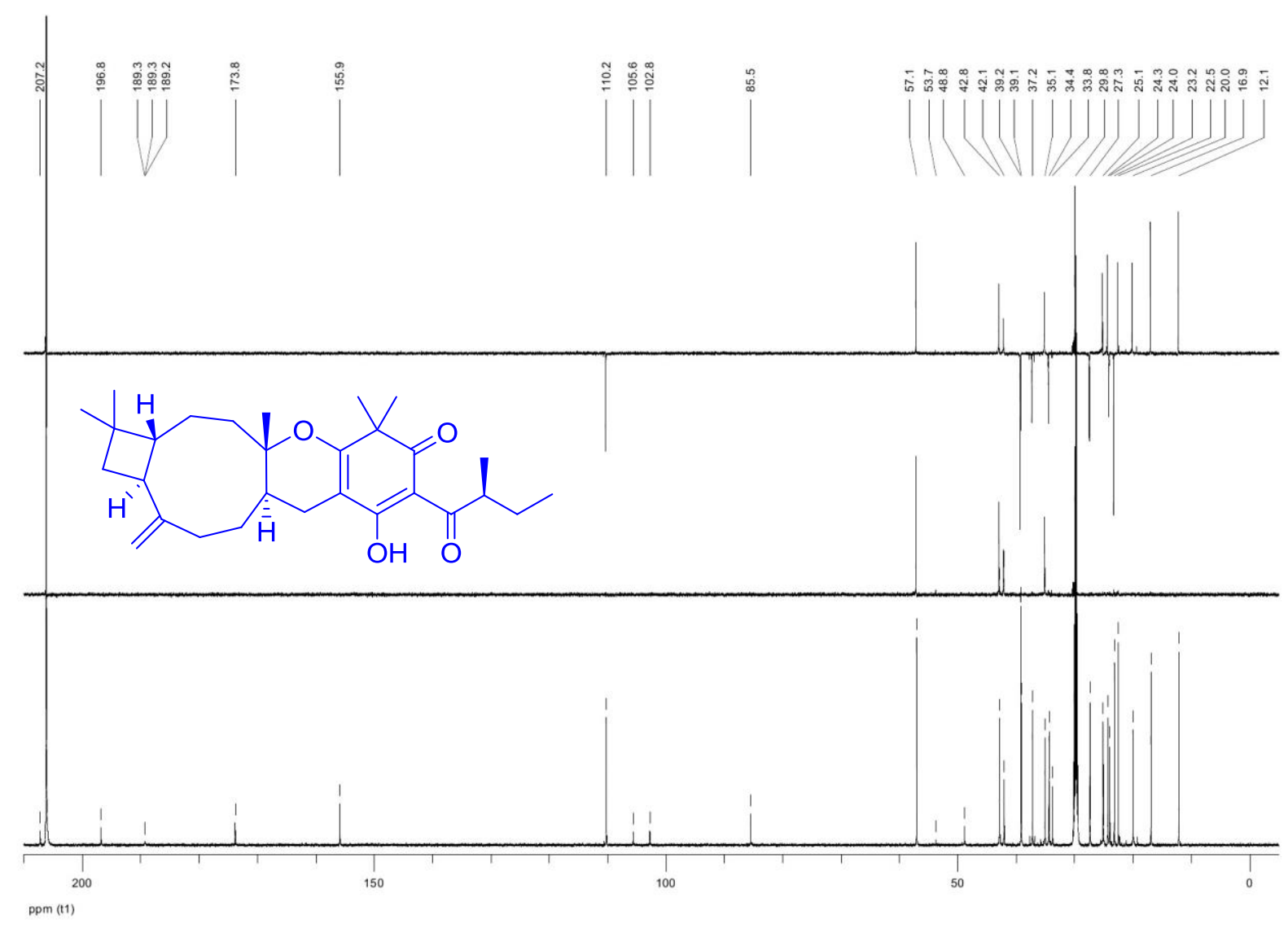

Figure S30. ${ }^{13} \mathrm{C}$ and DEPT (in acetone- $d_{6}$ ) spectra of hyperjapone E (5). 


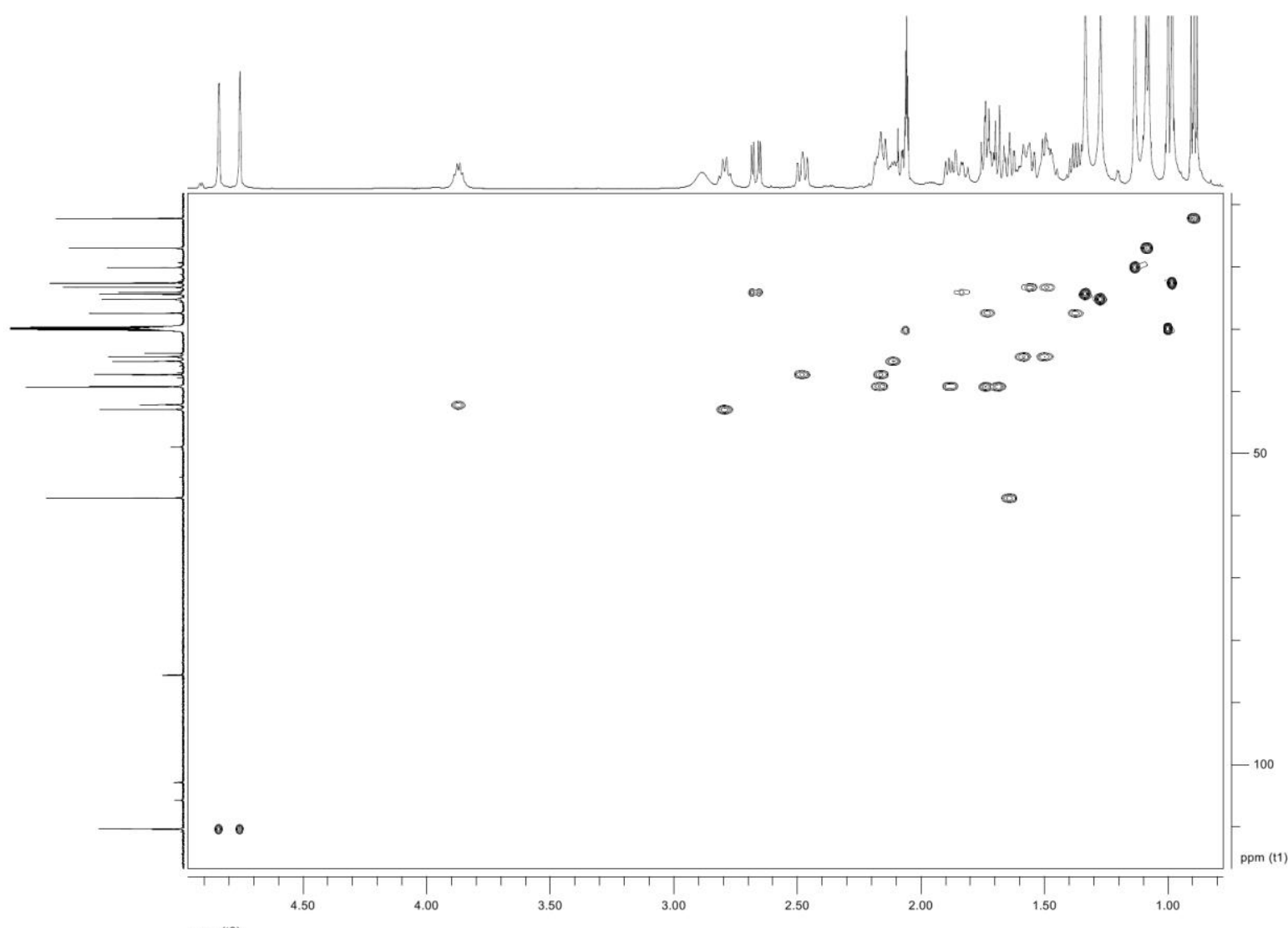

ppm (12)

Figure S31. HSQC spectrum of hyperjapone E (5).

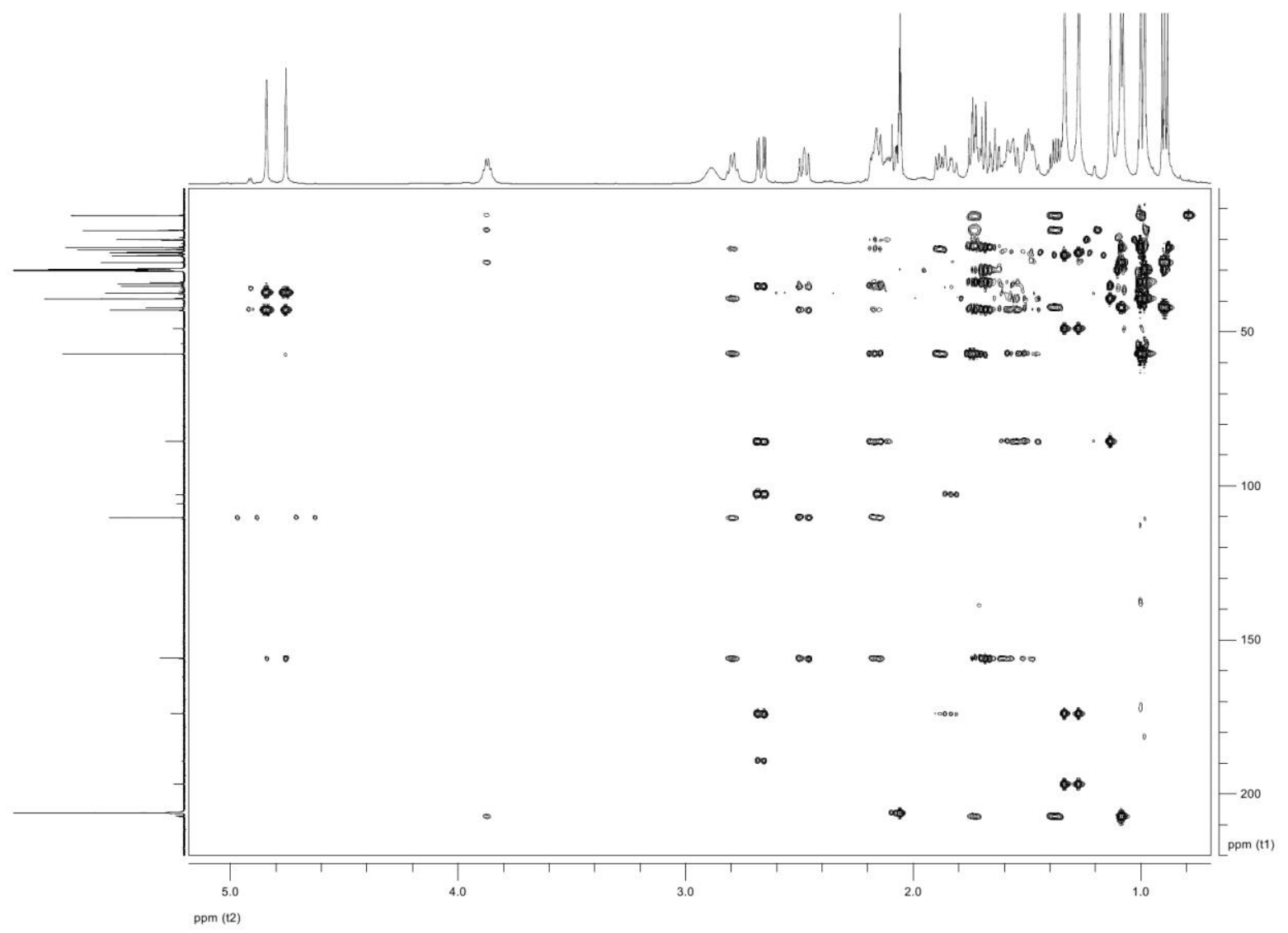

Figure S32. HMBC spectrum of hyperjapone E (5). 


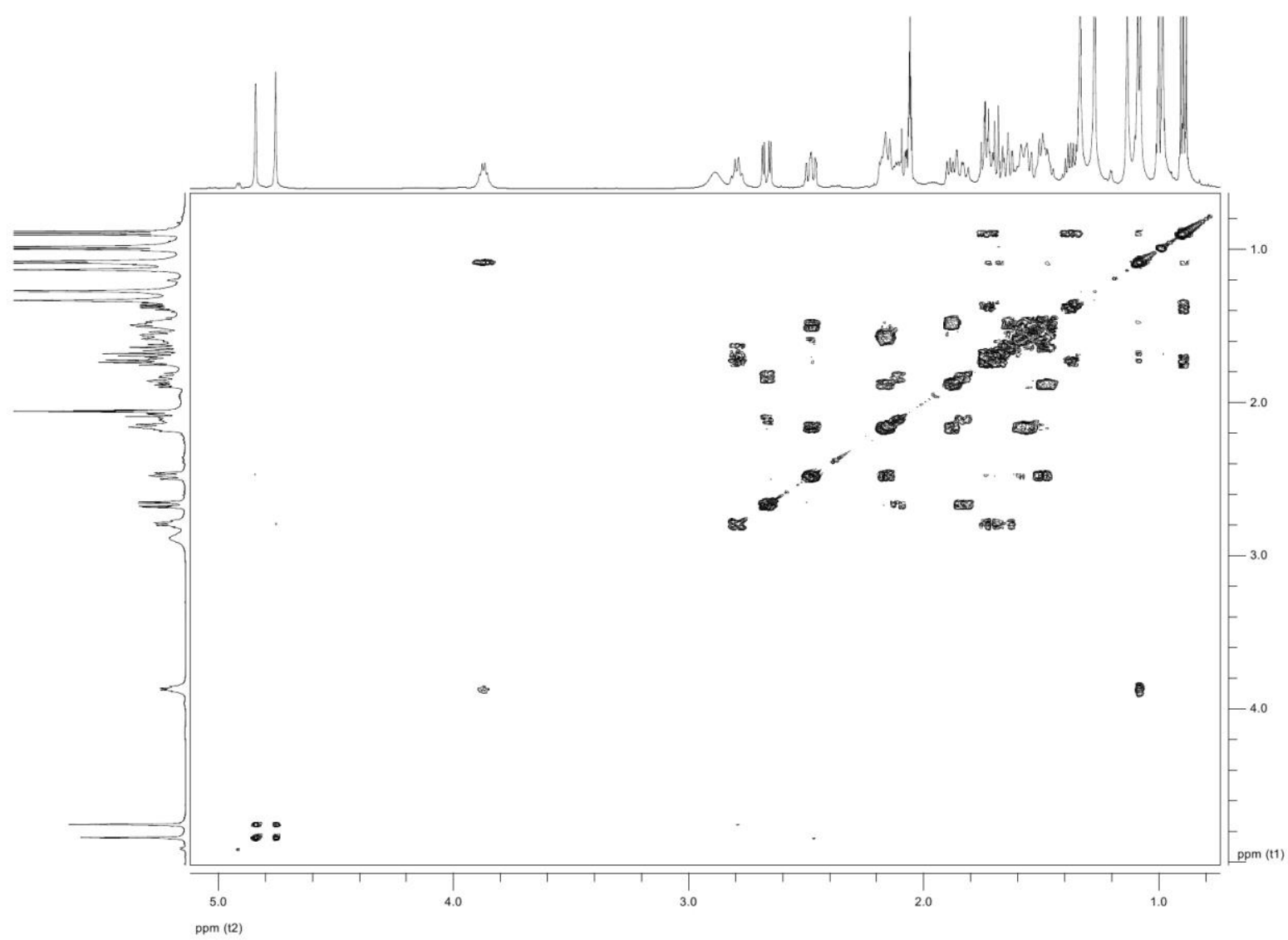

Figure S33. ${ }^{1} \mathrm{H}-{ }^{1} \mathrm{H}$ COSY spectrum of hyperjapone E (5).

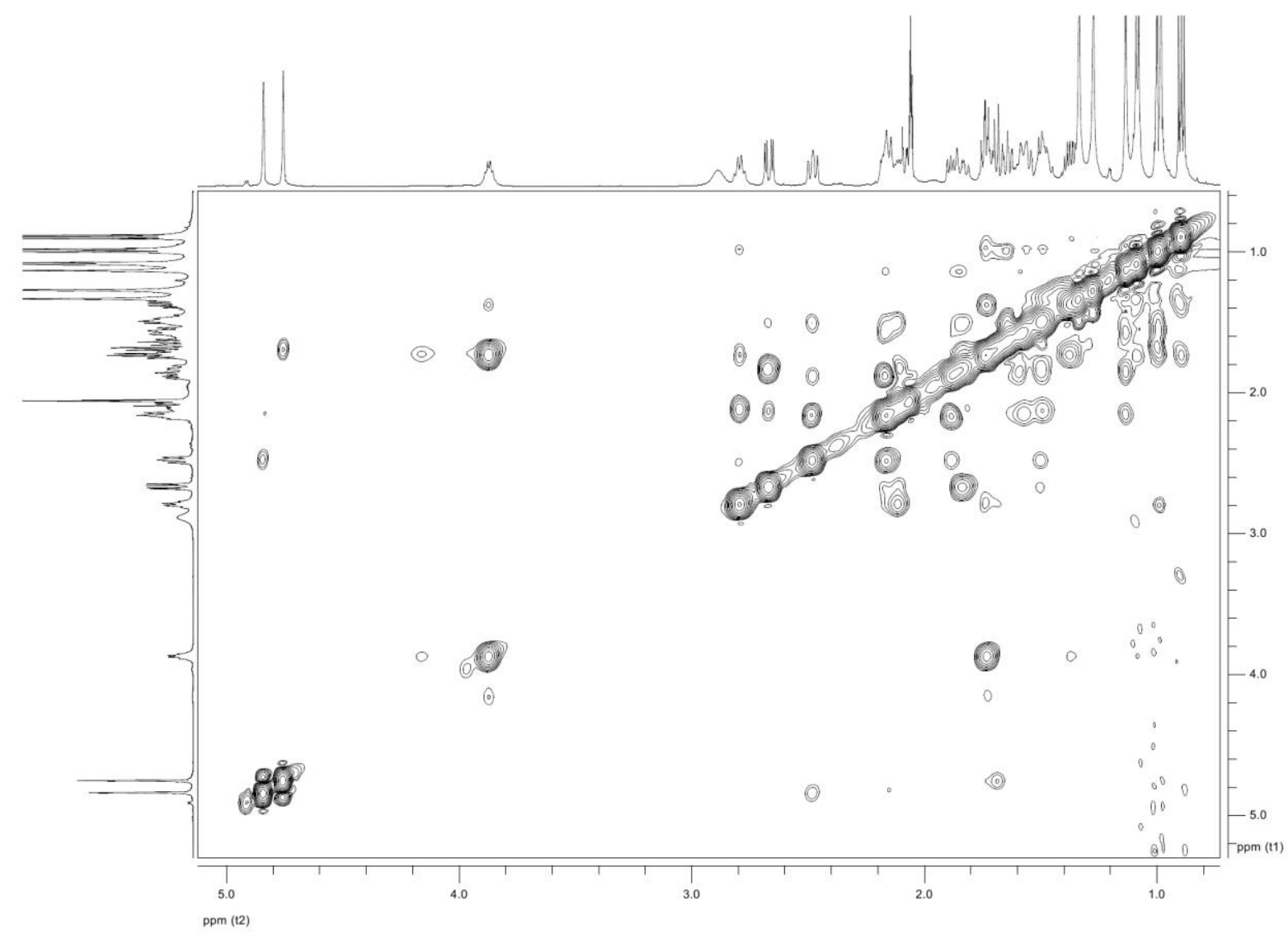

Figure S34. ROESY spectrum of hyperjapone E (5). 


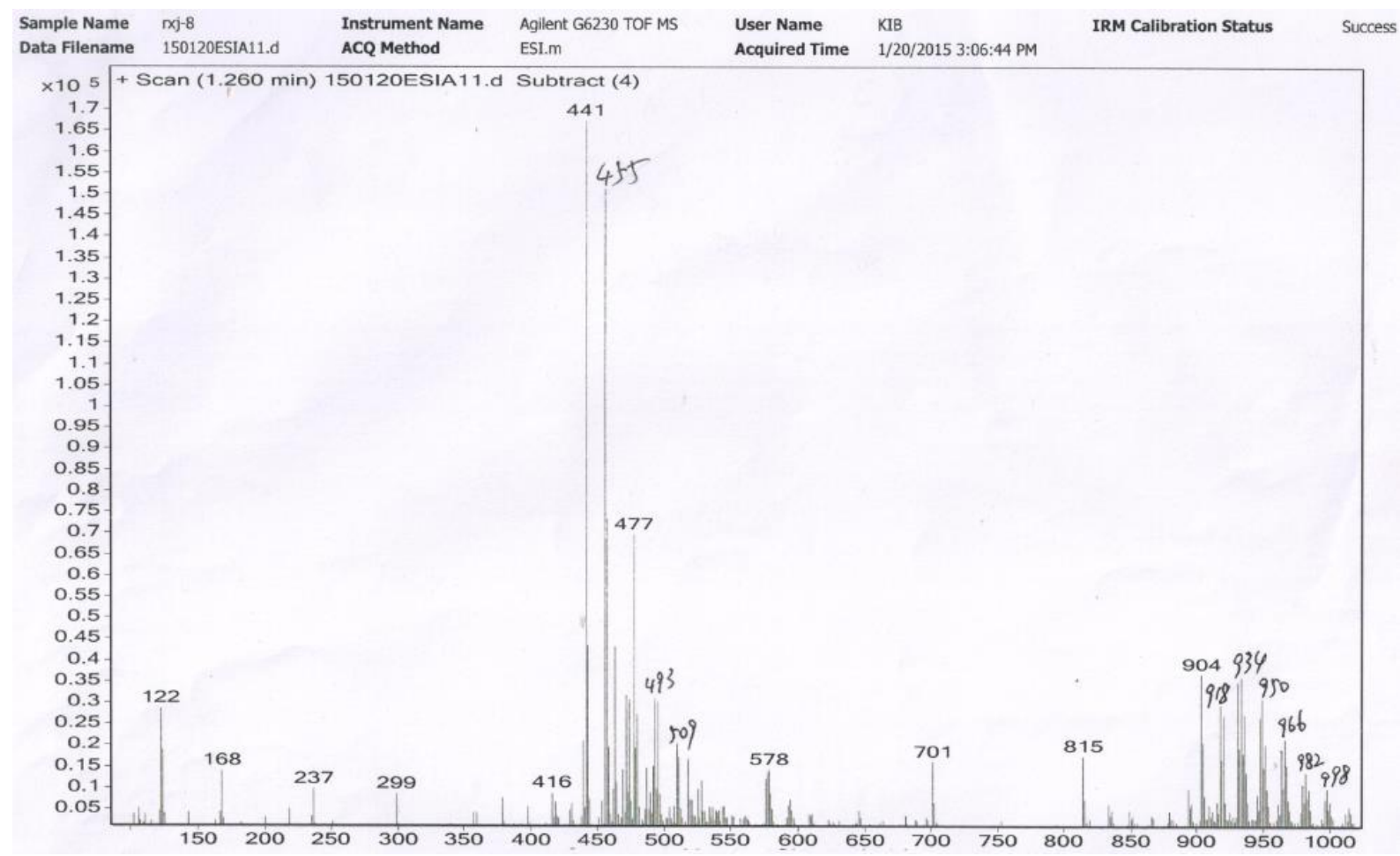

Figure S35. ESIMS spectrum of hyperjapone A (1).

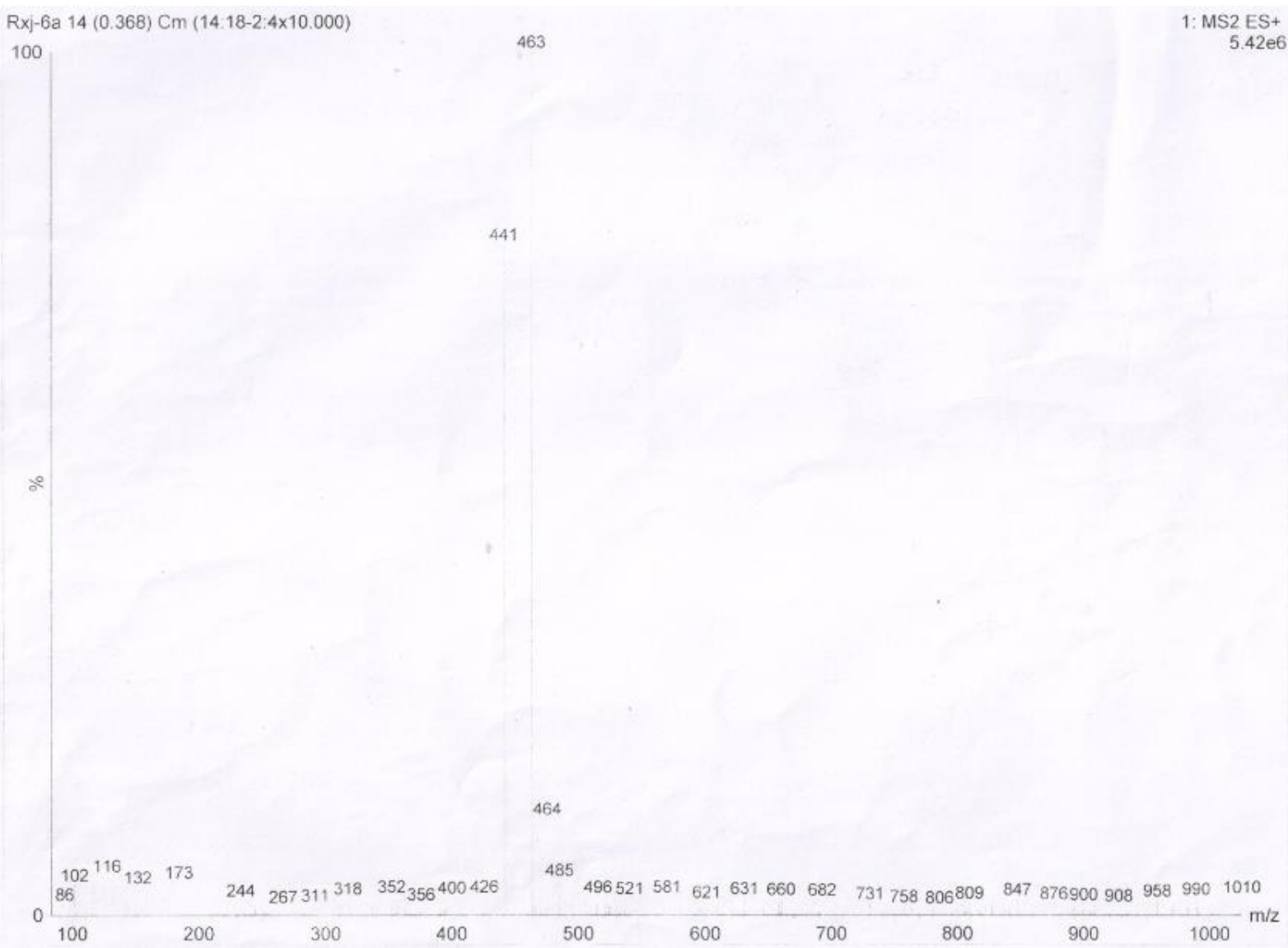

Figure S36. ESIMS spectrum of hyperjapone B (2). 


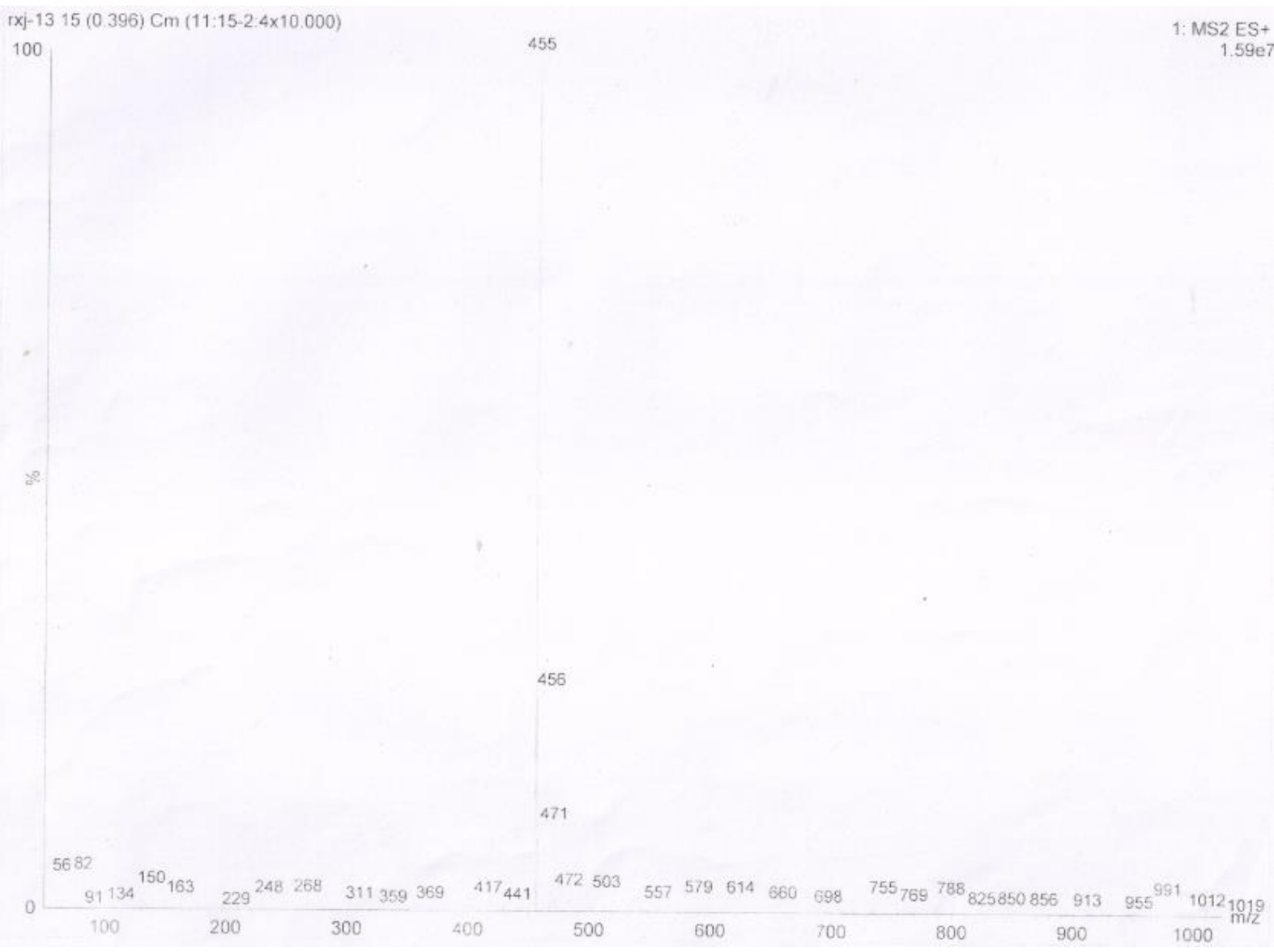

Figure S37. ESIMS spectrum of hyperjapone C (3).

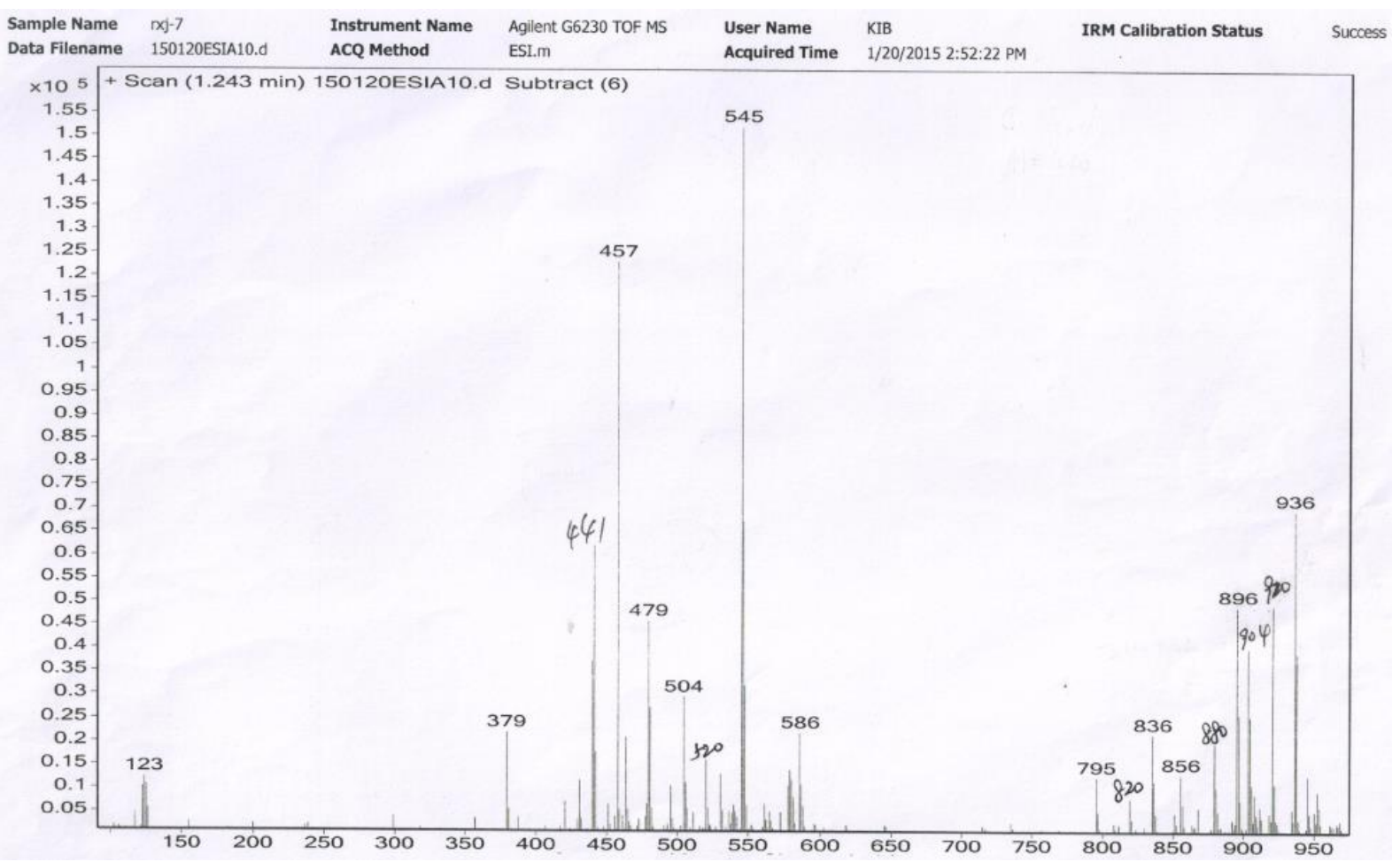

Figure S38. ESIMS spectrum of hyperjapone D (4). 


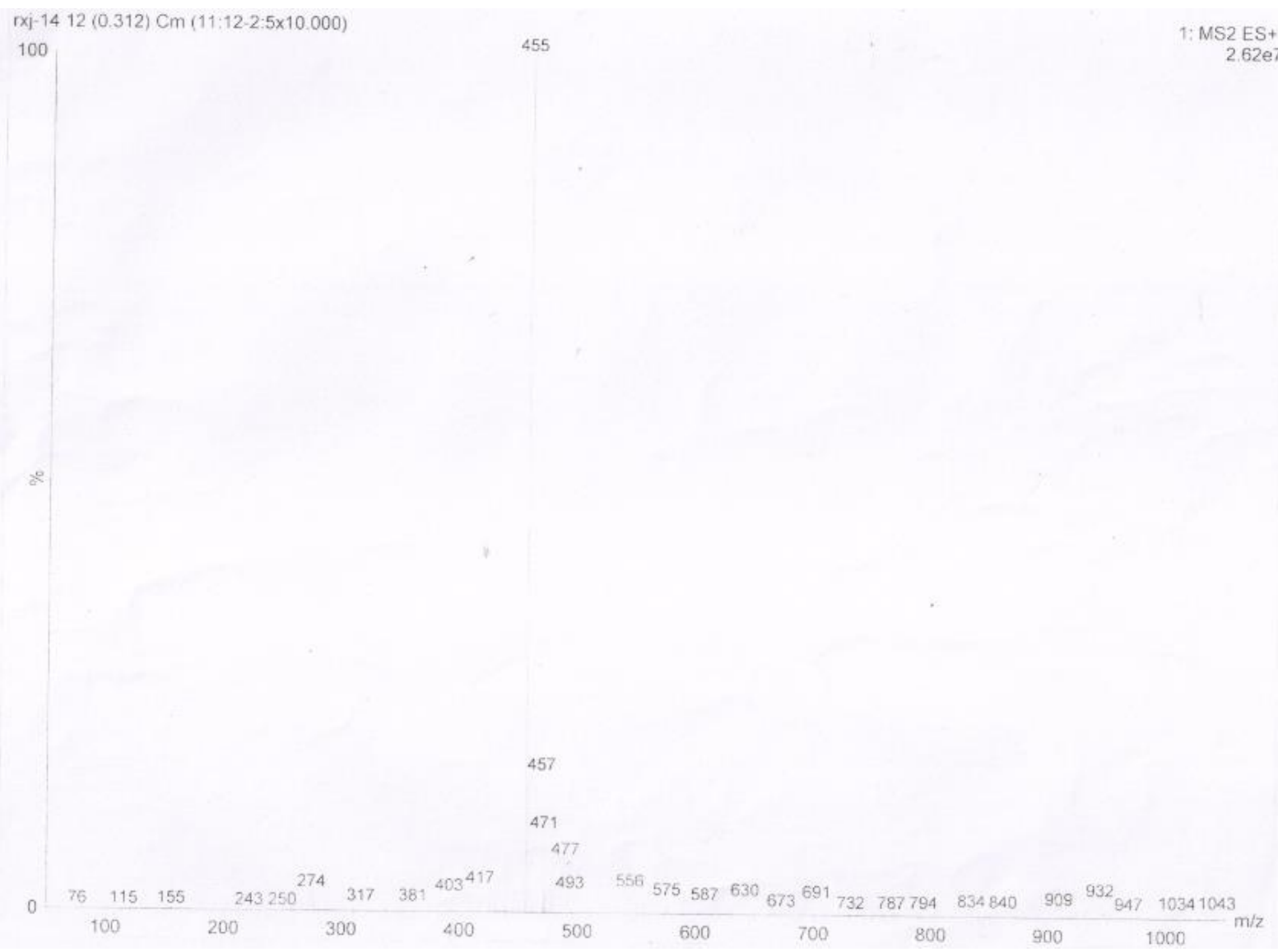

Figure S39. ESIMS spectrum of hyperjapone E (5). 


\section{Qualitative Analysis Report}

Data Filename

Sample Type

Instrument Name

Acq Method

IRM Calibration Status

Comment

Sample Group

Acquisition SW

Version
150120ESIA11.d

Sample

Agilent G6230 TOF MS

ESI.m

Success
Sample Name

Position

User Name KIB

Acquired Time 1/20/2015 3:06:44 PM

DA Method
ESI.m

Info.

6200 series TOF $/ 6500$ series

Q-TOF B.05.01 (B5125.2)

\section{User Spectra}

$\begin{array}{ccc}\text { Fragmentor Voltage } & \text { Collision Energy } \\ 200 & \text { Ionization Mode }\end{array}$

x10 $5+$ Scan (0.894 min) 150120ESIA11.d

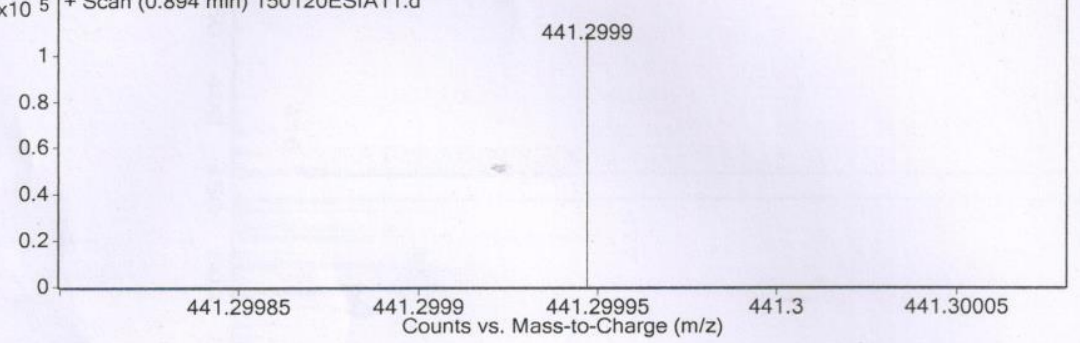

Peak List

\begin{tabular}{|l|r|l|l|l|}
\hline $\boldsymbol{m} / \boldsymbol{z}$ & $\mathbf{z}$ & Abund & Formula & Ion \\
\hline 441.2999 & 1 & 109143.81 & $\mathrm{C} 28 \mathrm{H} 41 \mathrm{O} 4$ & $\mathrm{M}+$ \\
\hline 455.2789 & 1 & 83073.87 & & \\
\hline 457.294 & 1 & 56197.8 & & \\
\hline 463.2815 & 1 & 35919.37 & & \\
\hline 477.2608 & 1 & 71726.89 & & \\
\hline 917.5527 & 1 & 33311.56 & & \\
\hline 922.0098 & 1 & 49015.93 & & \\
\hline 931.5325 & 1 & 31420.01 & & \\
\hline 933.5453 & 1 & 35519.79 & & \\
\hline 949.5396 & 1 & 30783.25 & & \\
\hline
\end{tabular}

\begin{tabular}{l|l|l|l}
949.5396 & 1 & 30783.25 \\
\hline Formula Calculator Element Limits
\end{tabular}

\begin{tabular}{|l|l|l|} 
Formula Calculator Element Liment & Min \\
\hline
\end{tabular}

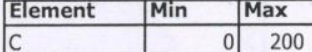

\begin{tabular}{|l|c|c|}
\hline $\mathrm{C}$ & 0 & 400 \\
\hline 0 & 0 & 9 \\
\hline
\end{tabular}

Formula Calculator Results

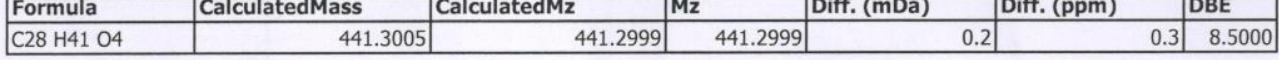

--- End Of Report -..

Figure S40. HR-ESIMS spectrum of hyperjapone A (1). 


\section{Qualitative Analysis Report}

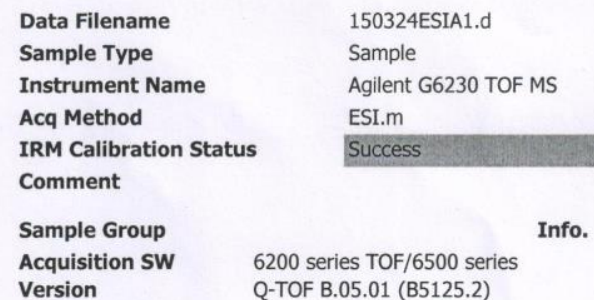

Sample Name nxj-6a

Position

User Name KIB

Acquired Time 3/23/2015 3:13:13 PM

DA Method ESI.m

Info.

Version

Q-TOF B.05.01 (B5125.2)

User Spectra

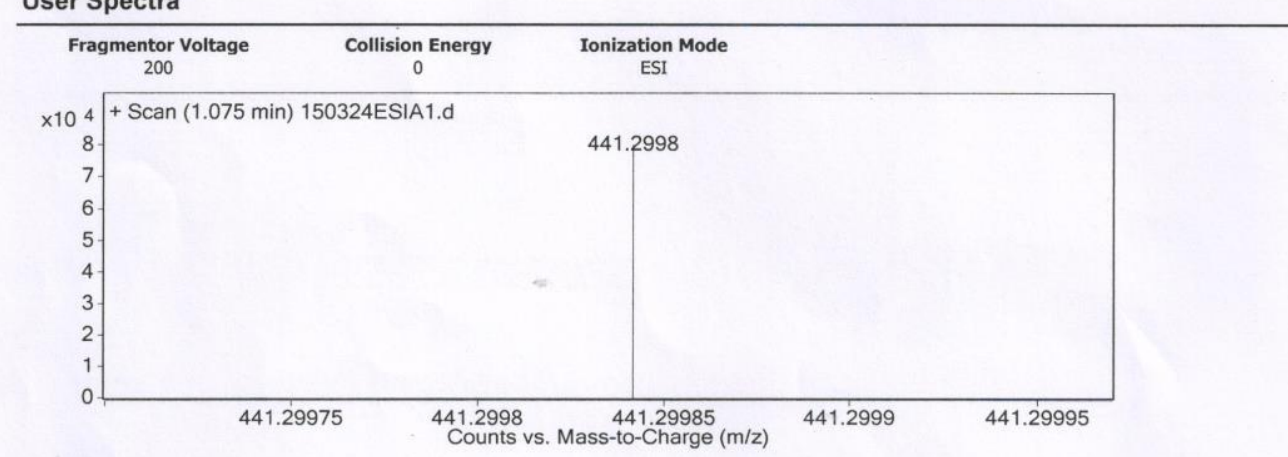

Peak List

\begin{tabular}{|l|l|l|l|l|}
\hline $\boldsymbol{m} / \boldsymbol{z}$ & $\mathbf{z}$ & Abund & Formula & Ion \\
\hline 121.0509 & 1 & 38675.86 & & \\
\hline 277.1773 & 1 & 21362.92 & & \\
\hline 441.2998 & 1 & 80081.97 & $\mathrm{C} 28 \mathrm{H} 41$ O4 & $\mathrm{M}+$ \\
\hline 442.303 & 1 & 21220.72 & $\mathrm{C} 28 \mathrm{H} 41$ O4 & $\mathrm{M}+$ \\
\hline 463.2827 & 1 & 10836.63 & & \\
\hline 903.5744 & 1 & 22784.25 & & \\
\hline 904.5777 & 1 & 13383.71 & & \\
\hline 922.0098 & 1 & 42830.13 & & \\
\hline 1343.8656 & 1 & 17373.82 & & \\
\hline 1344.8688 & 1 & 16089.98 & & \\
\hline
\end{tabular}

Formula Calculator Element Limits

Formula Calculator Element

\begin{tabular}{|l|l|l|}
\hline Element & Min & Max \\
\hline
\end{tabular}

\begin{tabular}{|l|r|c|}
\hline $\mathrm{C}$ & 0 & 200 \\
\hline $\mathrm{H}$ & 0 & 400 \\
\hline
\end{tabular}

\begin{tabular}{l|r|r}
\hline 0 & 0 & 9 \\
\hline Formula Calculator Results
\end{tabular}

\begin{tabular}{|l|l|l|l|l|l|l|l|}
\hline Formula & CalculatedMass & CalculatedMz & Mz
\end{tabular}

\begin{tabular}{|c|c|c|c|c|c|c|}
\hline Formula & CalculatedMass & CalculatedMz & Mz & Diff. (mDa) & Diff. (ppm) & DBE \\
\hline $\mathrm{C} 28 \mathrm{H} 41 \mathrm{O} 4$ & 441.3005 & 441.2999 & 441.2998 & 0.1 & 0.1 & 8.5000 \\
\hline
\end{tabular}

--- End Of Report ---

Figure S41. HR-ESIMS spectrum of hyperjapone B (2). 


\section{Qualitative Analysis Report}

\begin{tabular}{|c|c|c|c|}
\hline Data Filename & 150831ESIA4.d & Sample Name & $r x j-13$ \\
\hline Sample Type & Sample & Position & \\
\hline Instrument Name & Agilent G6230 TOF MS & User Name & KIB \\
\hline Acq Method & ESI.m & Acquired Time & 8/31/2015 2:53:49 PM \\
\hline IRM Calibration Status & Success & DA Method & ESI.m \\
\hline Comment & & & \\
\hline $\begin{array}{l}\text { Sample Group } \\
\text { Acquisition SW }\end{array}$ & TOF/6500 series & & \\
\hline
\end{tabular}

User Spectra

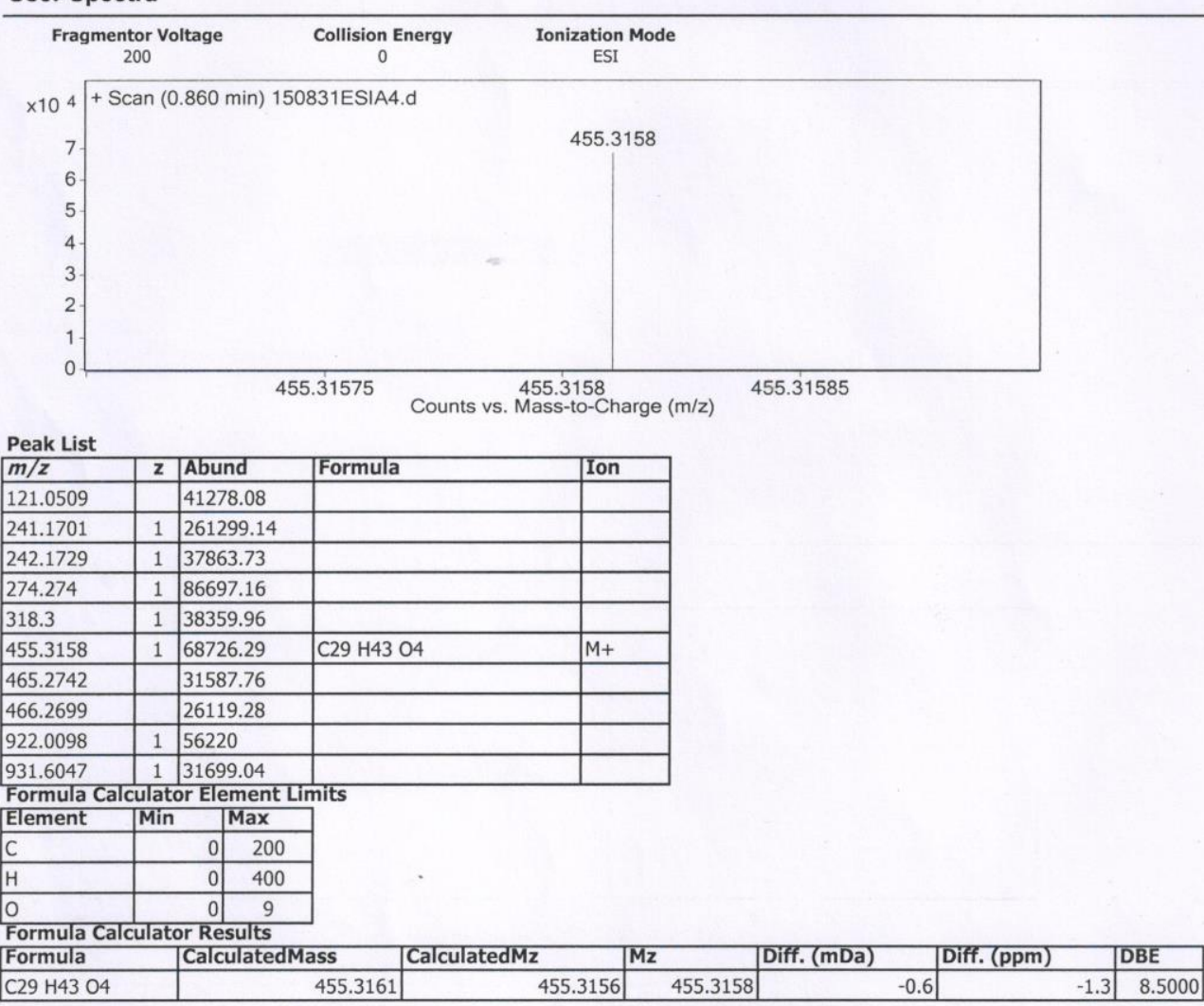

--- End Of Report --.

Figure S42. HR-ESIMS spectrum of hyperjapone C (3). 


\section{Qualitative Analysis Report}

\begin{tabular}{|c|c|c|c|}
\hline Data Filename & 150120ESIA10.d & Sample Name & $n x j-7$ \\
\hline Sample Type & Sample & Position & \\
\hline Instrument Name & Agilent G6230 TOF MS & User Name & KIB \\
\hline Acq Method & ESI.m & Acquired Time & $1 / 20 / 2015$ 2:52:22 PM \\
\hline IRM Calibration Status & Success & DA Method & ESI.m \\
\hline \multicolumn{4}{|l|}{ Comment } \\
\hline Sample Group & Inf & & \\
\hline $\begin{array}{l}\text { Acquisition SW } \\
\text { Version }\end{array}$ & $\begin{array}{l}\text { ies TOF/6500 series } \\
05.01(B 5125.2)\end{array}$ & & \\
\hline
\end{tabular}

\section{User Spectra}

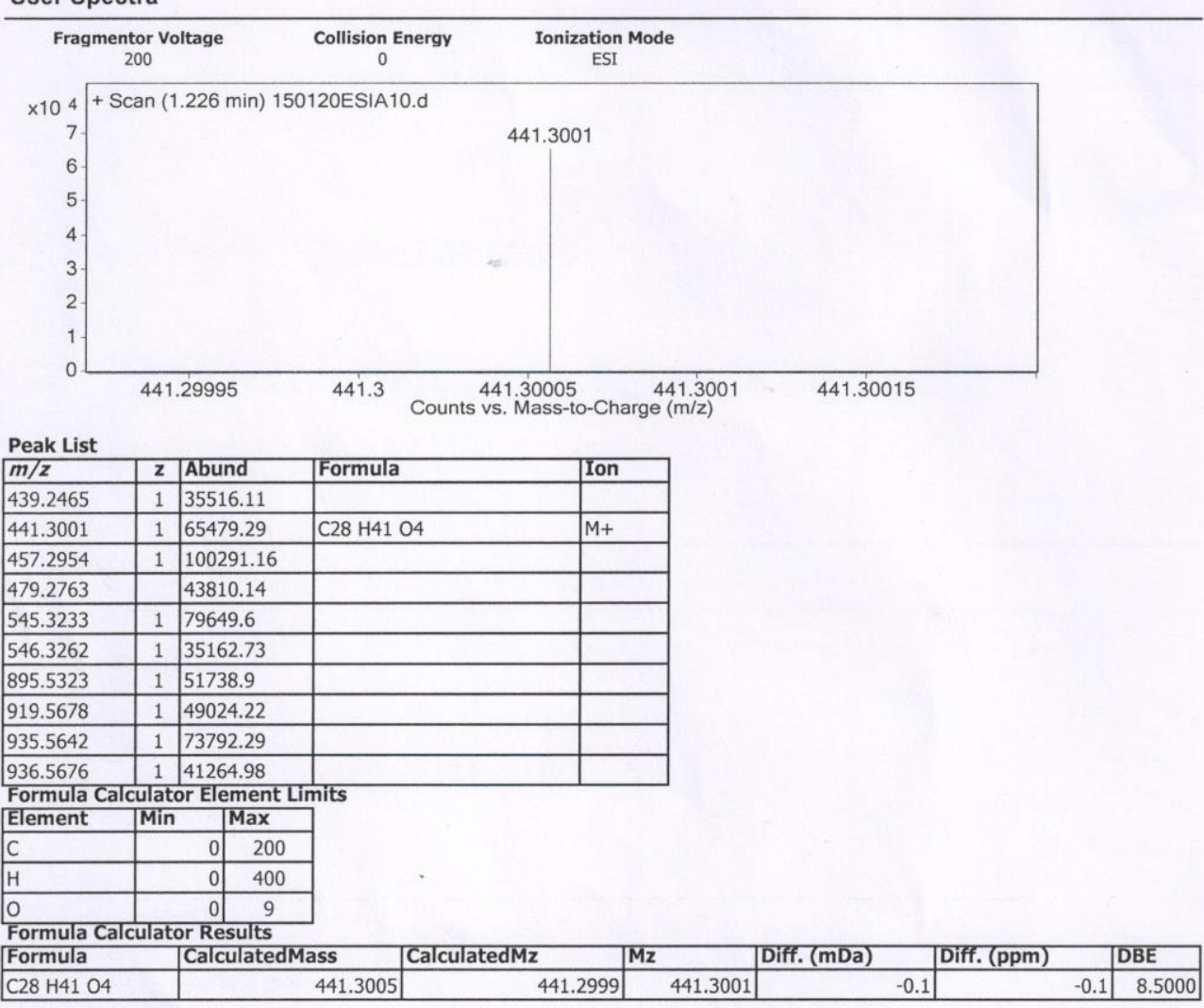

--- End Of Report --

Figure S43. HR-ESIMS spectrum of hyperjapone D (4). 


\section{Qualitative Analysis Report}

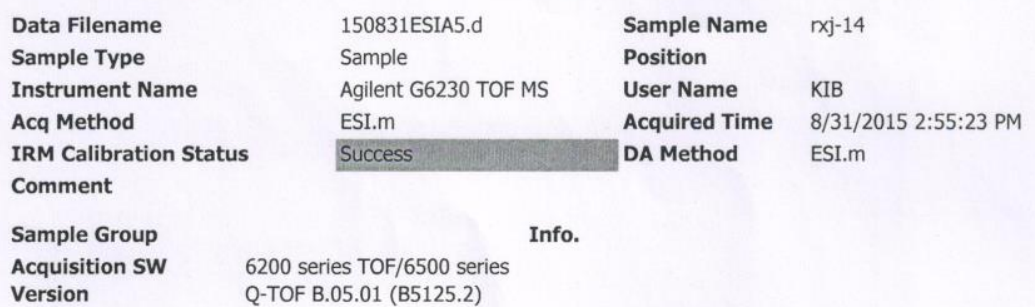

User Spectra

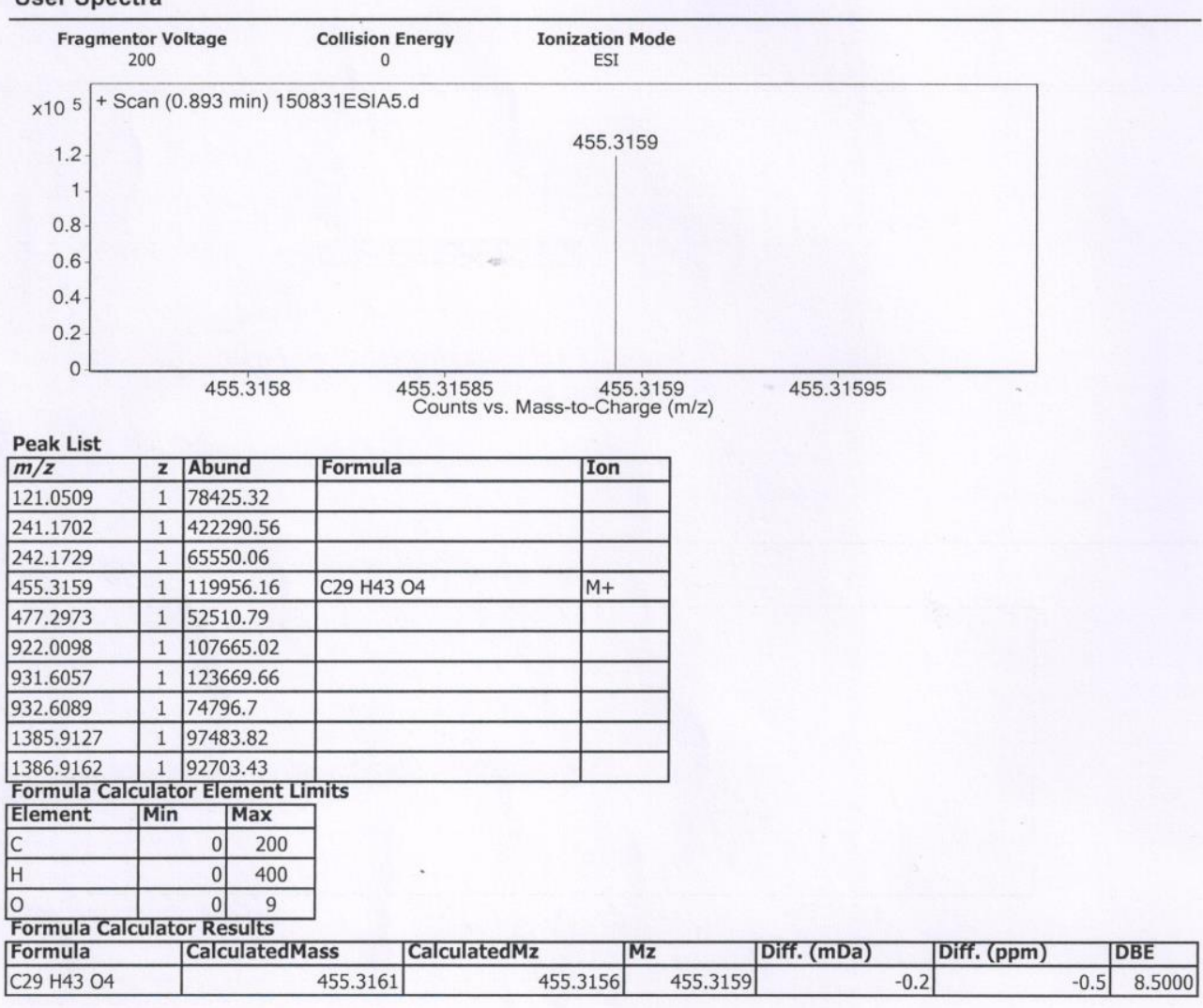

--- End Of Report -..

Figure S44. HR-ESIMS spectrum of hyperjapone E (5). 